The copyright of this thesis vests in the author. No quotation from it or information derived from it is to be published without full acknowledgement of the source. The thesis is to be used for private study or noncommercial research purposes only.

Published by the University of Cape Town (UCT) in terms of the non-exclusive license granted to UCT by the author. 


\title{
Modelling regime shifts in the southern Benguela: a frame-based approach
}

\author{
Michael Douglas Smith \\ Submitted in partial fulfilment of the requirements \\ for the degree of Master of Science (by coursework and dissertation) \\ in Applied Marine Science \\ Department of Zoology \\ Faculty of Science \\ UNIVERSITY OF CAPE TOWN
}

February 2009

Supervisors: A/Prof. Astrid Jarre (University of Cape Town)

Prof. Anthony M. Starfield (University of Minnesota) 


\section{Declaration}

1. I know that plagiarism is wrong. Plagiarism is to use another's work and to pretend that it is one's own. This includes copying phrases and sentences from another's writing, and inserting these into one's own work.

2. I have used a standard convention for citation and referencing. Each significant contribution to, and quotation in, this Report from the work, or works, of other people has been attributed, and has been cited and referenced. Where exact wording is used, this is placed in quotation marks, and the page number is included in the citation.

3. This Report is my own work.

4. I have not allowed, and will not allow, anyone to copy my work with the intention of passing it off as his or her own work.

SIGNATURE

DATE

$30-04-2009$

NAME

STUDENT NUMBER

SMTMIC Q




\begin{abstract}
Small pelagic fish populations in productive upwelling systems are characterised by long-term patterns of alternating dominance. Sardine and anchovy are the most important small pelagic species in the southern Benguela ecosystem, which has been shown to have undergone regime shifts during the past 50 years. Modelling regime shifts at an ecosystem scale can be of great importance in fisheries management, to aid in long-term planning and fishing strategy evaluation. Frame-based modelling has been successfully applied to regime shift dynamics in terrestrial ecosystems. The pattern of abrupt shifts between quasi-stable regimes suggests the usefulness of a frame-based approach in the southern Benguela ecosystem, with separate frames describing each small pelagic fish dominance pattern. Frame-based modelling is applied to sardine/anchovy dynamics under the influence of climate variability involving interaction with the small pelagic fishery. Four frames are used in the model: Both Species High; Sardine High / Anchovy Low; Anchovy High / Sardine Low; and Both Species Low. Switching rules for transition between the frames are described. Rapid prototyping is used to construct and test first- and second-generation prototypes of a frame-based model. A sensitivity analysis of the model is performed, and the model is found to be sensitive to the frame switching rules. The model is also reasonably sensitive to the sardine population model parameters, and the influence of juvenile sardine bycatch is noticeable in the "Sardine Low" frames. The model behaviour is relatively insensitive to climate variability, but the inherent degree of stochasticity in the sardine recruitment calls for continuous population monitoring and adjustment of fishing levels to avoid crashing the modelled sardine stock. Frame behaviour in the model is sensitive to sardine fishing activity. The model is exercised in a variety of scenario analyses, and confidence in the model is strengthened by the observed parallels to the real world. The use of the model as a "test platform" is explored to improve understanding of fishing impact on the dynamics of small pelagic populations. Previously identified advantages of the framebased modelling technique include their particular usefulness in inter-disciplinary teams and the ease with which a frame-based model can be expanded and modified, and the experiences of this
\end{abstract}


project support these findings. The use of frames as indicators adds information about the condition of the modelled stock at a given point beyond what can be inferred by population leveis alone. Frame-based modelling is also found to be an approach well-suited to the development and maintenance of the computer software which encapsulates the model, and as a common interface between biologists, programmers and non-specialist model users. Suggested applications of the model include deriving "probabilities of change" for use in an expert system to predict long-term ecosystem changes. Applications of the model in understanding the impact of survey data error and compliance issues are discussed.

Keywords: frame-based modelling, ecosystem, rapid prototyping, fisheries management, regime shifts, southern Benguela 


\section{Contents}

$\begin{array}{lr}\text { 1. Introduction } & 1\end{array}$

1.1 Dynamics of small pelagic fish dominance in upwelling systems 1

1.2 Frame-based modelling of ecosystem dynamics for management 7

2. Materials and methods $\quad 11$

2.1 Description of frames and frame-shifts in the Southern Benguela 11

$\begin{array}{lll}2.2 & \text { Rapid prototyping } & 17\end{array}$

$\begin{array}{lr}\text { 3. First Prototype } & 19\end{array}$

$\begin{array}{ll}3.1 \text { Description of the first prototype } & 19\end{array}$

3.2 Results from the first prototype 27

3.3 Analysis of results and recommendations for second prototype 30

4. Second Prototype 32

4.1 Description of second prototype

4.2 Results: Assumption and sensitivity analysis 46

4.3 Results: Exercising the model from second prototype 60

$\begin{array}{ll}\text { 5. Discussion } & 67\end{array}$

$\begin{array}{lll}5.1 & \text { Is the model useful? } & 67\end{array}$

5.2 Usefulness of the frame-based approach $\quad 69$

$\begin{array}{lll}5.3 & \text { Advantages of rapid prototyping } & 74\end{array}$

5.4 Applications of the model 75

5.5 Proposed further research and model expansion 76

$\begin{array}{lr}\text { 6. Conclusions } & \mathbf{8 0}\end{array}$

$\begin{array}{lr}\text { 7. Acknowledgements } & 82\end{array}$

\begin{tabular}{lr} 
8. & References \\
\hline
\end{tabular}

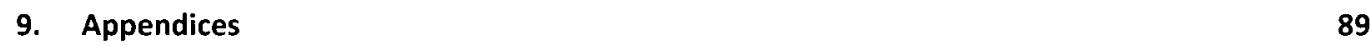

9.1 Appendix A: Sensitivity and assumption analyses data (for Table 6, Section 4.2.1) 89 


\section{List of Figures}

Figure 1 - Spawner stock biomass estimates of sardine and anchovy in the southern Benguela, showing a high degree of inter-annual variability. Note: figures before 1984 are reconstructed virtual population assessment (VPA) data (van der Lingen et al., 2006a, updated by Marine and Coastal

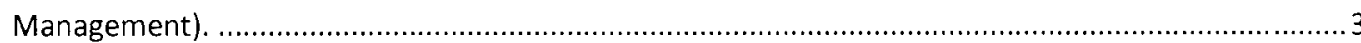

Figure 2 - Schematic of frames and transitions for the model. Numbered arrows refer to the shifts described in the Table 2.

Figure 3 - The graphical user interface (GUI) of the first prototype. The red line indicates the modelled anchovy stock, the blue line indicates sardine. Under the Variable TAC setting, the robot manager tries to maximise sardine catch without endangering the stock. The colours used by the

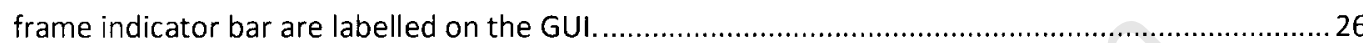

Figure 4 - A programme overview for Prototype 1. See text for a detailed description.....................26

Figure 5 - First Prototype output for a single run, no fishing. The blue line indicates sardine, the red indicates anchovy. Note that in the absence of fishing the sardine stock stays continually in a high frame.

Figure 6 - Ten consecutive runs on the first prototype with no fishing. The blue lines indicate sardine, the red indicate anchovy. The anchovy only sometimes switch to a "high" frame for some or all of the second decade, but always switch to "high" for the fourth decade. The moderate trend in the sardine population due to the ESI influence is clearly visible.

Figure 7 - A single run on the first prototype with moderate fishing (the blue line indicates sardine, the red indicates anchovy). Note the emergence of "low" sardine frames.

Figure 8 - First prototype, ten runs with high sardine fishing pressure (blue lines indicate sardine, red indicate anchovy). The stock collapsed completely during two of the runs.

Figure 9 - A conceptual graph of the sardine density dependence factor $\left(f_{D D}\right)$ as implemented in Prototype 2

Figure 10 - Programme overview for Prototype 2. See text for a detailed description. ...................40

Figure 11 - A single model run on Prototype 2 under moderate fishing with survey errors. The red line indicates the modelled anchovy stock, the blue line indicates the modelled sardine stock. The reported (inaccurate) sardine biomass is indicated by the dotted blue line.

Figure 12 - A sample run under automated management on the second prototype (blue line indicates sardine, red indicates anchovy). The colours used by the frame indicator bar are labelled on the GUI.

Figure 13 - The sample run from Figure 12, showing the diagnostics tab with the metrics for the run.

Figure 14 - Average annual sardine catch and risk of crash with increasing AutoManage severity. Data consists of averaged replicates of 1000 runs. Crashes are negligible up to $50 \%$ severity, from which point crash frequency increases to a maximum of almost $60 \%$ at maximum severity. Total catch increases with increasing severity up to $50 \%$, from which point the higher incidence of crashes offsets the higher catches obtained under higher fishing pressure.

Figure 15 - Frequency of "acceptable" years (sardine catch $>80 \%$ of average catch) with increasing AutoManage severity. Data consists of averaged replicates of 1000 runs. Although the average annual catch increases up to approximately $60 \%$ severity, there is also an increase in the frequency of "poor" fishing years. 
Figure 16 - Prototype 2, sardine fished heavily (at 0.6 ) for the first six years, then fished conservatively (at 0.3 ) for the rest of the run (blue line indicates sardine, red indicates anchovy). The "low" sardine frames delayed the sardine recovery for almost two decades, but once back in the "high" frames, the stock remained there under sustained moderate fishing.

Figure 17 - Sardine fished to vulnerability (at 0.6), then allowed to recover (blue line indicates sardine, red indicates anchovy). From year 30, anchovy are fished heavily in response to high stocks. Bycatch from the anchovy fishing causes a collapse of the sardine population even under light (0.2)

fishing

Figure 18 - Prototype 2, with ten successive runs of the model on sustained, unmonitored fishing at a moderate level (0.4) for each entire run (blue lines indicate sardine, red indicate anchovy).

Although the sardine population remains healthy for nine runs, on one of the runs the stochasticity of recruitment drives the stock to a vulnerable state, and lack of management compensation crashes the stock.

Figure 19 - A model run on Protype 2 with survey data error under a conservative AutoManage setting ( $20 \%$ severity). The solid blue line is the actual modelled sardine population, the dotted blue line is the (inaccurate) assessed population (the red line is the modelled anchovy population). Survey error is set at up to $20 \%$ of the modelled sardine biomass for each vear. Generally, there was little observable effect from inaccurate surveys, except in the case of years 30-32, where the actual population was close to a frame-switch threshold. Over-assessment (and subsequent over-fishing) in this period resulted in the switch to a "low" sardine frame.

Figure 20 - Relationships between the model world (in which our model is built and tested) and the real world. The model world is an appropriately simplified version of the real world which retains the system dynamics of the real-world interactions that our model is designed to explore (After Starfield and Jarre, in review). Note that data from the real world is used to calibrate the model, but our model does not aim to directly reproduce the data.

Figure 21 - Prototype 2 under heavy sardine fishing (at 0.6 ) for the first 9 years (blue line indicates sardine, red indicates anchovy). In response to the decline of the modelled sardine stock, fishing was reduced to 0.3 for the rest of the run, and sardine remained in a "high" frame.

Figure 22 - Prototype 2 under heavy sardine fishing (0.6) for the first 9 years (blue line indicates sardine, red indicates anchovy). In response to the decline in sardine population, sardine fishing was stopped completely until year 21 , when it was resumed at 0.3 for the rest of the run. 


\section{List of Tables}

Table 1 - Frames considered for the modelled small pelagic ecosystem of the southern Benguela...13

Table 2 - Shift conditions for switching between the frames described in Table 1....................... 14

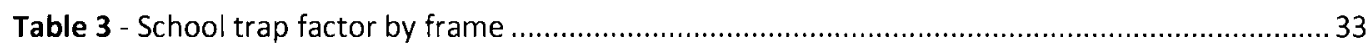

Table 4 - Determination of the sardine density dependence factor $\left(f_{D D}\right)$ by frame in the second prototype.

Table 5 - AutoManage function parameters for sardine fishing in Prototype 2 under the most "conservative" setting. Numbers in parentheses indicate the maximum adjustment of figures under the most "severe" management strategy.

Table 6 - AutoManage function parameters for anchovy fishing in Prototype 2 under the most "conservative" setting. Numbers in parentheses indicate the maximum adjustment of figures under the most "severe" management strategy.

Table 7 - Example run of ESI values and associated anchovy frame behaviour. Annual ESI is added to the running total unless annual $<4$, in which case the running total is reset to the annual figure. Daemon switches to "high" if running total $>15$, and switches to "low" if running total <4 (i.e., if annual ESI <4).

Table 8 - Summary results from sensitivity and assumption analysis. The numbers in the table refer to the test results in Appendix A (Section 9.1). Coloured cells indicated an assessment of the overall sensitivity of the output parameter (columns) to all the tests involving the given input parameter (rows).

Table 9 - Analysis of stochasticity and averaging effect. All runs performed with AutoManage at $50 \%$ severity. Standard deviation of Sardine Low frame duration reduced greatly as the number of runs increased.

Table 10 - Number of crashes at 500 runs with increasing AutoManage severity.

Table 11 - Ratios of SardHi frame to BothHi in the unfished system with varying cycle time of ESI function....

Table 12 - Comparison of sardine fishing performance at various levels of AutoManage severity with 


\section{Introduction}

\subsection{Dynamics of small pelagic fish dominance in upwelling systems}

The objective of this research is to evaluate the usefulness of the frame-based modelling technique to provide an adequately realistic simulation of sardine and anchovy interactions in the southern Benguela upwelling region over multi-decadal time-scales to serve as a test-bed for evaluating the effectiveness and benefits of different fisheries management strategies. An important goal of fisheries science is to assess the trade-offs between the conflicting objectives of ecological stability and long-term human well-being. In view of the high uncertainties in our understanding of marine systems, models such as the one described here are invaluable in assisting decision-makers to weigh the advantages and disadvantages of competing fisheries strategies in a changing environment. We intend to explore the usefulness of the frame-based modelling technique in approaching this kind of ecosystem challenge.

\subsubsection{Interactions between sardine and anchovy populations}

Sardine and anchovy (Sardinops spp. and Engraulis spp.) are two of the most widespread and consistently fished of commercial stocks. Collectively, the small pelagics are the largest component of the global capture fisheries, representing over $25 \%$ of the total catch each year (FAO, 2005). As a result of the important fisheries they sustain, the population dynamics of these fish have received much attention. Although there are certain regional variations in the details of species and the exact dynamics of the upwelling systems in which they flourish, there are sufficient similarities to draw useful parallels.

The dynamics of the food web in an ecosystem with small pelagics can display top-down characteristics (e.g. Japan, Ghana), or bottom-up (e.g. Benguela, Humboldt), but the small pelagics occupy a niche notable for very low species richness - the "wasp-waist" position (Cury et al., 2000). 
This means that the population variance of a very small number of species, whether through climate variability or human exploitation, can have significant effects on the ecosystem as a whole. In the southern Benguela ecosystem, the local species of sardine (Sardinops sagax) and anchovy (Engraulis encrasicolus) provide food for several threatened bird species (e.g. Cape Gannet and albatross), Cape fur seal, cetaceans and larger predatory fish. In South Africa, the sardine and anchovy fishery is the largest fishery by volume and the second largest in value (Shannon et. al., 2006), and so the success of the sardine and anchovy fishing industry is also of considerable human importance.

These species are also remarkable for the extremely high degree of variability in population sizes which they exhibit (e.g. Pauly and Tsukayama, 1987), and the biomass trajectory record from the southern Benguela (Figure 1) is fairly typical. Superimposed on the inter-annual variability are decadal-scale population fluctuations, which are generally characterised by one or other of the sardine and anchovy dominating, rather than both populations being simultaneously high or low. This pattern of variation has been noted in all ecosystems where the two species co-exist, not only the southern Benguela (e.g. Lluch-Belda et al., 1992; Schwartzlose et al., 1999; Jarre et al., 1998). The root causes of the fluctuations are believed to lie in long-term, low-frequency environmental factors (Alheit and Niquen, 2004), although the sardine population in particular may be severely affected by fishing (Boyer and Hampton, 2001; Fairweather et al., 2006a; Coetzee et al., 2006).

Because juvenile sardine school with anchovy in the southern Benguela, anchovy fishing inevitably results in significant juvenile sardine bycatch, and thus the sardine population may be affected even when not targeted (Shannon et al., 2006). This complication may be even more pronounced where the sardine population is already low, as there appears to be an increased incidence of juvenile sardine schooling with adult anchovy as the sardine population declines (e.g. Jordán et al., 1978), making them particularly susceptible to the "school trap", where the feeding and survival strategy of a mixed school is determined by the adult anchovy, resulting in sub-optimal schooling behaviour, 
reduced grow:t, and higher morteiity for the juvenile sardine stock \{ Bakun are Cury 1999; Bakun, 200: Curye: al., 2000).

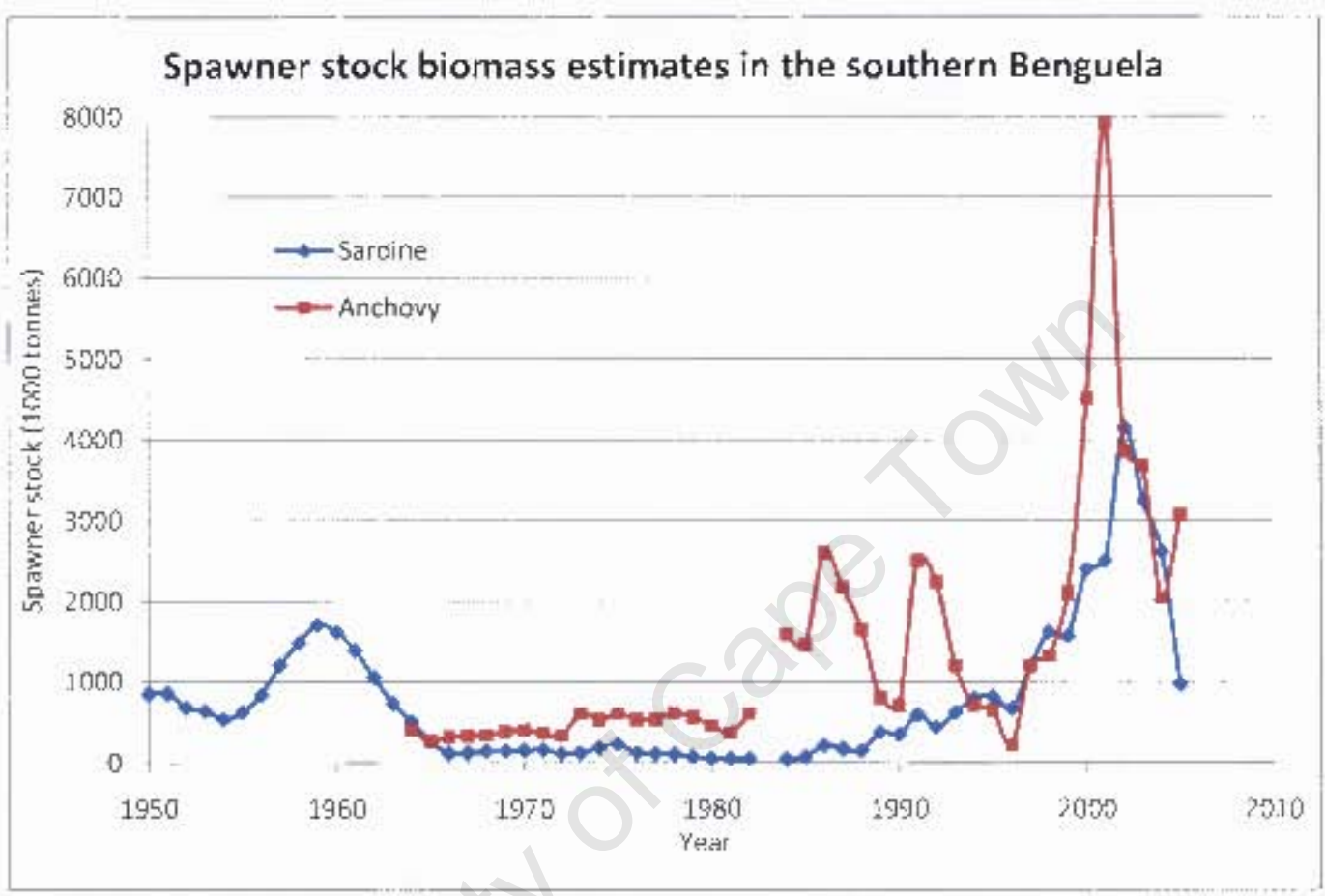

Figure 1 - Spawner stock biomass estimates of sardine and anchovy in the southern Benguela, showing a high degree of inter-annual variability. Note: figures before 1982 are 'Econstructed virtual populaton assessmert (VPAj data ivan der I inger e1 al. 2006a. updated by Mar r'e and Coastal Management;.

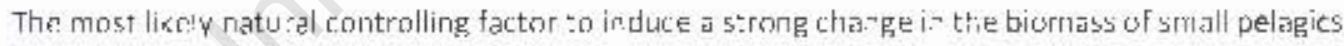

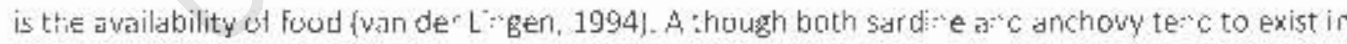
cacr. system, and a part cular system tends to bo dominated by cither one or the other at any given point, d'ect comperit: does not appear to expla "- the cata as the two species eat c ffere - food, with anktiowy predorni-a-tly employi g particu ate feeding on lage zoopla. eton and sardine ove whelm rg y choosi.ng to filter feed on small roopianktor and phy-oplankton fvan dor Linger. 1994). For bo:h sardine and afcrowy, foce availability is related to upwelling strengtr, but idiffere": ways: anchowy requ "e strong upwelling and coid water for spaw: "i="g success a"c su vival of le vae to recruitment, as :hese cond tions tavour the gr uwth of large zocplankton. Sarcine, in 
contrast, depend on warmer water for the preferential growth of smaller zooplankton, and exhibit reduced recruitment success under conditions of strong upwelling (Borges et al., 2003). Although a strong inverse correlation between small pelagics and their favoured prey is generally observed, it is difficult to determine whether this is due to top-down or bottom-up control: i.e., whether there is an increase in large zooplankton due to decreased predation by anchovy, or whether the increase in large zooplankton occurs because the small pelagic system is moving towards sardine dominance as a result of reduced predation pressure on sardine (Verheye and Richardson, 1998).

Historical records under negligible or non-existent fishing also support the regime shift patterns between sardine and anchovy dominance in upwelling systems, even in the absence of human intervention (Baumgartner et al., 1992). Natural fluctuations of the populations in the upwelling system off California are believed to have operated historically in alternating cycles of anchovy and sardine dominance, as evidenced by scale-deposition analysis of sediment samples (Baumgartner et al., 1992).

\subsubsection{Regime Shifts}

Regime shifts are described as major changes in the structure of an ecosystem which alter the energy flows in the system across several trophic levels and species (Jarre et al., 2006). The transition period should also be short in relation to the time spent within each regime (Jarre et al., 2006). Within the data record for the Benguela system, there have been clear regime shifts due to human influences (i.e. fishing pressure) and also regime shifts from largely environmental forcing (Cury and Shannon, 2004).

The data for the time series from 1950 in the southern Benguela have been analysed through the sequential t-test algorithm for regime shifts (STARS), and there was clear evidence of two major ecosystem changes in the 1960 s and early 2000 s (Howard et al., 2007). The first of these was 
thought to be due to excessive fishing pressure, while the later change was driven more by environmental influences than human activity (Howard et al., 2007). There is also some evidence of ecosystem shifts in the 1950 s and the mid-1970s (Howard et al., 2007).

The STARS analysis included a broad range of data series from Marine and Coastal Management, in part unpublished, which were kindly made available to us, complemented by oceanographic data series pertaining to coast and shelf extracted and kindly put at our disposal by Dr. Claude Roy (IRD Brest, France). With the oceanographic data it is possible to assess the suitability of the environmental conditions to either anchovy or sardine recruitment, even in the absence of survey data. Further support is found in seabird abundance data from the 1950 s to present, which critically depend on small pelagics. Another helpful data series stems from snoek (Thyrsites atun), which feeds largely on small pelagics, but is enough of a generalist that its stomach contents are thought to reflect prey species availability in the sea (McQueen and Griffiths, 2004). Snoek diet composition data suggest low anchovy abundance in the late 1950s, and an increasing proportion of anchovy in snoek diet (most likely due to depleted sardine stocks and relatively high anchovy abundance) in the late 1960s and early 1970s (Marine and Coastal Management, unpublished data) suggest anchovy dominance over sardine.

Indicators for such ecosystem regime shifts would ideally be data at a primary productivity level (e.g. Tester et al., 1997). In the southern Benguela ecosystem, however, the current understanding of the dynamics of primary production is not sufficient to observe regime shifts from phytoplankton data (Demarcq et al., 2008), and multiyear gaps as well as seasonal restriction in the zooplankton data (Verheye et al., 1998) hinder the understanding of long-term zooplankton dynamics (Verheye et al., 1998). The data from the planktivores, at the basis of the intermediate and high levels of the food web, allow for analysis of regime shifts at an ecosystem scale (Howard et al. 2007). 


\subsubsection{Modelling for fisheries management}

The modelling exercise conducted for this research is seen as a step in a larger process of building more useful systems for providing scientific support for fisheries management decisions. The models described and built in this study are all highly stochastic, as the pertinent features of the system (sardine and anchovy population levels, climate characteristics, etc.) are all characterised by high variability. Any outputs from the models are thus qualitative and probabilistic in nature: it is not possible to say, in a stochastic system, that if the fisheries are managed with a certain plan, that there will be a certain precise level of harvest of sardine and anchovy which can be expected. It is possible, however, to begin to assign probabilities to certain outcomes under various management strategies.

Models such as those described in this paper allow us to explore consequences on an ecosystem scale and then contribute to the "probability of change" for expert systems (such as proposed by Jarre et al., 2006). In the context of a complex ecosystem, models which look at the stocks at an ecosystem level (rather than single species under fishing pressure) are far more useful for exploring the effects of long-term ecosystem changes in a way which provides realistic outputs for management (Jarre et al., 2006). Importantly, objective-focussed models allow us to start linking management actions and strategies with specific objectives. Through the exercise of constructing and experimenting with the models built to meet specific objectives (rather than all-purpose simulations), an understanding can develop of what indicators are pertinent for a decision-making procedure. This helps to give more relevance to the current inputs to the decision process (survey fish stocks, climate data, etc.), and also may suggest additional data which would be useful as indicators for fisheries management. Indicators are valuable as tools for management and allow for multi-disciplinary analysis of collected data and the development of a knowledge base for management (Fairweather et al., 2006b). 
Rule-based modelling is particularly valuable in a multi-stakeholder context, where the comparative ease of understanding inherent in a rule-based system can make it easier to win support from nonscientific users and decision makers (Jarre et al., 2008).

\subsection{Frame-based modelling of ecosystem dynamics for management}

\subsubsection{The frame-based modelling paradigm}

Our specific area of investigation in this study is the applicability of frame-based modelling to evaluating fisheries management strategies. Traditional modelling techniques have faced challenges when attempting to describe complex ecosystem interactions. Classical predator-prey models such as those described by Lotka and Volterra in the 1920 s are mathematically neat, but fail to account for the complexities of real-world food webs and the stochasticity of species populations in an unpredictable environment. The other extreme, involving massively complex combined ecosystem models in which each physical and biological element is modelled individually, typically becomes too complex to be either reliable or useful. Compounding uncertainties in each of the components in such a model are an inescapable challenge, and the time and expense of developing such a system for management purposes is difficult to justify (Degnbol, 2003). In this light, it is useful to build a model by starting with a specific objective, and then create the simplest model which can adequately meet that objective. Any layer of complexity which is not strictly relevant in light of the objective can then be omitted for simplicity (Starfield and Bleloch, 1991).

To illustrate with a practical example, let us consider a model for the management of the sardine and anchovy fishery. A complex ecosystem model incorporating the climate and physical dynamics of the southern Benguela upwelling system would be extremely difficult and time-consuming to develop, and may not be realistic in its reactions to external factors such as fishing pressure. Although such models are under development (Shin et al., 2004; Shannon et al., 2009), it has not yet 
been possible to bridge the dynamics at various scales into a model useful for management. In pursuing an alternative approach, we rather start with a general objective:

"We need to model the population response of sardine and anchovy to the influences of fishing pressure and climate variability, such that we can make recommendations as to the most appropriate management strategy for their fisheries under given conditions of population structure and climate."

With this as our goal, anything which does not influence the management strategy can be disregarded. Seabird activity, benthic structure, interactions between all other parts of the ecosystem can all be eliminated. We do not pretend that the resulting model will be an accurate and comprehensive description of the ecosystem, and for the successful implementation of an ecosystem approach to fisheries (EAF), we may need to introduce some of these factors into a later version of the model. But we do believe that a model can be built which will answer our questions in a way which suggests an appropriate course of action for the fisheries management and takes into account the long-term trends and underlying health of the small pelagic populations.

We observe that ecosystem dynamics can often be considered in terms of quasi-stable periods of equilibrium, punctuated by relatively abrupt shifts to a new, also quasi-stable, state (e.g. Jarre et al., 2006). An early application of frame-based modelling described shifts in the character of a pine forest in terms of stable states (or "frames") which last for several decades, until an abrupt shift moves the forest to an alternative, also stable, state (Tester et al., 1997). Each frame in such a system can be modelled independently, provided that the rules which determine the switching between frames are adequately described. The objective of the pine forest model was to optimise time spent in certain frames for the purposes of forestry management, and so while in any particular frame, the model needed only to determine whether it stayed in that frame for another year or switched to an alternative frame. 
For the pelagic fisheries, we observe that each of sardine and anchovy populations appear to fluctuate in a way that could be described by a "high" and "low" population state for each species. The ecosystem as a whole displays periods of "high" population for both sardine and anchovy, periods where only one species is dominant, and periods where both species are in a "low" population state. If our aim is to understand the frame-switching well enough to consider management implications, we need to describe each frame well enough to determine whether the system stays in that frame or moves into another frame. It will of course also be necessary to have a reasonable understanding of the mechanics within the individual frames.

Inherent in frame-based modelling is the concept of a "daemon", which is described as an agent (independent of the frames) which monitors the dynamics within the frames, and which will prompt the model to switch frames. The default behaviour of the overall model is to stay within a frame unless a daemon prompts a shift to a new frame. The switching rules are thus encapsulated in the daemon, not within each specific frame.

\subsubsection{Spatial aspects}

The general approach for using frames to model ecosystem dynamics is a three-part process (Starfield and Chapin, 1996; Rupp et al., 2000a):

1. Break down the system into suitable spatial units (or blocks).

2. Model the dynamics within a particular spatial unit with a frame-based model

3. Model the dynamics between adjacent blocks with cellular automata.

For this study, a fine-resolution partition of the area into blocks is not useful, as the spatial aspects within a region (e.g. Southern Benguela, Eastern Cape, etc.) are not relevant: the populations under consideration are mobile throughout the region, rather than being spatially discrete. Furthermore, 
management of the fisheries is not spatially specific: the TAC (Total Allowable Catch) quotas for each species are allocated annually to the entire region. Thus the ecosystem dynamics of the entire area can be described by frame-based modelling alone. 


\section{Materials and methods}

\subsection{Description of frames and frame-shifts in the Southern Benguela}

An important feature of frames in small pelagic systems is the potential for short residence times and fast frame switching due to the short lives of the species involved. In contrast to, for instance, a model of a forest in which the trees can live for many decades, the species that we are modelling recruit after one year and live for 3-8 years. Thus there is the potential for a significant change to take place in the population levels in time periods of the order of 1-2 years (van der Lingen et al., 2006a).

The regime shifts in the southern Benguela are driven by bottom-up ecosystem influences, in contrast to the less productive northern Benguela, which appears to be more susceptible to the topdown influence of fishing to initiate regime shifts (Cury and Shannon, 2004). The southern Benguela saw a sharp decline in sardine stock sizes after poor recruitment and heavy fishing in the 1960s, followed by a recovery in the sardine stocks from the mid-1980s (van der Lingen et al., 2006a). In the northern Benguela, by contrast, when the sardine population declined after heavy fishing and poor recruitment from 1965-75, the system did not exhibit a simple shift to an anchovy regime, as the ecosystem niche had been filled instead by other planktivorous fish such as horse mackerel (Trachurus capensis) and bearded goby (Sufflogobius bibarbatus) (Boyer and Hampton, 2001). It is believed that heavy fishing on anchovy during the 1970 s exerted a top-down control which prompted the switch to an alternative goby / horse mackerel regime in the northern Benguela (Cury and Shannon, 2004).

The northern and southern Benguela show sharply contrasting regime shifts and responses to fishing pressure, despite the many similarities between the ecosystems (Cury and Shannon, 2004). An advantage of frame-based modelling in the face of such systems is that it allows for adaptation and inclusion of alternate new frames in the event that an ecosystem undergoes a fundamental change, 
rather than requiring an entirely new nodel 〈Rupp et al, 2000hl. Changes within a single frame, such as the sehriviour of ranchovy i" periods o "low" populatio", can also be conlined to that particular trane arid do not affect the res: of the model.

The traditional approach io modelling small pelagics has been to model alterriating dour ance of sardine and anchovy in a two state system (Jarre et a ., 1998; Shannon et al., 2003). We selieve tha: there is evidence of alternative states in which both species are si nulta ieously "high" or "low" (Howarc et al., 2007; Jarre et al., 2007), ard so we have inc:uced four frarres in our rodel.

The frames we consider mav be ustrated as i; Figure 2 . Note that the colours usec "or the frames in Figure 2 are retaned throughout the paper allc used in frame indicator hars "or each prototvpe.

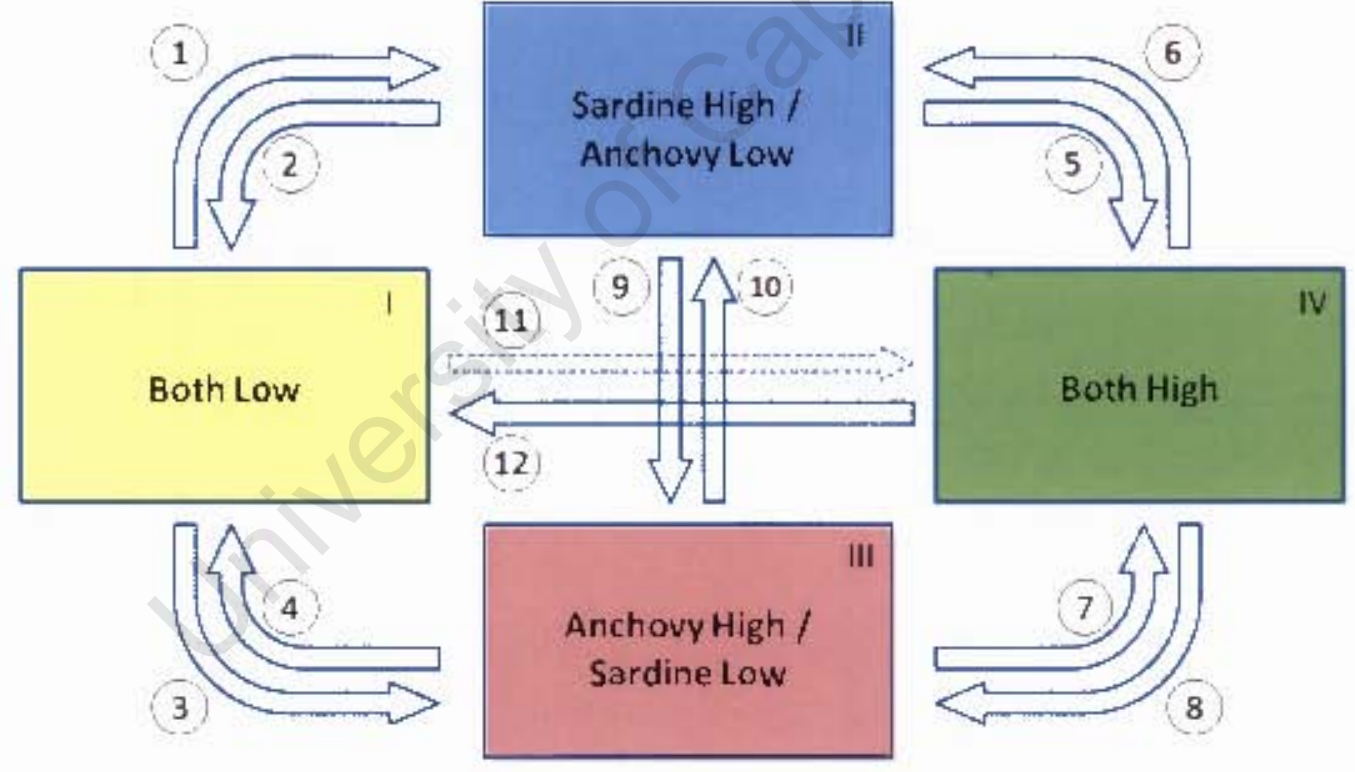

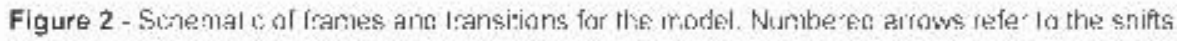
descr bec in the Table 2 
The frames which we consider are described in Table 1:

Table 1 - Frames considered for the modelled small pelagic ecosystem of the southern Benguela.

\begin{tabular}{|c|c|c|}
\hline Frame Name & Frame Characteristics & Examples / Literature \\
\hline $\begin{array}{l}\text { I. Both Species } \\
\text { Low }\end{array}$ & $\begin{array}{l}\text { Low stock sizes and low to moderate recruitment } \\
\text { of both species. Likely the result of simultaneous } \\
\text { over-fishing of sardine in conjunction with an } \\
\text { environment which is unfavourable for anchovy. }\end{array}$ & Mid-1960s [1] \\
\hline $\begin{array}{l}\text { II. Sardine high } \\
\text { / anchovy low }\end{array}$ & $\begin{array}{l}\text { High sardine population with moderate to high } \\
\text { recruitment, and poor to moderate anchovy } \\
\text { recruitment. }\end{array}$ & $\begin{array}{l}\text { Late } 1950 \text { s (snoek diet } \\
\text { data and small pelagic } \\
\text { larvae monitoring data } \\
\text { suggest sardine } \\
\text { dominance [1]) } \\
\text { Mid-1990s [1] }\end{array}$ \\
\hline $\begin{array}{l}\text { III. Anchovy high } \\
\text { / sardine low }\end{array}$ & $\begin{array}{l}\text { Low sardine population with high anchovy } \\
\text { population and highly variable anchovy } \\
\text { recruitment. Most likely due to (previous or } \\
\text { continued) overfishing of sardine in an } \\
\text { environment favourable for anchovy. Heavy } \\
\text { anchovy fishing may also have a negative } \\
\text { influence on sardine due to juvenile sardine } \\
\text { bycatch. }\end{array}$ & Early 1980s [1] \\
\hline $\begin{array}{l}\text { IV. Both species } \\
\text { high }\end{array}$ & $\begin{array}{l}\text { Anchovy will tend towards a "high" state under } \\
\text { suitable environmental conditions. Sardine will } \\
\text { tend to remain "high" under carefully managed, } \\
\text { light fishing even if environmental conditions are } \\
\text { sub-optimal. }\end{array}$ & $\begin{array}{l}\text { Early } 2000 \text { s [1]. Appears } \\
\text { to also have been } \\
\text { influenced by the } \\
\text { increased habitat made } \\
\text { available by increased } \\
\text { upwelling along the south } \\
\text { coast.[2] }\end{array}$ \\
\hline \multicolumn{3}{|c|}{ [1] Marine and Coastal Management (unpublished data) } \\
\hline
\end{tabular}

The conditions which would prompt switching between these frames are detailed in Table 2. 
Table 2 - Shift conditions for switching between the frames described in Table 1.

\begin{tabular}{|c|c|c|}
\hline Shifts & Mechanism & Examples and Literature \\
\hline \multicolumn{3}{|c|}{ From Both Species Low: } \\
\hline $\begin{array}{l}\text { Switches to } \\
\text { Sardine High } \\
\text { (1) }\end{array}$ & $\begin{array}{l}\text { in conditions of weak upwelling (which favours small } \\
\text { meso-zooplankton and flagellates). Such conditions are } \\
\text { not as favourable to anchovy due to reduced } \\
\text { productivity of large diatoms [1]. }\end{array}$ & Early to mid-1990s. \\
\hline $\begin{array}{l}\text { Switches to } \\
\text { Anchovy High } \\
\text { (3) }\end{array}$ & $\begin{array}{l}\text { under continuous fishing pressure on sardine and } \\
\text { strong upwelling (which favours diatom growth and } \\
\text { large meso-zooplankton, good for anchovy). }\end{array}$ & $\begin{array}{l}\text { Possibly occurred with } \\
\text { the shift in upwelling } \\
\text { strength in the early } \\
1970 \text { s [2] }\end{array}$ \\
\hline $\begin{array}{l}\text { Switching } \\
\text { directly to } \\
\text { Both High (11) }\end{array}$ & $\begin{array}{l}\text { is not thought to be possible. Under a theoretically } \\
\text { "favourable for all" situation, the anchovy population } \\
\text { should recover faster due to their faster population } \\
\text { growth rate and younger age at maturity, so the system } \\
\text { should move through the Anchovy High frame first. }\end{array}$ & $\begin{array}{l}\text { Unobserved and } \\
\text { considered implausible. }\end{array}$ \\
\hline \multicolumn{3}{|c|}{ From Sardine High: } \\
\hline $\begin{array}{l}\text { Switches to } \\
\text { Both Low (2) }\end{array}$ & $\begin{array}{l}\text { in conditions of continued weak upwelling (which } \\
\text { remains unfavourable to anchovy recovery) and } \\
\text { excessive fishing pressure on sardine. This may either } \\
\text { be direct sardine fishing or excessive bycatch of juvenile } \\
\text { sardine from anchovy- directed fishing. }\end{array}$ & $\begin{array}{l}\text { Early } 1960 \text { s, following } \\
\text { heavy sardine-directed } \\
\text { fishing }\end{array}$ \\
\hline $\begin{array}{l}\text { Switches to } \\
\text { Anchovy High } \\
\text { (9) }\end{array}$ & $\begin{array}{l}\text { under excessive fishing pressure on sardine and strong } \\
\text { upwelling (which favours diatom growth and is thus } \\
\text { good for anchovy). As before, fishing pressure on } \\
\text { sardine may be either direct or bycatch-driven. }\end{array}$ & $\begin{array}{l}\text { Observed in other } \\
\text { systems. }\end{array}$ \\
\hline $\begin{array}{l}\text { Switches to } \\
\text { Both High (5) }\end{array}$ & $\begin{array}{l}\text { under continued low fishing pressure on sardine (or a } \\
\text { reduction in sardine fishing) coupled with improving } \\
\text { environmental factors for anchovy recruitment (such as } \\
\text { stronger upwelling). }\end{array}$ & $\begin{array}{l}\text { 1999/2000. The } \\
\text { oceanography through } \\
\text { the late } 1990 \text { s became } \\
\text { more favourable for } \\
\text { anchovy, particularly } \\
\text { with the cooling of the } \\
\text { Agulhas Bank [3] }\end{array}$ \\
\hline
\end{tabular}


Table 2 (contd.)

\begin{tabular}{|c|c|c|}
\hline \multicolumn{3}{|c|}{ From Anchovy High: } \\
\hline $\begin{array}{l}\text { Switches to } \\
\text { Both Low (4) }\end{array}$ & $\begin{array}{l}\text { in conditions of continued fishing pressure on sardine } \\
\text { (which inhibits sardine recovery) and deteriorating } \\
\text { environmental conditions for anchovy. }\end{array}$ & Mid 1980s? \\
\hline $\begin{array}{l}\text { Switches to } \\
\text { Sardine High } \\
\text { (10) }\end{array}$ & $\begin{array}{l}\text { under low fishing pressure on sardine (which allows the } \\
\text { sardine to recover) and reduced environmental } \\
\text { favourability for anchovy. Environmental factors which } \\
\text { are less favourable for anchovy will tend to aid the } \\
\text { sardine recovery with sufficiently low sardine fishing. }\end{array}$ & $\begin{array}{l}\text { Observed in other } \\
\text { systems. }\end{array}$ \\
\hline $\begin{array}{l}\text { Switching to } \\
\text { Both High (7) }\end{array}$ & $\begin{array}{l}\text { would occur under continued favourable environmental } \\
\text { conditions for anchovy recruitment (strong upwelling, } \\
\text { etc) and reduced fishing pressure on sardine, which } \\
\text { would allow for a recovery of the sardine population } \\
\text { while remaining conducive to a high anchovy } \\
\text { population. }\end{array}$ & $\begin{array}{l}\text { Hypothesised for } \\
\text { southern Benguela }\end{array}$ \\
\hline \multicolumn{3}{|c|}{ From Both High: } \\
\hline $\begin{array}{l}\text { Switches to } \\
\text { Both Low (12) }\end{array}$ & $\begin{array}{l}\text { under excessive fishing pressure on sardine coupled } \\
\text { with deteriorating environmental conditions for } \\
\text { anchovy. }\end{array}$ & $\begin{array}{l}\text { Hypothesised for } \\
\text { southern Benguela }\end{array}$ \\
\hline $\begin{array}{l}\text { Switches to } \\
\text { Anchovy High } \\
\text { (8) }\end{array}$ & $\begin{array}{l}\text { under excessive sardine-directed fishing and continued } \\
\text { favourable environmental conditions for anchovy. }\end{array}$ & 2005-present [2] \\
\hline $\begin{array}{l}\text { Switching to } \\
\text { Sardine High } \\
\text { (6) }\end{array}$ & $\begin{array}{l}\text { would occur under continued low or absent fishing } \\
\text { pressure on sardine, coupled with deteriorating } \\
\text { environmental conditions for anchovy. }\end{array}$ & $\begin{array}{l}\text { Hypothesised for } \\
\text { southern Benguela }\end{array}$ \\
\hline $\begin{array}{l}\text { [1] van der Lin } \\
\text { [2] Howard (20 } \\
\text { [3] Roy et al. (2 }\end{array}$ & $\begin{array}{l}\text { en et al. (2006b) } \\
\text { 7) } \\
\text { 07) }\end{array}$ & \\
\hline
\end{tabular}

The driving forces of the shifts described above are:

- Fishing pressure, both from the sardine and from the anchovy fishery. Most influence from the fishery is felt in the sardine population, whether from direct increased sardine mortality from targeted fishing of the sardine stock, or from increased juvenile sardine bycatch mortality from the anchovy fishery. Sardine bycatch should be more significant in the "low"" sardine frames due to increased mixed schooling (Bakun, 2001). 
- Environmental factors, which operate most markedly on anchovy but also affect sardine, (albeit to a lesser degree as they are less selective planktivores (van der Lingen et al, 2006b)). In addition to upwelling strength and the related availability of suitable plankton prey, factors such as the strength of transport currents towards and around the Cape of Good Hope in Novermber-December and the water temperature on the Agulhas Bank in September-October are important for successful anchovy recruitment (Miller and Field, 2002). Both species predominantly spawn on the Agulhas Bank and rely on transport currents to carry the larvae to the West Coast (van der Lingen et al., 2001). Relatively minor environmental shifts have been shown to produce significant shifts in geographical and population structure of anchovy (Roy et al., 2007).

- Current population level may be a factor due to sardine recruitment being limited by density-dependence (e.g. van der Lingen et al., 2006c), and the higher probability of the "school trap" phenomenon when the sardine population is low (Bakun, 2001).

Note that the default behaviour in all frames is to remain in that frame. A shift will only occur if conditions are met to force that shift. The rules which govern the shifts and the definitions of the frames are believed to be a useful representation of the underlying ecosystem, and thus are retained throughout the modelling exercise. The specific details of the models for each frame and the details of the daemons which prompt shifts between the frames will be determined individually for each successive prototype.

The time-step for the model is one year. Both sardine and anchovy spawn annually, and fisheries management strategy is unlikely to be updated more frequently than annually (although the TAC may be updated throughout the season), so reducing the time-step does not appear to confer any advantage. 


\subsection{Rapid prototyping}

The modelling paradigm which is employed in the frame-based approach uses rapid prototyping to test initial hypotheses and assumptions. Based on the success (or limitations) of an initial prototype, a more detailed model can be developed, incrementally adding more complexity as gaps are identified and confidence in the general usefulness of the model grows. This allows the modeller to test an hypothesis during the model development and quickly adapt the model in light of the results.

There is also a great practical advantage to producing successive generations of models which are complete in themselves, because at any stage of the process there is a model available which can be exercised to address any urgent questions (Starfield, 1997). It may not be the best possible model, or the final generation of what is planned, but it is more immediately useful than a large and complex system which will only be useable once all the pieces are in place.

There are also advantages to starting with a simplified model even in cases where it is predicted that a detailed model will ultimately be needed. A simple initial model aids in clarifying objectives of the final model and improves understanding of the system which is being modelled (Starfield and Bleloch, 1991). Assumption and sensitivity analyses performed on an early prototype can then be used to inform the next generation of model (Starfield, 1997). Through the process of constructing a simplified "thought experiment" prototype and subjecting it to a rigorous analysis of assumptions and sensitivities, it will likely become clearer what data are needed, where the deficiencies in understanding are, and how to plot the course for a more complex version if necessary (Starfield and Jarre, in review). There is also a need for a thorough examination of plausible alternatives to the mechanisms involved wherever assumptions are made in the model (Nicholson et al., 2002).

As a mechanism and laboratory for conducting thought experiments, simple models may be more useful for communicating ideas and clarifying objectives in an inter-disciplinary team. In contrast to inscrutable or "black-box" models, which may be counter-productive at promoting common 
understanding in a an inter-disciplinary environment, simple models serve well as clarifying tools (Nicholson et al., 2002). Simple models can be adapted and redeveloped easily and cheaply as the group objectives become clearer.

For this study, all model design work was done in custom-written computer programmes (each prototype in a separate programme). The software for each prototype was developed entirely by the author. The code was written in C\#, and the graphical user interface (GUI) for each model was designed for Microsoft ${ }^{\oplus}$ Windows ${ }^{\circledast}$ compatibility.

The term "crash" is often used in fisheries modelling to indicate a precipitous decline in stock size. With reference to our model, we refer to a "crash" of the sardine stock as an event in which the modelled sardine population drops to zero. Although a zero-size population is seldom achieved in real-world fishing (as the increasingly scarce target fish offer decreasing financial returns for the fishing effort), it is a useful simplification to allow our population model to be fished to zero for two reasons. Firstly, if the sardine were fished to extremely low stock sizes, it is possible that the ecosystem dynamics would be fundamentally affected (e.g., shift to a jellyfish/goby regime, as observed in the northern Benguela). Secondly, our model is designed as a prototype training tool for fisheries management. In this respect, a situation of totally depleted sardine should be regarded as a failure of the fisheries management for that model run. 


\section{First Prototype}

\subsection{Description of the first prototype}

\subsubsection{Programme overview}

The initial prototype simulates 50 years of operation with a 1-yr time-step. The forcing factors which are included are:

- Sardine fishing activity, which is seen as influencing the sardine population model

- A general "Environmental Suitability Index" (ESI), which acts as a proxy for upwelling strength, sea surface temperature, spawning success, larvae condition, transport strength around the Cape of Good Hope and food availability. This factor strongly influences the modelled recruitment success of the anchovy population, and has a much weaker inverse influence on the sardine recruitment.

- Current population level of sardine, which is understood to influence recovery rate of the population due to density-dependent factors when the population is high.

Factors which are consciously ignored by this prototype include:

- More specific details on the factors making up the ESI, which would provide excessive additional complexity for the first prototype.

- The influence of the anchovy fishery on the anchovy population. Anchovy appear to have sufficiently random recruitment at observed levels of spawning stock size that it was not considered useful to use a detailed population model for that species.

- The influence of juvenile sardine bycatch from the anchovy fishery. A potential factor to be considered in later prototypes is that in reduced populations of sardine, increased frequency of juvenile sardine schooling with anchovy has been reported. This would lead to a higher 
rate of juvenile sardine bycatch when the sardine population is already low if anchovy

fishing continues.

- Compliance issues within the fishing industry. Examples of compliance issues would be illegal, unregulated and unreported (IUU) fishing operations, including unreported discard mortality. Either of these would result in a higher fishing mortality than the TAC set by fisheries management would suggest.

- Specific ecosystem influences, such as predator species populations.

We assume that the frame forcing factors which operate in the ecosystem actually operate only on individual species, and so our initial prototype operates with an independent forcing agent (daemon) operating on each species.

For this prototype, as the species are modelled independently, the models within each of the frames are effectively the sum of whichever state the individual species are in. Thus the programme includes a sardine model which behaves differently in "high" and "low" states, and an anchovy model, similarly with two states. The model for the "Anchovy High / Sardine Low" frame is the combined model of the "high" state anchovy model and the "low" state sardine model.

Note: All population numbers used in the models are more or less arbitrary, and are useful only for comparative purposes. Some understanding of the stock biomasses involved could be obtained by assuming that all figures are in units of million tonnes of fish. This would bring stock sizes into the same order of magnitude as the historical biomass estimates.

Note: All random numbers have been generated to fit a truncated Gaussian distribution (by averaging three random numbers), rather than a standard "flat" random number generation. 


\subsubsection{Anchovy Model}

The anchovy population is modelled entirely stochastically. The population is random about a defined midpoint, with a defined variability.

- Anchovy Low: the population fluctuates about 0.5 , with a variability of $+/-0.3$

- Anchovy High: the population fluctuates about 1.5 , with a variability of $+/-0.8$

Note that the model for anchovy looks at the frame rather than the ESI for a specific year. We will see later that the anchovy daemon will prompt a shift to a new frame for anchovy based on the ESI, but the actual determination of the population is done according to the frame.

\subsubsection{Sardine Model}

The sardine follow a stochastic population model. The model determines the population for each successive year according to Equation 1.

$$
N_{t+1}=N_{t} e^{-z}+b_{t}\left(\frac{N_{t}}{N_{t}+B}\right)-F_{t}
$$

- $N_{t}$ : the modelled sardine population in year $t$. We use an arbitrary initial value of $N=1$ for the model.

- $z$ : the natural mortality, is considered to be constant (set to 0.5 ).

- $B$ : which determines the recruitment, is constant (set to 0.3 ).

- $F_{t}:$ which represents the modelled sardine mortality due to fishing in year $t$.

- $\quad b$ : the recovery rate, is variable both within and between frames: 
- To introduce a level of stochasticity to the population, $b_{t}$ (the actual value of $b$ used for the population generation of a particular year) is also randomised. The base value for $b$ is 0.6 , with a variance of $+/-0.3$ in any given year.

- $b$ is scaled down by a factor of 0.8 for a given year if ESI $>5$ (indicating that the environment favours anchovy and is therefore less favourable for sardine).

- Based on density-dependency, the term is scaled up by a factor of 1.3 if the current frame is a Sardine Low system.

\subsubsection{Forcing factors}

The two forcing factors we consider are:

\section{a. Environmental Suitability Index (ESI)}

We consider the ESI to act as a proxy for the net effect of all the climatic and geographic forcings which affect the small pelagics. With our time-scales, the most significant observed effect is a roughly decadal temperature cycle, which is reflected in variation of sea-surface temperature (SST) data. The ESI is an integer value from 0-9, with a higher value indicating a more favourable environmental situation for anchovy recruitment.

Our model for the ESI involves a randomly generated integer which moves about a defined midpoint. Over the 50 year cycle, the ESI is determined according to this pattern:

- $\quad$ Year 0-9: $\mathrm{ESI}=2,+/-1$

- Year 10-19: $\mathrm{ESI}=6,+/-1$

- Year 20-29: $\mathrm{ESI}=2,+/-1$ 
- $\quad$ Year 30-39: $\mathrm{ESI}=8,+/-1$

- Year 40-50: $\mathrm{ESI}=2,+/-1$

\section{b. Sardine fishing}

We use a Total Allowable Catch (TAC) model for the fisheries management, assuming $100 \%$ compliance by the fisheries and $100 \%$ success in catching the full TAC for a given year. In order to be able to compare the effects of different fishing strategies, we have modelled the following scenarios:

- No fishing.

- A fixed TAC for the entire 50-yr run. While unrealistic in practice, this does give an interesting reference point for alternative strategies. The model allows for a userdefined figure for the fixed TAC.

- Variable TAC. Under this setting, a simulated "robot manager" reacts to the changing population levels. This function looks at the stocks annually and sets the TAC for the following year according to a set of rules:

If $\mathrm{Pop}_{(\mathrm{t}-1)}>0.6, \mathrm{TAC}=0.4$

If $0.6 \geq \operatorname{Pop}_{(t-1)}>0.4, \mathrm{TAC}=0.2$

If $0.4 \geq P_{\text {op }}(t-1), T A C=0$ 


\subsubsection{The Daemons}

Prototype 1 has a separate daemon for each of sardine and anchovy, such that the sardine daemon will push that species between "high" and "low" frames, and the anchovy daemon will operate similarly on the anchovy stock to prompt a shift between "high" and "low" frames.

The state of the population will not shift frame unless it is specifically prompted: i.e., the default response of system is to remain in its current frame.

\section{a. Sardine Daemon}

The sardine daemon is directed by the current population of sardine.

- If sardine is in a "high" state, the daemon will prompt the system to shift to a "low" frame if the sardine population is below 0.4 for each of three consecutive years.

- If sardine is in a "low" state, the daemon will prompt a shift to "high" if the yearly sardine population exceeds 0.7 for three consecutive years.

\section{b. Anchovy Daemon}

The anchovy daemon considers the Environmental Suitability Index, not the anchovy population.

- If the anchovy is in a "high" state, the daemon will prompt a shift to "low" if the ESI has been below 4 for three consecutive years.

- If the anchovy is in a "low" state, the daemon will prompt a shift to "high" if the ESI has been above 5 for three consecutive years. 
Looking back at the rules for ESI variation, this means that the modelled anchovy stock will invariably follow the following pattern (with a lag time of approximately 3 years):

- $1^{\text {st }}$ decade: "low" frame.

- $2^{\text {nd }}$ decade: may shift to a "high" frame for some or all of the decade.

- $3^{\text {rd }}$ decade: "low" frame.

- $4^{\text {th }}$ decade: definitely shift to a "high" frame.

- $5^{\text {th }}$ decade: “low" frame.

\subsubsection{Running the First Prototype}

The model in the first prototype runs according to this routine:

- After establishing the initial conditions, the programme generates data for fishing activity and climate effects based on the current frame.

- The daemons then look at the current and historical environmental situation and population levels, and decide whether to shift to a new frame or remain in the current frame.

- The sardine and anchovy stocks spawn, with their recruitment characteristics based on the current frame.

- Repeat for each subsequent year in the run.

A conceptual overview of the programme is shown in Figure 4. 


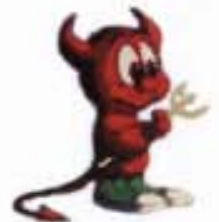

Check with disemons whether frames switch

Anchovy Daemon:

$\rightarrow$ Env Suit. Incex

Sardine Daemon:

$\rightarrow$ Population level
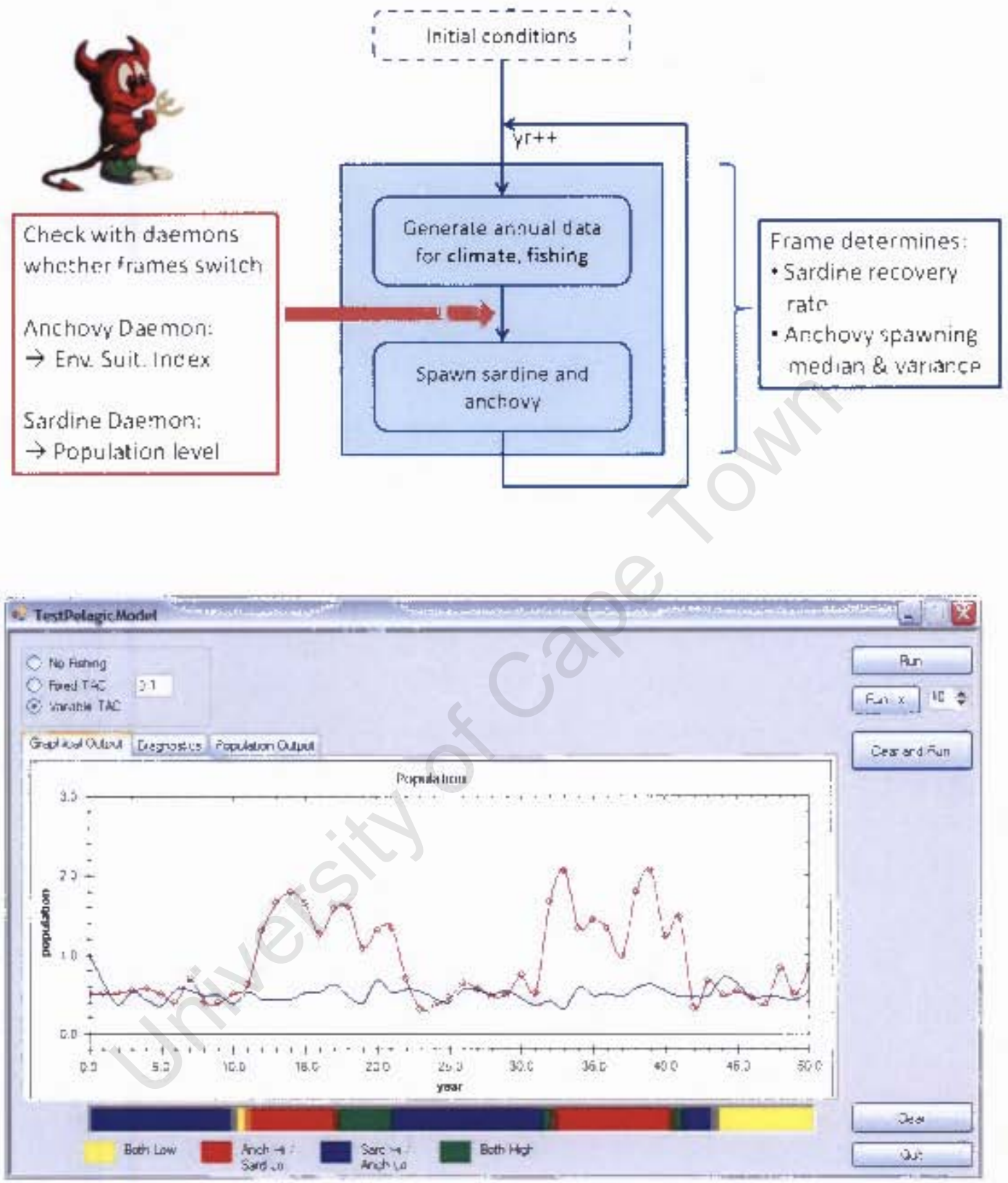

Figure 3. The graphical use- intertace (Cul) of the first prototype the red line ind:wat os the modelled anchowy stock the blue ine irdicalcs sardinc. Urder the Varable $-h \mathrm{c}$ setting the robot manager tries to maximise sardirie calch withoul endangermig the stock. The ceours Lsed by the frame indicator bar are labelled an the GUl. 


\subsection{Results from the first prototype}

A samp e output from the first prototype is showin in Figure. 5 . The mocel run was for 50 years, with no fishing throughout the run. The oius: line indicates mocelled sarutine popuiation; the red line indicates modellec anchovy population.

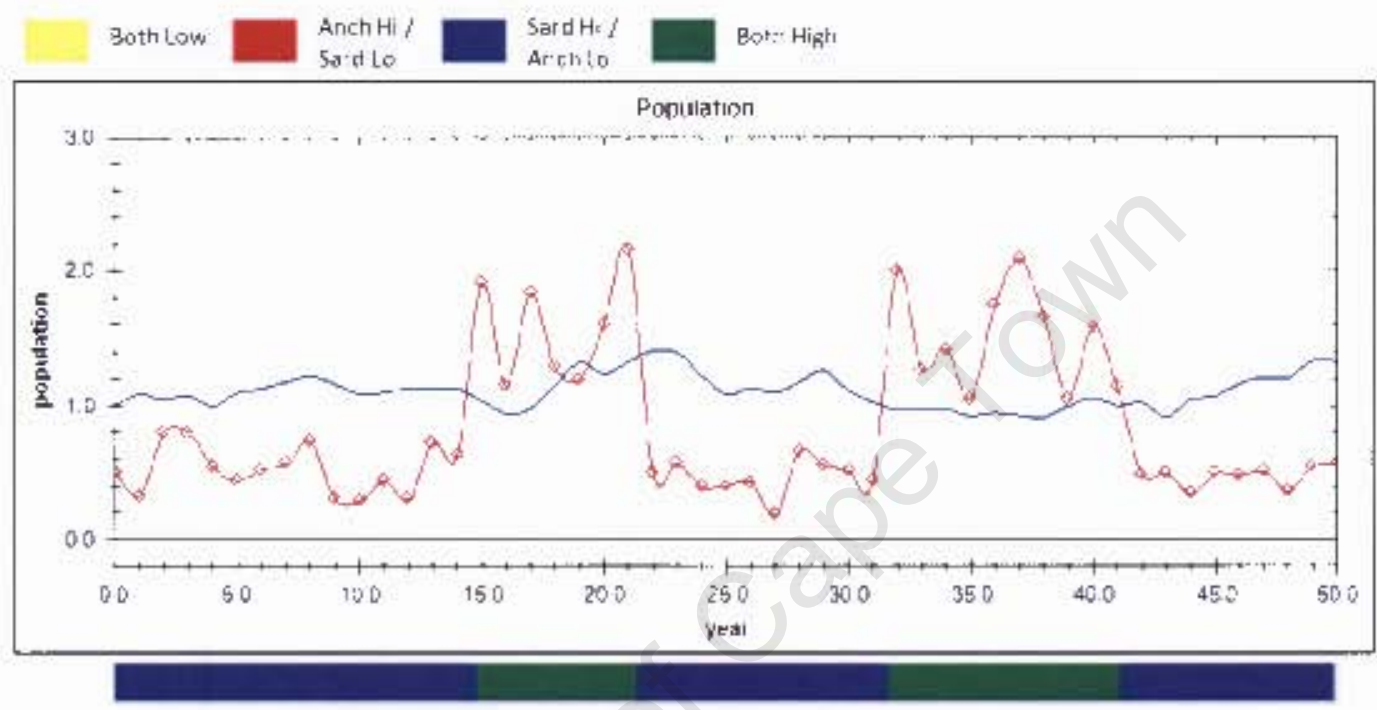

Figure 5 First Frototype output : or a single run. no fishir:g. Yhe blue line indicates sard.ne the red indlcates anchowy. Note that in the abscnoe of fishing the sardine stock stays continually in a high irame.

Figure 6 shows a similar result, also with no fishing, but in this case the results from ten runs have becen super mposed in eachother. Note that the sarcine stay continually in a "high" same in the: assence of fish ing. A m lo trend in the sardine populat on cle lo the ESI variation can also se observed. 


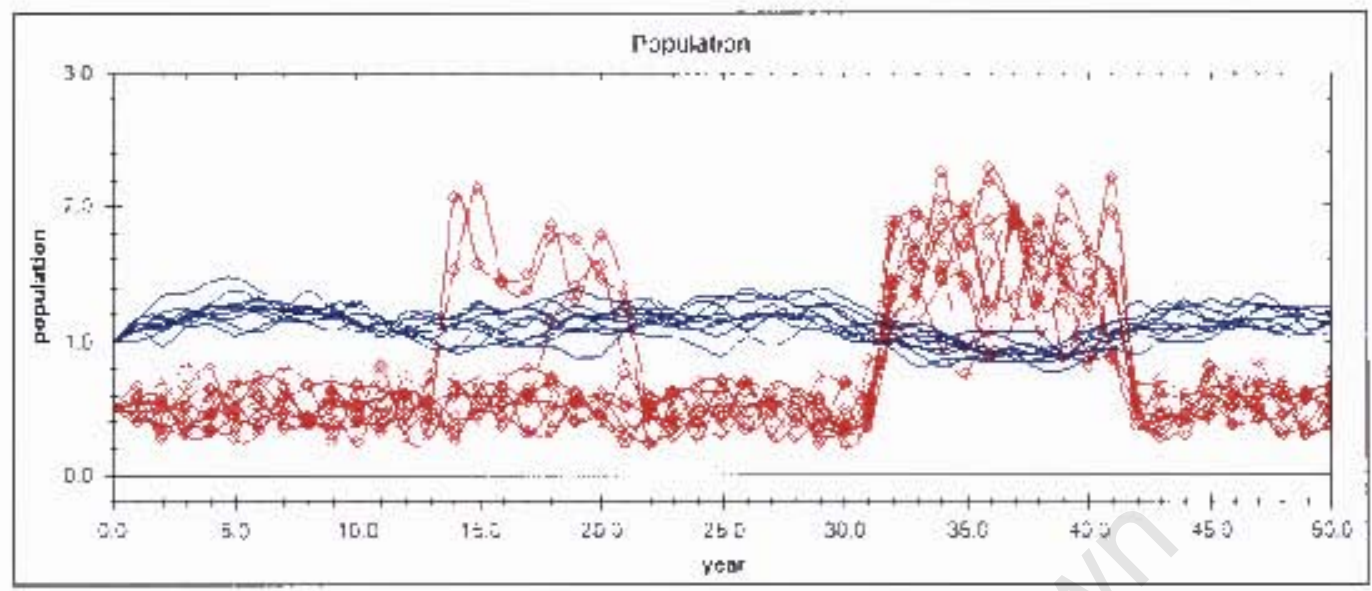

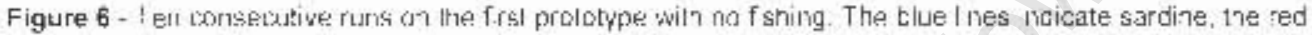

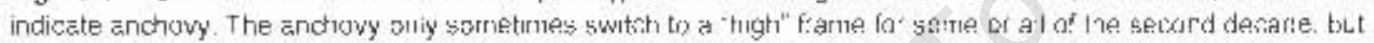
aliways switch to 'high' fo: the fourth decade. The nogerate trend in the sarcine posu ation tue to the ESI influense is clearly visable.

Figure 7 shows the eflest of mocerate tishine fconstant $\mathrm{XAC}_{\text {. }}$. Although the saroine population is not vet imser" ed by fishing, the pressure is sufficien: to promot a frame switch into the "low" sardine Tramies.

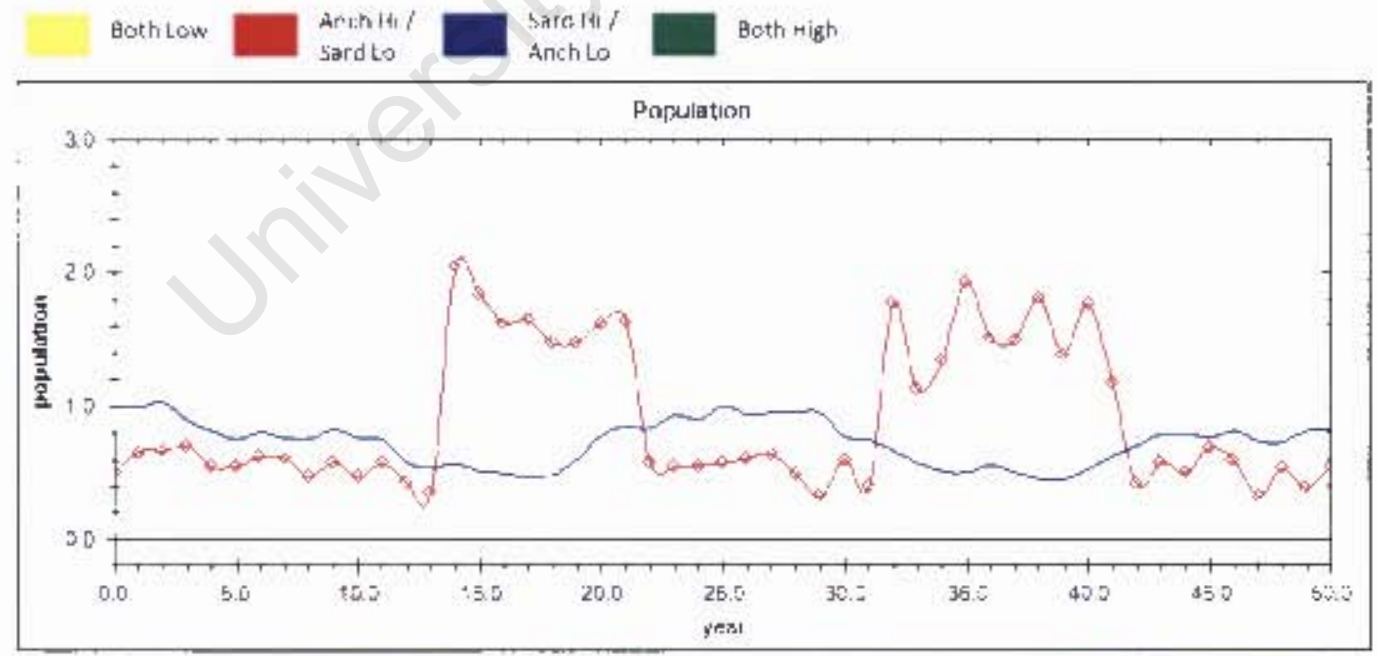

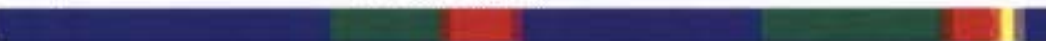

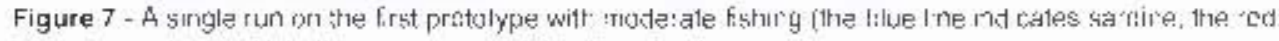
indicates anchovyi. Note the emergence of "low" sarcine trames. 
If the fishing encl is increäsed, it r:ay exert sufficient oressure that the sardine stock colleoses. By using multiple successive runs, nin estimnte crin be made $\mathrm{u}^{*}$ the likelihood o* stock collapse at vririous Icvols o ${ }^{*}$ ishing. Figure 8 shows the resul: of ten runs at a dangerous level of sardine fishing:

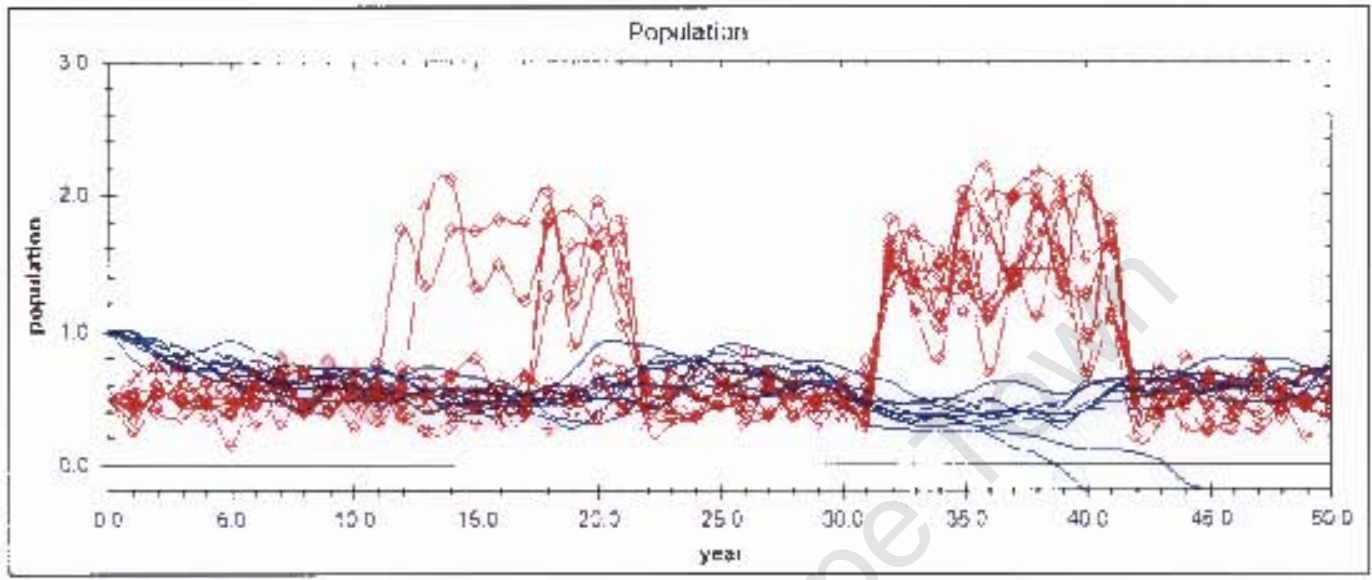

Figure 8 - Frst arototype, ten r.us with high sardine f shıng pressure (tue lines incicate sarcine, red inxicate archowy. The stock collapsed compleie.y during two of pe iuns.

Results such $r: 5$ those in Figure 8 -illowed us to evaluä:e "së"e" f shine limits of sardine under the modelled constra ins. Comvaring data on crash likelihood and average rnnual catch for di"zerent levels of fishing would be the first stes towards estaolishing marlagertent guidelines concerning the apt mal lewe s of fishing aressure w" ch can safely be sustained by the madelled sardine stock. Although the results "rom the firs: prozotyse were encournging, thorc wins irisufficient ssecies incerertion so usefu'ly simulato the complexitios of the real ecosystert. Certain asvecs of t"e

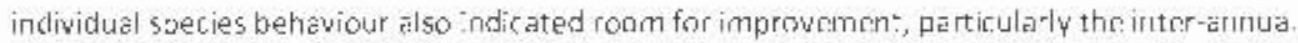
sopulation variabilizy $n$ the m:udelled sardine stock and the density-deatendent reaction of the sardine in the "low" "rames. Additional deta could also he collected "rom the m:odel to susoort menngement derisions. There was clear indication shat a more advarıed rtodel wou d be able to hand.e these issues mor setisfactorily. 


\subsection{Analysis of results and recommendations for second prototype}

Looking at the results of the first prototype, certain limitations became apparent which would need to be addressed in a more complex version:

- The model needed inter-species interaction, specifically in order to be able to model the effect of juvenile sardine bycatch from the anchovy fishing industry. As this can have a marked effect on the recovery of a struggling sardine population, it is a vital aspect for management consideration (de Moor and Butterworth, 2008).

- The capacity for an interactive approach to the fisheries management is needed, allowing the model user to adjust strategy in response to modelled population changes. This would be a more realistic scenario than simply setting a blanket policy for an entire 50-year run, and also allow the model to serve as a training tool to help users understand the impact of management intervention in the fisheries of the two stocks.

- The first prototype was not aliased with respect to starting population conditions. The starting conditions affected the modelled populations for the first 3-5 years, which has an impact on the statistical data collected for each model run. The record of each model run should rather start once the impact of initial conditions is no longer observable, so that the statistics more accurately reflect the behaviour of the system.

- Additional metrics for the system performance could be recorded, such as the standard deviation of populations in each frame and the bycatch of sardine from the anchovy fishery (once the anchovy fishery has been included).

- The sardine population was far more stable than the survey data would suggest. The recruitment variability in the sardine model should be adjusted to give a modelled population behaviour which is more consistent with the data record. 
- The ideal fishing strategy for sardine in the first prototype is to keep them in a "low" frame, where the increased recovery rate allows us to fish more heavily. This is inconsistent with the data record of fishing sardine in "high" and "low" states: in the real ecosystem, a "low" sardine population cannot be heavily fished without risking total collapse of the fishery, and this should be reflected in the model. The stems from two features in the model:

- The variability of the sardine recruitment is too low: with more variability there is a much greater chance that an unusually low recruitment in one year could critically imperil an already low sardine population.

The implementation of density-dependence in the model is flawed: it implies that the optimal situation for the species is to be permanently fished down into a "low" frame, which contradicts our understanding of a "low" frame as one where the species is vulnerable to collapse. For instance, we note that a "low" sardine frame is characterised by sub-optimal species behaviour such as a propensity to school with anchovy.

The theoretical benefit from density dependence in a "low" frame should be out-weighed by the relative scarcity of adult sardine and the resultant sub-optimal schooling. In a healthy population (i.e., in a "high" frame) the density dependence should still be a factor. 


\section{Second Prototype}

This section consists of a description of the second prototype model, followed by two results sections. After building the revised model, we performed a sensitivity and assumption analysis to build confidence in the model outputs. These analyses form the first results section. We then exercised the model in various scenario evaluations to explore some of the potential applications where the model could be useful.

\subsection{Description of second prototype}

The second prototype is based on the first model, with several significant enhancements and changes. Although the results from the first prototype were encouraging, it was recognised that there were aspects to both the model design and the parameters used that failed to give sufficiently useful outputs.

Like the initial model, the second prototype simulates 50 years of operation with a 1-yr time-step in each model run. Details for the modelled populations of sardine and anchovy are given below, along with an overview of the forcing factors and model mechanics.

\subsubsection{Sardine Model}

The sardine stock follows a simple stochastic population model, with the same underlying population equation as the first prototype (Equation 1). The parameters of the population model were adjusted to give higher variability, as the first prototype had produced a sardine population which was excessively stable compared to real-world data. The mortality, recovery rate and recruitment variability were all adjusted to provide a higher average population in the unfished 
system, but with a much higher inter-annual variability. The default parameter values for the second prototype can be seen on the interface in Figure 13.

Other specific improvements are detailed below:

- The parameter representing the fishing mortality in the population model was adapted to include a bycatch mortality of juvenile sardine from the anchovy fishery. The sardine model was also refined to store the recruitment level of each year, which was used as the population of juveniles for the following year's bycatch calculations.

The bycatch of juvenile sardine caught by the anchovy fishery in a given year was modelled as a product of the anchovy fishing level and the propensity for common schooling in the sardine population. We assumed a relatively conservative $20-40 \%$ propensity for juvenile sardine to school with anchovy (based on Fairweather et al., 2006a: Fig. 8a). This is represented in the model as a "school trap factor" $\left(f_{s t}\right)$, which is determined as in Table 3.

Table 3 - School trap factor by frame

\begin{tabular}{|l|l|}
\hline Frame & School Trap Factor \\
\hline Both high & $\begin{array}{l}\mathrm{f}_{\mathrm{st}}=0 \\
\text { When the sardine population is healthy (in a "high" frame), } \\
\text { the juvenile sardine are assumed to be able to find adult } \\
\text { sardine schools to swim with easily. }\end{array}$ \\
\hline Sard Hi / Anch Low & $\begin{array}{l}\mathrm{f}_{\text {st }}=0.4 \\
\text { The highest incidence of common schooling occurs when } \\
\text { anchovy schools are abundant and sardine are scarce. }\end{array}$ \\
\hline Anch Hi / Sard Low Low & $\begin{array}{l}\mathrm{f}_{\text {st }}=0.2 \\
\text { Due to the low level of sardine, the juveniles would tend to } \\
\text { school with anchovy. However, the lack of suitable anchovy } \\
\text { schools limits their ability to do so. }\end{array}$ \\
\hline
\end{tabular}

Once the school trap factor has been set, the level of juvenile bycatch is determined by the population of juvenile sardine (from the recruitment in the sardine population model for the previous year). The proportion of anchovy (as a percentage of population) which are caught in that year is given by the anchovy fishing model, and it is assumed that the same 
proportion of the vulnerable juvenile sardine (i.e., the population of sardine juveniles which are schooling with anchovy) will be caught as bycatch. The final calculation of the bycatch mortality is made according to Equation 2. In the equation, $S$ indicates sardine and $A$ indicates anchovy.

$$
S_{\text {bycatch }}=S_{\text {juveniles }} \times f_{\text {st }} \times \frac{A_{\text {catch }}}{A_{\text {population }}}
$$

The bycatch mortality is then added to the total sardine fishing mortality for the year.

- The density dependence of the sardine model was redesigned. The first model had a higher recovery rate in a "low" frame, which resulted in a more robust modelled sardine population which escaped a "low" frame very easily, even under significant fishing pressure. This is inconsistent with the data record, and also implies that the highest recovery rates are seen when the population is dangerously low, which is biologically unrealistic. The second prototype handles density dependence by modifying the recovery rate in the population model with a factor, $f_{D D}$, which is determined as in Table 4.

Table 4 - Determination of the sardine density dependence factor $\left(f_{D D}\right)$ by frame in the second prototype.

\begin{tabular}{|l|l|}
\hline Frame & Density Dependency (in sardine) \\
\hline Both High & $\begin{array}{l}f_{D D} \text { increases from a base value of } 1 \text { as the population } \\
\text { drops. The increase is proportional to the difference } \\
\text { between the current population and the theoretical } \\
\text { carrying capacity }\left(p_{\max }-p_{\text {current }}\right) \text {. If the population exceeds } \\
p_{\max } \text { the density dependence remains flat at } 1 .\end{array}$ \\
\hline Sard Hi / Anch Low & $\begin{array}{l}f_{D D} \text { stays at } 1 \text { throughout. } \\
\text { The assumption is that density dependence does not } \\
\text { operate in the sardine low frame as the population is too } \\
\text { low. }\end{array}$ \\
\hline Both Low & \\
\hline
\end{tabular}

A conceptual plot of the recovery rate with population would be as in Figure 9. 


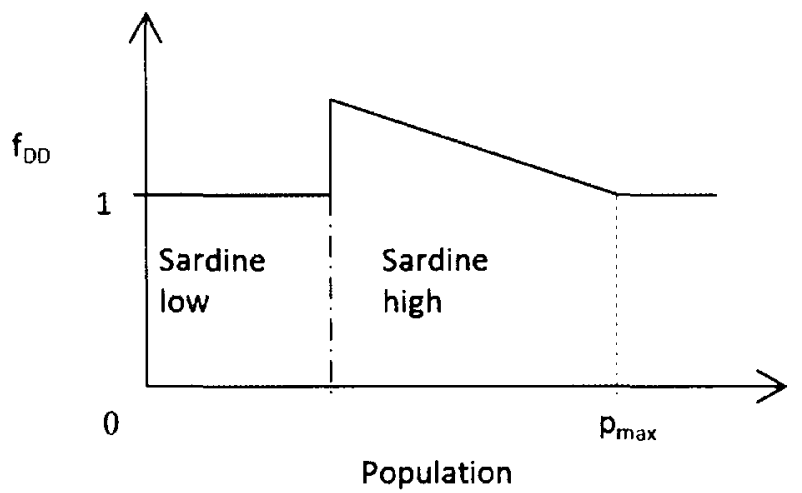

Figure 9 - A conceptual graph of the sardine density dependence factor $\left(f_{\supset D}\right)$ as implemented in Prototype 2.

\subsubsection{Anchovy Model}

As with the first prototype, the anchovy population is modelled entirely stochastically, with the population fluctuating randomly about a defined mid-point, with a defined variability (listed below). The mid-point and variability used are determined by the anchovy frame state, and have been scaled to produce a modelled anchovy population which varies on a similar scale to the modelled sardine population.

- Anchovy Low: The population fluctuates about 0.6 , with a variability of $+/-0.4$

- Anchovy High: The population fluctuates about 2.5 , with a variability of $+/-2.0$

Also as with the first prototype, the model for the anchovy population reacts to the current frame state rather than the ESI for the current year.

An anchovy fishery was included. The impact of the anchovy fishery is limited in that the fishery is not modelled to have any effect on the underlying anchovy population. The biological rationale in this model is that the caught anchovy would overwhelmingly have died by other means had they not been fished (e.g. Jarre et al., 1998). The advantage of including the anchovy fishery is that it allows 
us to model juvenile sardine bycatch from the anchovy harvesting operations. The modelled anchovy population is still determined for each year by the frame state of the model.

\subsubsection{Forcing functions}

The forcing factors affecting the modelled ecosystem are:

\section{a. Environmental Suitability Index (ESI)}

As with the first prototype, we parameterise the various climatic and environmental effects (temperature fluctuation, nutrient availability, transport currents, etc.) into a single factor. The ESI is an integer value from 0-9, with a higher value indicating a more favourable environmental situation for anchovy recruitment.

The ESI in the second prototype is based on a sine function with a 20 -year periodicity ( 10 years high, 10 years low). Using this sine function as a midpoint, the actual ESI for a given year (which is rounded to the nearest integer) has a small degree of random variability from the base function. The sine function is centred on a value of 5 , and has amplitude of $+/-3$. The variability of the $\mathrm{ESI}$ is $+/-1$ from the base function.

The anchovy daemon (which drives the anchovy frame-switching) bases its switching rules on the ESI values. As the anchovy population is determined by frame state, the population will still switch abruptly between high and low states, despite the sinusoidal forcing function.

\section{b. Sardine fishing}

The fisheries model for the sardine population has been substantially refined, with more complex fishing strategies possible than in the first prototype. There are several possible 
scenarios for setting the total allowable catch (TAC) and general management strategy for a given simulation:

- No fishing.

- A fixed TAC (defined by the user) for the entire 50-yr run.

- As with the first prototype, there is an AutoManage function (the "robot manager"), which controls the fishing according to a set of predefined rules and adjusts fishing effort annually. The guidelines for the robot manager have been scaled to correspond to the values typically observed in the modelled populations.

The AutoManage function was given a sensitivity setting which allows the user to set the fishing strategy along a scale from "conservative" to "severe". Using the more "severe" management strategy, the robot manager would be quite likely to crash the sardine stock, but would also take far higher catches in a run for which the sardine survived. Note that the adjustment does not change the frame definitions or the modelled population settings, only the fishing settings.

All adjustments of management parameters on the scale from "conservative" to "severe" were done linearly between the maximum and minimum settings. The "conservative" settings represent the maximum yield with zero risk of crashing the sardine stock.

Moving the strategy from conservative towards severe increases the sardine catch in the high and moderate population levels, and the threshold for being considered "high" or "moderate" population is reduced. The TAC in the "low" population level is 0 for all settings, although the threshold for classifying the stock in a "low" population is reduced under more severe management. 
Table 5 summarises the scales used for the robot manager at the default "conservative" values. The maximum adjustments under the most "severe" settings are given in parentheses. TAC settings are based on the previous year's population estimate.

Table 5 - AutoManage function parameters for sardine fishing in Prototype 2 under the most "conservative" setting. Numbers in parentheses indicate the maximum adjustment of figures under the most "severe" management strategy

\begin{tabular}{|l|l|l|l|}
\hline & Low population: & Moderate population: & High population: \\
\hline Range & $0 \leq$ Pop $<0.5$ & $0.5 \leq$ Pop $<1.0$ & $1.0 \leq$ Pop \\
& $(0 \leq$ Pop $<0.3)$ & $(0.3 \leq P o p<0.6)$ & $(0.6 \leq$ Pop $)$ \\
\hline TAC & $0(0)$ & $0.2(0.4)$ & $0.4(0.6)$ \\
\hline
\end{tabular}

- The option for medium-term management evaluation was added. In the "Active Management" mode, the user is asked every three vears for a decision on the TAC for each species, and these values will be used for the next three vears of fishing. In this way, the user can practice reacting to the data in an ongoing manner, and adjusting the fishing strategy in real-time in response to observed population changes.

\section{c. Anchovy Fishery}

The second prototype includes an anchovy fishery in order to model the effects of juvenile sardine bycatch (from the anchovy fishery) on the modelled sardine population. As in the sardine fishery, there are several different management models that the user can select:

- No fishing

- A fixed (user-defined) TAC for the entire run

- The AutoManage function was also expanded to include the anchovy fishery. The TACS for the anchovy fishery are set differently from the automated sardine management, 
however: the AutoManage function considers the anchovy frame which the model is currently in, and bases the catch as a percentage of the spawner stock biomass (taken from the previous year's population estimate).

As with the sardine fishing management, the thresholds for anchovy fishing are also adjusted on a sliding scale from "conservative" fishing to "severe". Table 6 summarises the anchovy TACs under the AutoManage function. Again, the maximum levels (under the most "severe" setting) are given in parentheses.

Table 6 - AutoManage function parameters for anchovy fishing in Prototype 2 under the most "conservative" setting. Numbers in parentheses indicate the maximum adjustment of figures under the most "severe" management strategy.

\begin{tabular}{|l|l|l|}
\hline & Anchovy Low Frame & Anchovy High Frame \\
\hline TAC & $20 \%(30 \%)$ of Pop & $40 \%(60 \%)$ of Pop \\
\hline
\end{tabular}

- The "Active Management" mode, allowing for medium-term management evaluation, is also available with the anchovy fishery. Under this mode, the user must set fishing levels for both species every three years. 


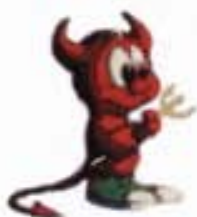

Run Daemons to set frame state for the year:

- Auchory Daemon:

$\rightarrow$ look at E5

- Sardine Daemon:

$\rightarrow$ look at pop level

- Set school trap

factor $\left(f_{-}\right)$based on

frame nitial conditions

Bufferkeriod to stabilise nade

$-$<smiles>c1ccccc1</smiles>

ncrement year

Establ sh Environmenta|Suitabil'ty Index (ESI) for the year 
The rules of the daemons were refined to give more plausible mechanisms for frame switch.

Cumulative indicators with "reset catastrophe" events are used rather than arbitrary arithmetic operations. The new daemon rules are described below:

\section{a. Sardine Daemon}

The sardine daemon was redesigned to consider the sum of the sardine populations over the last three years, rather than requiring three successive years above a particular level (as was the case in the first prototype).

- If sardine is in a "low" frame:

The new daemon required a total population from the past three years of at least 3.0 to shift the sardine to a "high" frame, rather than an equivalent rule requiring three successive years of at least 1.0 population.

- If sardine is in a "high" frame:

The sardine will switch to a "low" frame if there is a total population of less than 1.8 from the past 3 years.

This is more representative of the actual operations in the ecosystem, as two sufficiently poor sardine year classes would be likely to shift the population to a low frame in spite of a single moderate year class in between them. Likewise, two sufficiently strong year classes with one moderate year class between them should be sufficient to push the sardine into a "high" frame.

Note also that these rules do not require three years before a new switch can take place. If there are two consecutive extraordinarily good years which have a total population over 3.0 , then under these rules the daemon will prompt a frame shift without waiting for the third year. 


\section{b. Anchovy Daemon}

The anchovy daemon considers the Environmental Suitability Index, not the anchovy population. Unlike the first prototype, the anchovy daemon does not look for three consecutive years with ESI above a certain threshold. The ESI for each year is added to a running total, and when the cumulative value is over 15 , the daemon will prompt a shift to a "high" frame. To avoid a long succession of poor years prompting such a shift, the cumulative total is reset and the daemon prompts a shift to a "low" frame if the ESI for a given year is below 4. Table 7 shows an example of the frame shifts which would take place under an arbitrary series of ESI values.

Table 7 - Example run of ESI values and associated anchovy frame behaviour. Annual ESI is added to the running total unless annual $<4$, in which case the running total is reset to the annual figure. Daemon switches to "high" if running total $>15$, and switches to "low" if running total $<4$ (i.e., if annual ESI $<4$ ).

\begin{tabular}{|l|c|c|c|c|c|c|c|c|c|}
\hline Year & $\mathbf{1}$ & $\mathbf{2}$ & $\mathbf{3}$ & $\mathbf{4}$ & $\mathbf{5}$ & $\mathbf{6}$ & $\mathbf{7}$ & $\mathbf{8}$ & $\mathbf{9}$ \\
\hline ESI for the year & 2 & 3 & 4 & 6 & 7 & 8 & 6 & 4 & 3 \\
\hline Running total ESI & 2 & 3 & 7 & 13 & 20 & 28 & 34 & 38 & 3 \\
\hline Anchovy frame state & low & low & low & low & high & high & high & high & low \\
\hline
\end{tabular}

Because of the fairly regular sinusoidal variability of the ESI, the anchovy daemon will prompt for a switch between "high" and "low" frames at approximately 10-year intervals, and the switching will lag the ESI function by approximately 2 years. This is in line with previous treatment of the lag time of anchovy population response to change in conditions (Howard et al., 2007).

\subsubsection{Additional enhancements to the second prototype}

\section{a. Introduction of variable survey accuracy}

In order to simulate errors in the survey data, it is possible to introduce a specified level of inaccuracy in the surveyed sardine population with respect to the modelled population. If the Auto Manage function is selected with this feature enabled, the robot manager will react to the 
surveyed li.e., irraccuratej population changes, and not to $\mathrm{t}^{\mathrm{n}} \mathrm{c}$ act. al population. A samp o rin- of t.is type is shown in Figare 11.

1 "e similated survey results are a. 50 shown during t"e rin of an Active Manegencent exercise, with the actual popilation evels shown at the end of the fun.

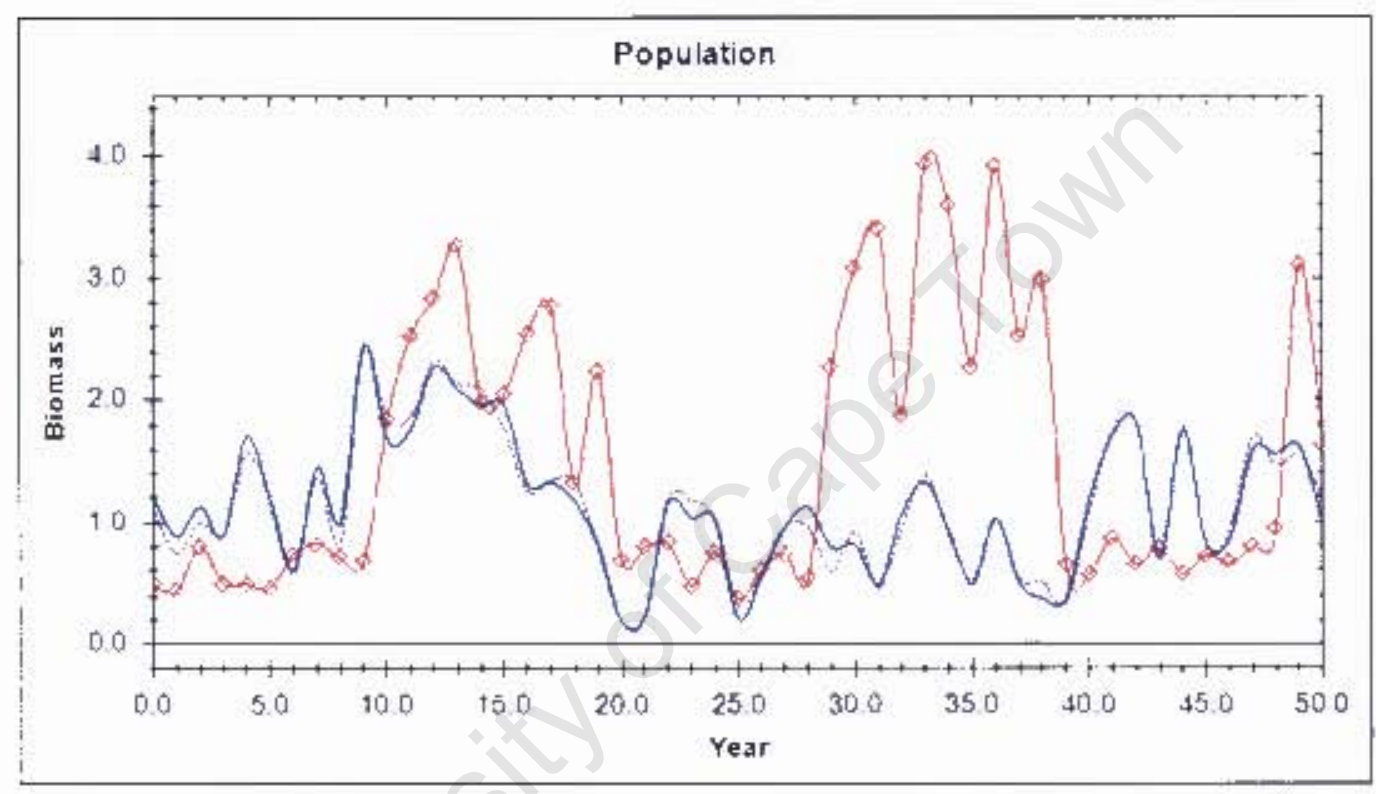

Figure 11 - A single model nun an Pralatype 2 under moderate fishing with survey errors. I ne ed I:ne

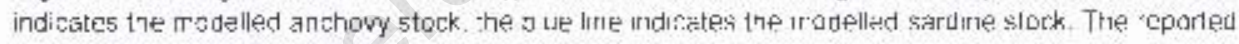
(inaccliatc) sardiat biomass is indicated oy the dotted blue ine,

\section{b. Improved diagnostics}

Metrics are improved to answer more " r teresting quiestions. Note that th s is merely a postprocessing aspect: the operation of the model is naffected, but we are able to extract riare value from it. Standard functions wh ch have been included are the standard dowiation of various outputs icatch data, populations, ctc. $i$, and the percentage of vears in which a value s.rpasses a certain threshold ie. $y_{2}$. catch is at least $80 \%$ of mean catch for the fun i- This is particular $y$ useful in the cor:ex: of the management obiectives w " 
more easily understandable way of representing the inter-annual variance for stakeholders (both management and fishers).

As in the first prototype, if the model is used with multiple runs, these metrics are averaged in the final output. For a "multiple runs" test, the model can also record the number of runs for which the modelled sardine population crashed.

The full list of metrics provided at the end of each run for the second prototype given below. Note that all figures (other than total number of sardine stock crashes) are averaged for multiple runs.

- Total time spent in each frame

- Average residence time in each frame before switching out

- Number runs in which the sardine stock crashed

- Sardine metrics:

- Average annual population

Total catch (over 50 yrs)

- Average annual catch

- Std. deviation of annual catch

Percentage of years in which the catch exceeds $80 \%$ of the average catch

Average annual juvenile bycatch 
- Anchov'r metrics:

\author{
6. Average an"ual population \\ - Tota catchiover 50 yrs) \\ Average annual ratch
}

As w th the first orotorype, the graphical out out uses a blus: " o to ndicate the modelled sardire stork, and a red line so indicate the modelled anchowy stock. The colours used by the frame - dicator are labelled in Figure 12.

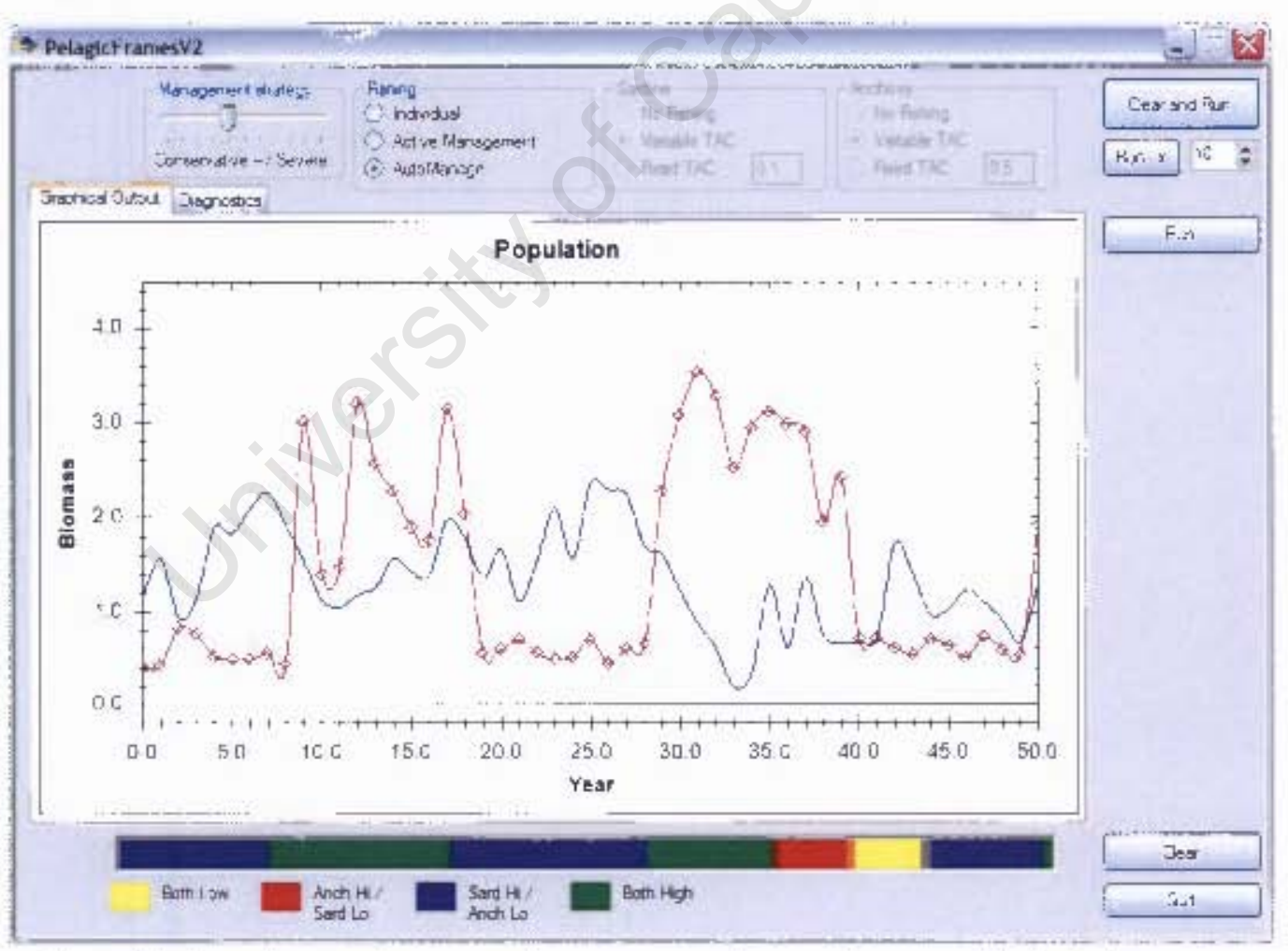

Figure 12 - $\dot{A}$ sanple run under auton:ated management on the second prototype fblue line ind rates sart $r$, red indicales ancr buy). The calour's ussed ty the frame ind cator bar arc labelled on the GJ: 


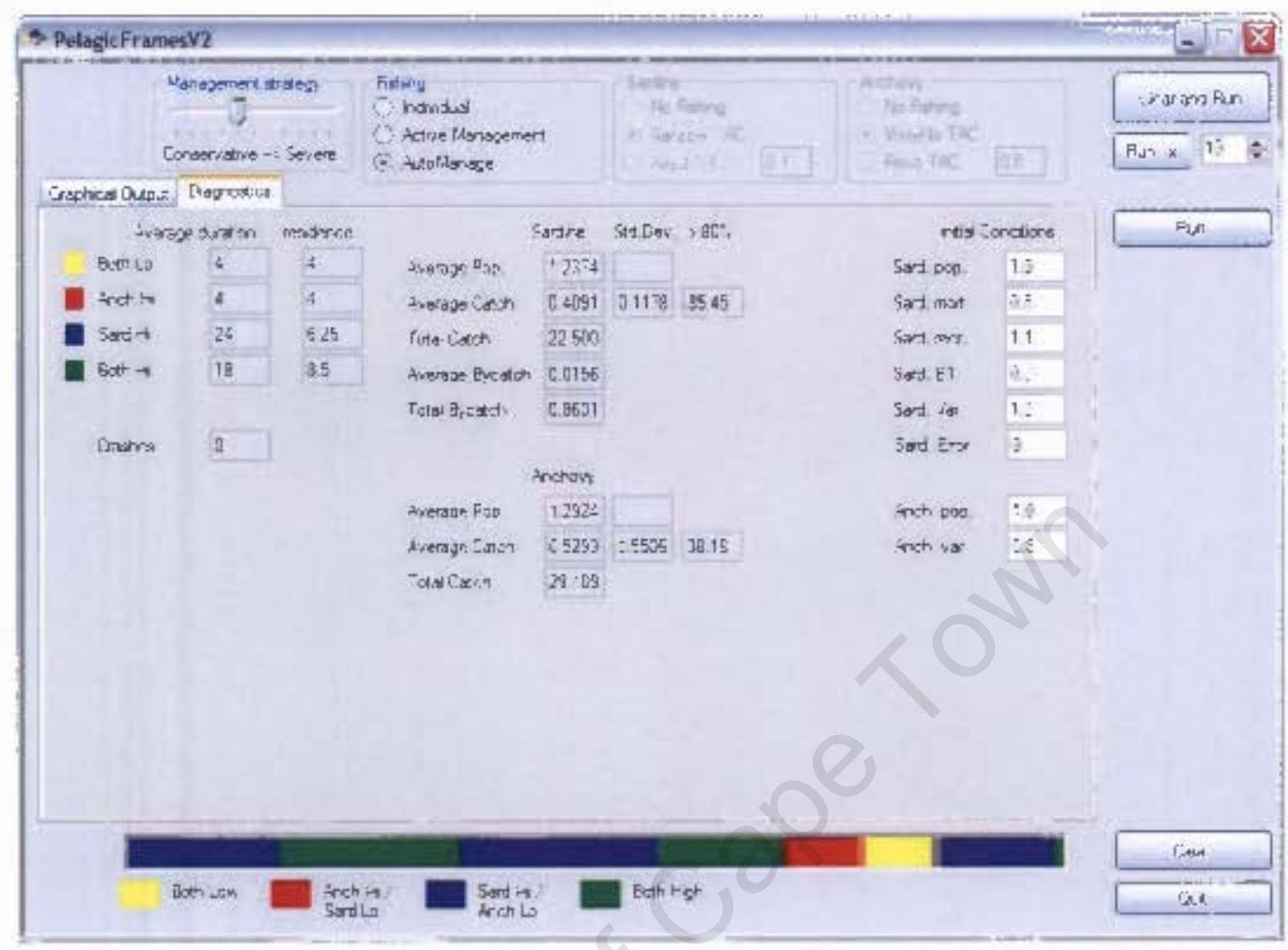

Figure 13 - Tre sample run from Figure 12. showing the diagnostics tab with the metnc-s for the 'un

\subsection{Results: Assumption and sensitivity analysis}

Imple it in the modelling aporoach is the need to test the as.sumptions used to build the ecosystem representasion, and an analysis of the sensit vity of the outputs to in put parameter values. The. model has scvera ir purs, mary of whice require numerical values. Such data as exist from the eal wo ld often "ave a thigh degree of uncertai"ry and as such an aralysis needs to be performed of the sersitivity of the mode to the values of those ir puts (Starfield and Jarre, in revew).

In light of our abjective of invesigating cow a management strategy desigerd around a frame-based model might operete, it is important to understa"d the se sitivities to the frame states. The key Sensilivities to test in our model are therefore the thresholds for frame switching of borh the sardine ard anchow daemors. Several other outputs of tre model, such as the sardine bycatch and the 
anchovy population level, are directly related to the time spent in certain frames. Other outputs, such as the sardine population level, are not directly tied to frame residence, but are nonetheless influenced by it. We are also interested in the sensitivity of the model to density dependency of the sardine population, as well as the parameters of the "school trap" relationship.

The model also incorporates certain assumptions that required testing:

\section{a. Daemon indicators}

The new daemon rules included in the second prototype were believed to represent the ecosystem better, but this assumption needs to be tested.

Assumption analysis on the second prototype indicated that changing the sardine daemon to a "cumulative population" indicator (rather than three successive good years) had negligible effect on the sardine output parameters. There was a significant effect on the sardine bycatch from the anchovy fishery and the frame behaviour.

The change of indicators for the anchovy daemon from a switch based on three successive good years to a cumulative ESI forcing agent (with an abrupt crash in a poor year) was found to have little effect on any of the output parameters other than frame behaviour.

Certain other assumptions were not tested:

\section{b. Anchovy fishing}

Our model has assumed that the anchovy population is totally unaffected by fishing pressure. Ideally, we would like to test the effect of the anchovy fishery on the anchovy population. In the current model, the anchovy population parameters are determined by the ESI, and as a result the modelled population actually cannot crash, no matter how hard it is fished. This is a 
limitation of the model, as there is data evidence that it is possible to crash an anchovy population through sustained excessive fishing in conjunction with poor recruitment (as observed in Peru in the 1970s (e.g. Pauly and Palomares, 1989)). Anchovy in the Benguela have not had consistently poor recruitment conditions for more than two years running within the data record (Miller and Field, 2002), so this is a useful simplification with the caveat that it assumes that reasonably conservative fishing strategies continue to be practiced in the southern Benguela.

To address this issue in more detail it would be necessary to use a population model for anchovy, so that the anchovy population in a given year was dependent to some degree on the previous year's population. This may be a suitable area of the model to explore in a later version (see Section 5.5.1).

\section{c. Survey data accuracy}

The model has been built with the capacity to introduce a random error into the survey data with respect to the actual modelled sardine population. It would be useful to explore the impact of a certain level of error on the validity of fisheries management strategies. The results of the scenario evaluations concerning this question are shown in Section 4.3.2.

\subsubsection{Sensitivity overview}

The initial sensitivity analysis was performed across a broad range of model parameters, and the effects were recorded against a broad range of model outputs. The results were generally as expected, and in this way served to reinforce confidence in the model. In some areas, the results also indicated that a more directed analysis may be beneficial. 
The parameters were tested under two sets of conditions: with no fishing; and with the AutoManage function simulating fishing activity. To understand the expected level of sensitivity of the model to the tests themselves, an analysis was performed on the AutoManage rules as well:

- The modelled frame behaviour was found to be strongly sensitive to the AutoManage rules, and as a result, the sardine bycatch was also strongly affected. This is to be expected, as the bycatch is related to the propensity of sardine to school with anchovy, and the common schooling is only incorporated into the "low" sardine frames of the model.

- The sardine catch was significantly sensitive to the AutoManage settings, particularly as regards TAC levels.

- The sardine population was also significantly affected. Increased fishing had a significant negative impact on the modelled sardine population, and reduced fishing conversely resulted in a higher average model population. Lowering the population through fishing could also force the sardine into a "low" frame, in which the recruitment is reduced (as density-dependence does not operate in the model's "low" sardine frames).

Once satisfied that the tests would give useful results, a more detailed analysis was made of the sensitivity of various other factors. A summary of the results of the sensitivity analysis is given in Table 8. The colours for each cell indicated in the table represent the aggregate assessment of all the results of tests performed for that cell. The detailed results of all the tests are provided in Appendix

A. 
Table B - Sunnary resuits trom sensit,vity and assumption: ar alys S. The aumbers in the tatle refer to the tesl

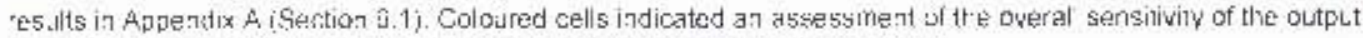
parameter :coumr.s) to all the 1ests : nvolving the given r.put parameter (rowsi.

\begin{tabular}{|c|c|c|c|c|c|c|c|c|}
\hline & \multicolumn{2}{|c|}{ Averase Population } & \multicolumn{2}{|c|}{ Sardine catch } & \multicolumn{2}{|c|}{ Anthovy cedtch } & \multicolumn{2}{|c|}{ Frame selaviour } \\
\hline & Sard & Anch & Auge & std. dev. & Ave. & bycatch & Durution: & Res. \\
\hline \multicolumn{9}{|l|}{$\begin{array}{l}\text { Alto Manage } \\
\text { sardine tirestolds }\end{array}$} \\
\hline \multicolumn{9}{|l|}{$\begin{array}{l}\text { Auto Mอา } 2 \text { ge } \\
\text { 5ardine TAC evels }\end{array}$} \\
\hline & & & & & & & & \\
\hline $\begin{array}{l}\text { Sardine Caemor } \\
\text { C.Imulative } 453 \text { years }\end{array}$ & Bis & 1.2 & 1.3 & 124 & 15. & 1,6 & 1.7 & 1.8 \\
\hline $\begin{array}{l}\text { Sardine switching imits } \\
\text { Thresholds }\end{array}$ & 2. & 22 & 2.3 & 2.4 & 25 & 2.6 & 2.7 & 2.8 \\
\hline $\begin{array}{l}\text { Grichowy Dámcr } \\
\text { Cumblative } 453 \text { yea's }\end{array}$ & 1 & 31 & 3.3 & 34 & 35 & 3.6 & 3.7 & 3.8 \\
\hline $\begin{array}{l}\text { Anctowy switching limits: } \\
\text { Upper threstold }\end{array}$ & 11 & 4,2 & 4.3 & 44 & 4.5 & 4.6 & 4.7 & 48 \\
\hline $\begin{array}{l}\text { Ant:fowy switching limlts: } \\
\text { Poor wear thres old }\end{array}$ & 5.1 & 52 & 5.3 & 5.4 & 12.5 & 5.6 & 5.7 & 5.8 \\
\hline $\begin{array}{l}\text { Sardine recovery rate: } \\
\text { scale fartor }\end{array}$ & 6.1 & 6.2 & 63 & 6.4 & 6.5 & $\overline{6 . \varepsilon}$ & 6.7 & 6.8 \\
\hline $\begin{array}{l}\text { Sardine sctool trap } \\
\text { factor }\end{array}$ & 71 & 7.2 & 7.3 & 8.4 & 75 & 7.6 & 2.7 & 73 \\
\hline Variance $o^{2}-$ mate & 81 & 8.2 & 8.3 & 84 & 8.5. & $\bar{a}, 6$ & 8) & 3.8 \\
\hline \multicolumn{9}{|l|}{ Colour key: } \\
\hline Negligible effect & & & & Extremely & ensizive & & & \\
\hline
\end{tabular}

Tre specific trends observed ate ciscussed beiow:

1. Sarcine daemon rules: Cumularive sosu ation vs. 3 consecu-ive years over a th: eshold:

The frame behaviour was mildly serisit ve to the caemon ru es, and as a result the modelied 5ardine bycatch showec sone sensitivity.

2. Sarc rie switching threshold:

The robot mandser is desiuned to try and operate at the lower edge of the "hight" sn--dine frames. Thus, i* the threshold for switchine is raised, the model will more casily go to a "low" sardine fa ne. Bycatch o juvenile sardine "rom the anchowy f'shine will iner ease ias bycatch 
is only implemented in the "low" sardine frames), and the average sardine population will be reduced by the combination of increased bycatch and reduced recruitment (as the density dependence does not operate in the "low" sardine frames).

3. Anchovy daemon: Cumulative ESI vs. consecutive good or bad years

The model was largely unaffected by which of the daemon rule sets was implemented.

4. Anchovy switching limits

This had a slight effect on frame behaviour, and thus a slight effect on anchovy catch and sardine bycatch. As the anchovy population is largely determined by frame state (which sets both the midpoint and the variance of the annual population), lowering the threshold for switching to the "high" anchovy frames results in more time spent in the these frames, and thus an increased average population. The modelled sardine bycatch operates in both the "Anchovy High / Sardine Low" and the "Both Low" frames but the school trap factor is stronger in the former, and thus with more time in the "high" anchovy frames there is an overall increase in sardine bycatch. Raising the threshold had the reverse effects on both average anchovy population and sardine bycatch.

5. Anchovy poor year threshold

Although the poor threshold seems to have a strong effect on the anchovy population, anchovy catch and frame switching, this is in fact more to do with the magnitude of the shift in the sensitivity analysis: because the ESI is limited to a small number of discrete values, it is only possible to adjust it by a relatively large amount. Thus although the magnitude of the resultant changes in the output parameters appears high, it is consistent with the relatively large changes to the threshold which were made. Using smaller graduations of the ESI would 
allow this to be tested more precisely, but that precision may not be useful with respect to the high uncertainty inherent in evaluating environmental factors.

6. Sardine recovery rate scale factor

The scaling of the density dependence has a fairly strong effect on the sardine population, as well as on the variability of sardine catch and the bycatch. The density dependence generally helps the modelled sardine population to avoid the "low" frames by increasing recruitment as the population declines. With the scale factor lowered, the sardine population more easily declines low enough to prompt a switch to a "low" frame, and the average sardine population is consequently also lower. As a result of more time in the low frames, there is also a significant increase in juvenile sardine bycatch. Increasing the sardine recovery rate had the opposite effect, with more time spent in sardine "high" frames, lower juvenile sardine bycatch and higher average sardine population.

7. Sardine school trap factor

The results for the sensitivity of the model outputs to the school trap factor were inconclusive. A limitation of the tests in this regard is that the school trap factor only comes into play where the system is in a "low" sardine frame, and the robot manager is generally good at avoiding fishing the sardine down to that level. In the unfished system, the modelled sardine population stays in a "high" frame continually.

Observations of the modelled populations under managed fishing indicate that the implementation of the school trap factor gives rise to a realistic reaction of the stocks to anchovy fishing in frames where the sardine population is in a "low" frame. This is further explored in the scenario evaluations (see Section 4.3.1). 
In order to test the behaviour of the system in the "low" sardine frames and study the sensitivities of sardine bycatch, the robot manager was adjusted to a more severe fishing strategy. Although this would crash the stocks on some of the runs, it would also allow us to observe automated runs with sardine spending considerable time in the "low" states.

\section{Climate variance}

With the same underlying waveform and periodicity, the inter-annual variance of the ESI around the wave function had no significant impact. Note that the underlying waveform determines the upper and lower bounds of the ESI function, and thus the frame switching behaviour of anchovy is not significantly affected. The cumulative ESI indicator used by the anchovy daemon effectively smoothes out a lot of the effect of year-to-year climate variance on the anchovy population, which is reasonable for a species which lives 3 years.

\subsubsection{Analysis of stochasticity and averaging effects}

Averaged results from large numbers of runs were used extensively in the sensitivity analysis as a way of filtering out the influence of the high degree of stochasticity on the results from any individual model run. A model "run" is regarded as a simulation of a single 50-yr time series. Because the programme allows for multiple sequential runs to be performed in a row and the averaged results displayed, test for the sensitivity analysis were often performed on sets of 100,500 or 1000 runs. Even at high numbers of runs, repeated tests often displayed a high degree of variability, and thus the tests were generally repeated three times to give some idea of the consistency of a particular metric. These repeated tests (sets of multiple "runs") are referred to as "replicates" in the descriptions of the sensitivity analyses.

The initial tests of the sensitivity and assumption analysis (which are represented in Table 8) were performed over 100 runs, with three replicates. In several cases a high degree of variability of the 
results was observed, even averaging over such a large number of runs. Even in a stochastic system, the law of large numbers would be expected to steer the results towards uniformity when enough runs are being averaged. It was therefore decided to do an analysis of the variability of the averaged results over different numbers of runs.

\section{a. Effects of the number of model runs performed on the results}

Runs were done with the AutoManage function set at $50 \%$ severity and the averaged results recorded for 20, 100 and 500 runs. In each case, the results taken were the total time spent in the "low" sardine frames (per run), and the number of crashes of the modelled sardine stock in the series. Results are listed in Table 9.

Table 9 - Analysis of stochasticity and averaging effect. All runs performed with AutoManage at $50 \%$ severity Standard deviation of Sardine Low frame duration reduced greatly as the number of runs increased.

\begin{tabular}{|c|c|c|c|c|c|c|c|c|c|c|c|}
\hline Replicate: & 1 & 2 & 3 & 4 & 5 & 6 & 7 & 8 & 9 & 10 & Diagnostics \\
\hline \multicolumn{12}{|l|}{20 runs } \\
\hline $\begin{array}{l}\text { Sardine Low } \\
\text { duration }\end{array}$ & 5.2 & 1.5 & 1.9 & 2.7 & 3.1 & 2.8 & 3.6 & 4.3 & 3.0 & 7.6 & $\begin{array}{l}\text { Mean: } 3.57 \\
\text { stdDev: } 1.78\end{array}$ \\
\hline No. of crashes & 3 & 0 & 0 & 0 & 1 & 1 & 0 & 0 & 0 & 1 & $\mathrm{p}(\mathrm{crash}) \leq 15 \%$ \\
\hline \multicolumn{12}{|l|}{100 runs } \\
\hline $\begin{array}{l}\text { Sardine Low } \\
\text { duration }\end{array}$ & 4.1 & 4.1 & 4.1 & 3.3 & 2.2 & 5.5 & 2.7 & 3.4 & 5.1 & 2.6 & $\begin{array}{l}\text { Mean: } 3.71 \\
\text { stdDev: } 1.07\end{array}$ \\
\hline No. of crashes & 0 & 0 & 2 & 4 & 0 & 7 & 5 & 3 & 5 & 2 & $p($ crash $) \leq 7 \%$ \\
\hline \multicolumn{12}{|c|}{500 runs } \\
\hline $\begin{array}{l}\text { Sardine Low } \\
\text { duration }\end{array}$ & 5.0 & 3.5 & 3.1 & 3.3 & 4.2 & 3.3 & 5.0 & 4.7 & 3.7 & 3.5 & $\begin{array}{l}\text { Mean: } 3.93 \\
\text { stdDev: } 0.73\end{array}$ \\
\hline No. of crashes & 13 & 17 & 3 & 12 & 3 & 12 & 17 & 3 & 15 & 5 & $p($ crash $)<4 \%$ \\
\hline
\end{tabular}

Although the mean duration over ten replicates is reasonably consistent, the standard deviation is higher with fewer runs. The confidence with which the probability of crash can be predicted is also far higher at 500 runs per test. 
When viewing the highly variable results of the "20 run" replicates, it is perhaps worth noting that the total number of comparative time-series for fished small pelagic systems worldwide is considerably less than 20. A certain level of caution may therefore be recommended in analysing the historical data: although the cause and effect relationships often seem convincing, the degree of stochasticity inherent in the system may be remarkably high. The uncertainty in deductions made from such a small number sample size should be understood. Again, the manner in which the model reproduced real-world features serves to increase confidence in the model.

\section{b. Effect of the severity of fishing under environmental and recruitment uncertainty}

The number of crashes is particularly interesting in this analysis, as the runs are performed with a robot manager which is programmed to compensate annually for stock fluctuations and avoid imperilling the sardine stock. Although the manager has been set at a less conservative setting to ensure some comparative results, it is still actively adjusting the fishing strategy to try to avoid crashes. However, the degree of stochasticity inherent in the system sometimes exceeds the robot manager's ability to do so. In light of this, we investigated how the relative levels of severity of the AutoManage function affected the risk of crash.

The default (most "conservative") setting of the AutoManage function was designed to maximise sardine catch while minimising the risk of sardine stock collapse. To investigate whether the settings were too conservative, replicates of 500 runs were performed at increasing levels of AutoManage severity and the probability of crash observed. The results are detailed in Table 10. 


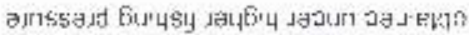

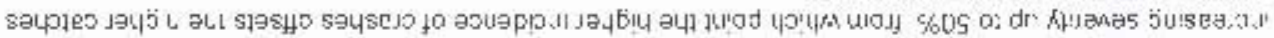

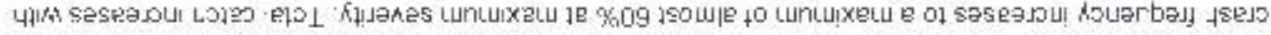

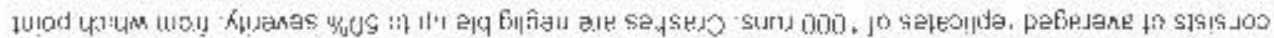

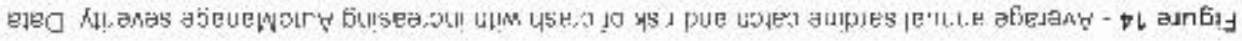

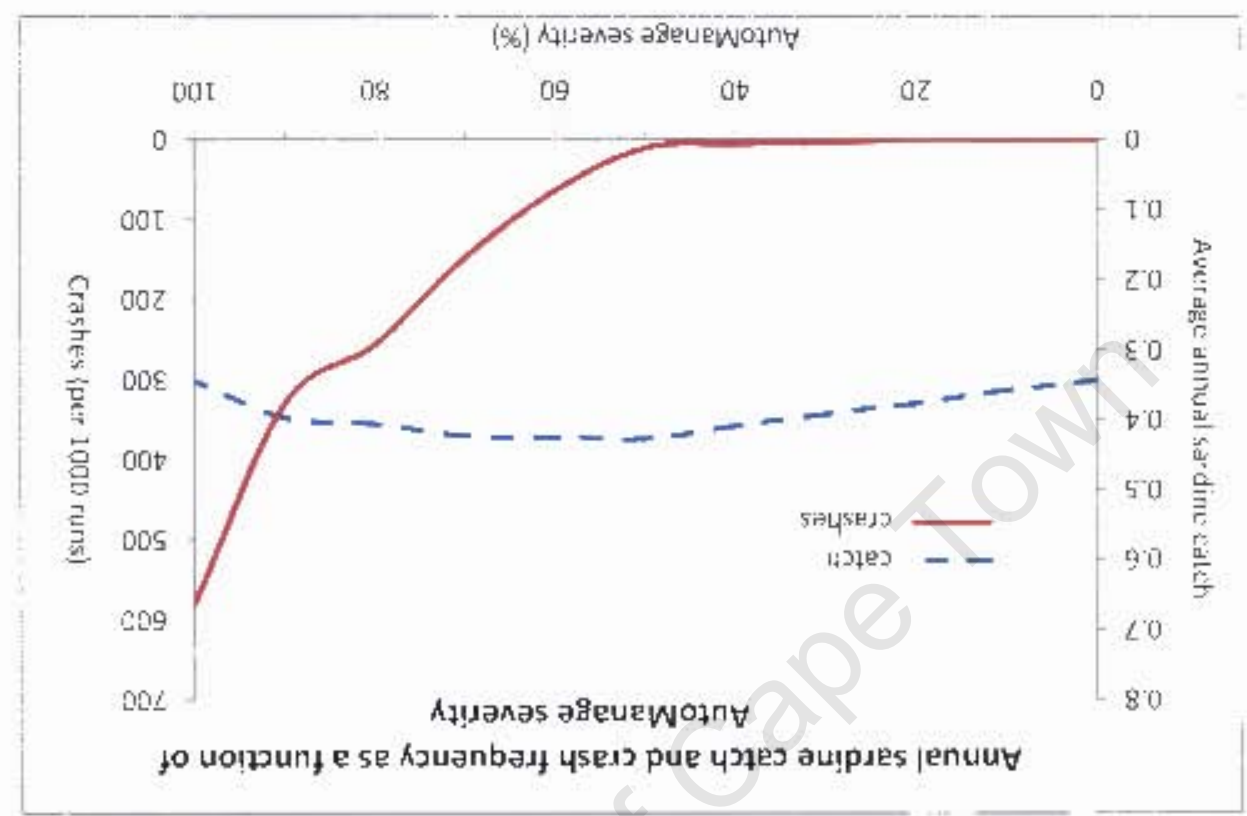

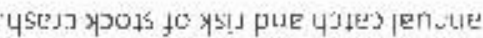

аใе.

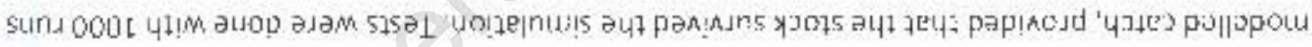

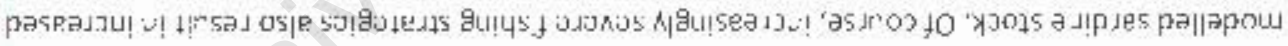

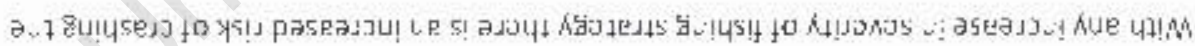

\begin{tabular}{|c|c|c|c|c|c|}
\hline$z$ & $t$ & 5 & 0 & 0 & \%OE \\
\hline 0 & 0 & 0 & $z$ & 0 & $\% 02$ \\
\hline 0 & 0 & 0 & 0 & $\varepsilon$ & $\% 00$ \\
\hline 0 & 0 & 0 & 0 & 0 & \%o \\
\hline 5 & $t$ & $\varepsilon$ & 2 & I & 1) \\
\hline :ә]eว!|d & 이 & 51 & 13 : & & to k1!dusas \\
\hline
\end{tabular}

K7 Janas 9 EEUE以 
There was a low increase in probability of crash up until about $50 \%$ severity, above which the probability increased rapidly. The results are summarised in Figure 14.

When considering the results of the catch/crash risk assessment, it is important to consider the ecosystem challenges involved. The risk of crash accelerates rapidly from the $50 \%$ severity level, which also approximately gives the maximum average annual yield over the 50 years of each single run. Although the ultimate crash risk is of the order of $60 \%$, the average catch at the maximum severity level is roughly equivalent to the most conservative setting. This result comes from two factors which may not be immediately apparent:

Firstly, the crashes may only occur near the end of the 50-year simulation, and thus the modelled fishery will already have enjoyed decades of high-yield (and high-risk) fishing, resulting in a high average catch for a crashed run even with a few zero-yield years at the end of the run. Secondly, the levels of fishing allowed by the AutoManage function under the most severe levels of management afford extremely high yields in the runs which are fortunate enough not to crash the stocks at all.

\section{c. Inter-annual stability of the modelled sardine catch}

Although standard deviation is a concept which is familiar to the scientific community, it can be somewhat intangible for other stakeholders (e.g. fishers or managers). To improve the communicability of results, the inter-annual variability of sardine catch for a given run was expressed as the percentage of years in that run which were "acceptable". An acceptable year was defined as one in which the sardine catch was $>80 \%$ of the average annual catch for that run. 
The :wo majo' goas of toe robo: manager are to arhirve t?e highest sustainable vield (wish an approariate level of cau:ion wh thegards to c'ashing the sacline stock), whilr at the same time keeping the inter-annual variability af catr: (alnd thus fisher ncome) as small as possible. An rxrept vinally hig: income year would not be of such concern, of course: avoiding yrass with exceptionally low sardine catc? is the impartant point.

A comparison was made o: the percenage of "good" yras of fishing at iricrcasing lcuris of \&..:oManage severity. As with thr orevious expe-iment, the tes: $s$ were done wi:h 1000 "uns, w:h three reslicales al each level.

Taere is a clear trend of increasing variability of catrh wit? increasingly scucre fshcrics managemrint. Ac w th the serdine cras: risk assessment, loe sit.ation is relat vely stable up :o aouroximate y 50\%, severity. The results ars summarised in Fig re 15.

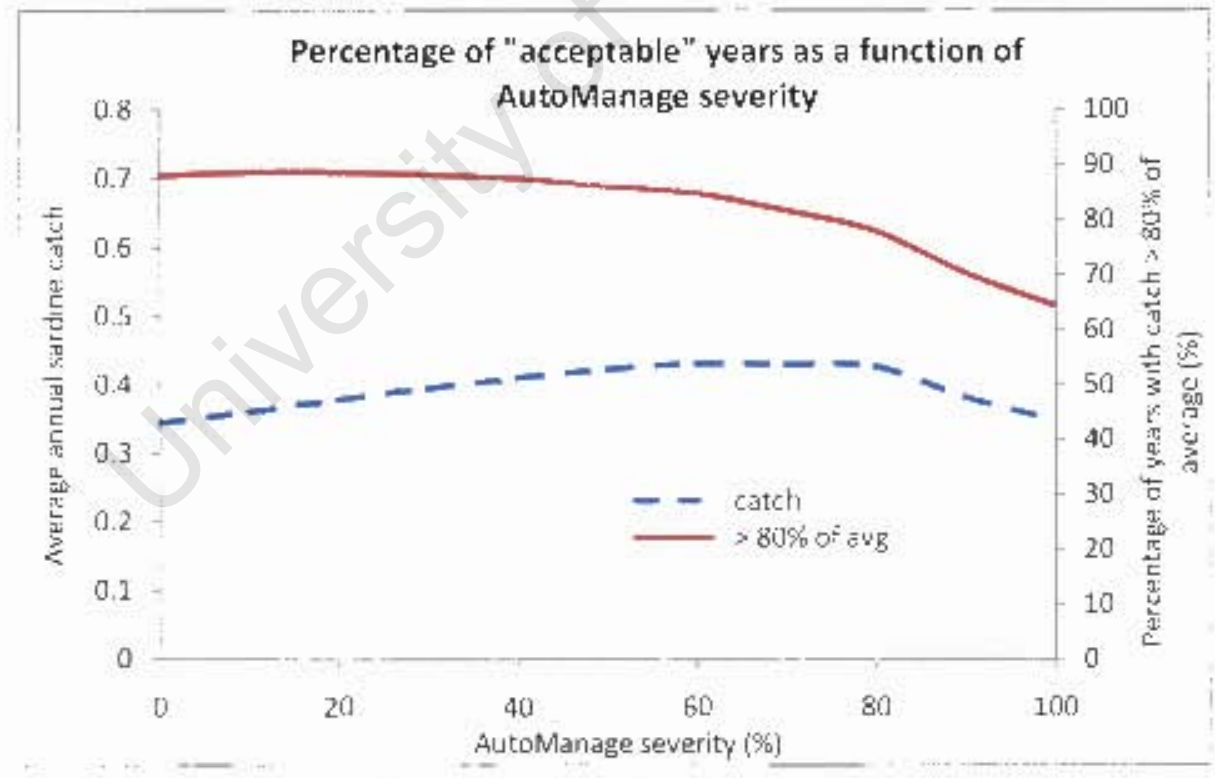

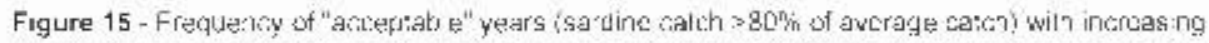
Autchanage severity. Data oorsists of averaged replicates of 1000 runs Although the average trificil catch increases up to approximatey $60 \%$ severity, there is al 50 an ircrease ir the frequercy of "poo' tishing yea's 
To give some perspective to the performance of the robot manager, it was attempted to manually replicate a similar level of average catch and consistency as is seen when the AutoManage function is set to a reasonably conservative level. Under Active Management (i.e. setting the catches manually every three years of a model run) it was very difficult to reliably match the figures for both catch and consistency that the rule-based AutoManage function was able to achieve. The robot manager, setting catches every year, was found to be good at keeping catches stable in a highly stochastic model.

\subsubsection{Periodicity of climate function}

The underlying frequency of the ESI forcing function is set at a $20 \mathrm{yr}$ periodicity for the model (10 yr cycles alternating between good and bad ESI). With many of the daemon indicators looking at cumulative figures over 3 years, it is useful to investigate the effect of changing the cycle time of the ESI function on the frame behaviour of the model, particularly as it approached the timescale of the daemon indicators.

The ESI function was moved from its decadal cycle time to cycles of 13,7 and 5 years, and the average time spent in either Sardine High or Both High was compared. Tests were performed over 1000 model runs, with 3 replicates averaged for each cycle time. No fishing was included in the simulations, so the frame state of the system only alternated between Sardine High / Anchovy Low and Both High. Because of the differing number of natural cycles which will be accommodated in a 50-year span, the cycle ratio must also be considered to understand the frame behaviour.

To clarify: with a 10-yr cycle time and a 50-yr model run, we would expect three full cycles of one state and two full cycles of the other, with a total of five cycles fitting into the 50 -yr run. Thus we would have a natural frame ratio of $3: 2$. The exact ratio is also determined by the timing of the 
frame switches in the run - again, for example, with a 10-yr cycle time, a 1:1 ratio could be achieved if the first switch occurred five years into the run. The results are summarised in Table 11.

Table 11 - Ratios of SardHi frame to BothHi in the unfished system with varying cycle time of ESI function.

\begin{tabular}{|l|l|l|l|l|}
\hline Cycle Time (yrs) & 5 & 7 & 10 & 13 \\
\hline $\begin{array}{l}\text { Observed } \\
\text { SardHi : BothHi }\end{array}$ & $28.8: 21.2$ & $27.5: 22.5$ & $28.8: 21.2$ & $24.6: 25.4$ \\
\hline $\begin{array}{l}\text { Expected } \\
\text { Cycle ratio }\end{array}$ & $25: 25$ & $26: 24$ & $29: 21$ & $25: 25$ \\
\hline
\end{tabular}

Recall that the anchovy daemon requires multiple consecutive good years to switch to a "high" anchovy frame, but can switch to a "low" frame after a single bad year. Thus we see that with short cycle duration, the system spends more time in the anchovy "low" frames than might have been expected from the cycle ratios alone. Some of the implications of this result are explored further in the environmental scenarios (Section 4.3.2).

\subsection{Results: Exercising the model from second prototype}

\subsubsection{Fishing strategy scenarios}

Several managed runs were performed with interesting results of sardine recovery from an initial low population level. The low level was precipitated in each case by heavily fishing the modelled sardine stock, and then different management options were explored from that position. It rapidly became clear that the "low" sardine frames, regardless of fishing severity, were highly vulnerable to crash. In these frames, the margins of safety were small enough that inter-annual variability of recruitment could imperil the modelled stock at very low populations. 


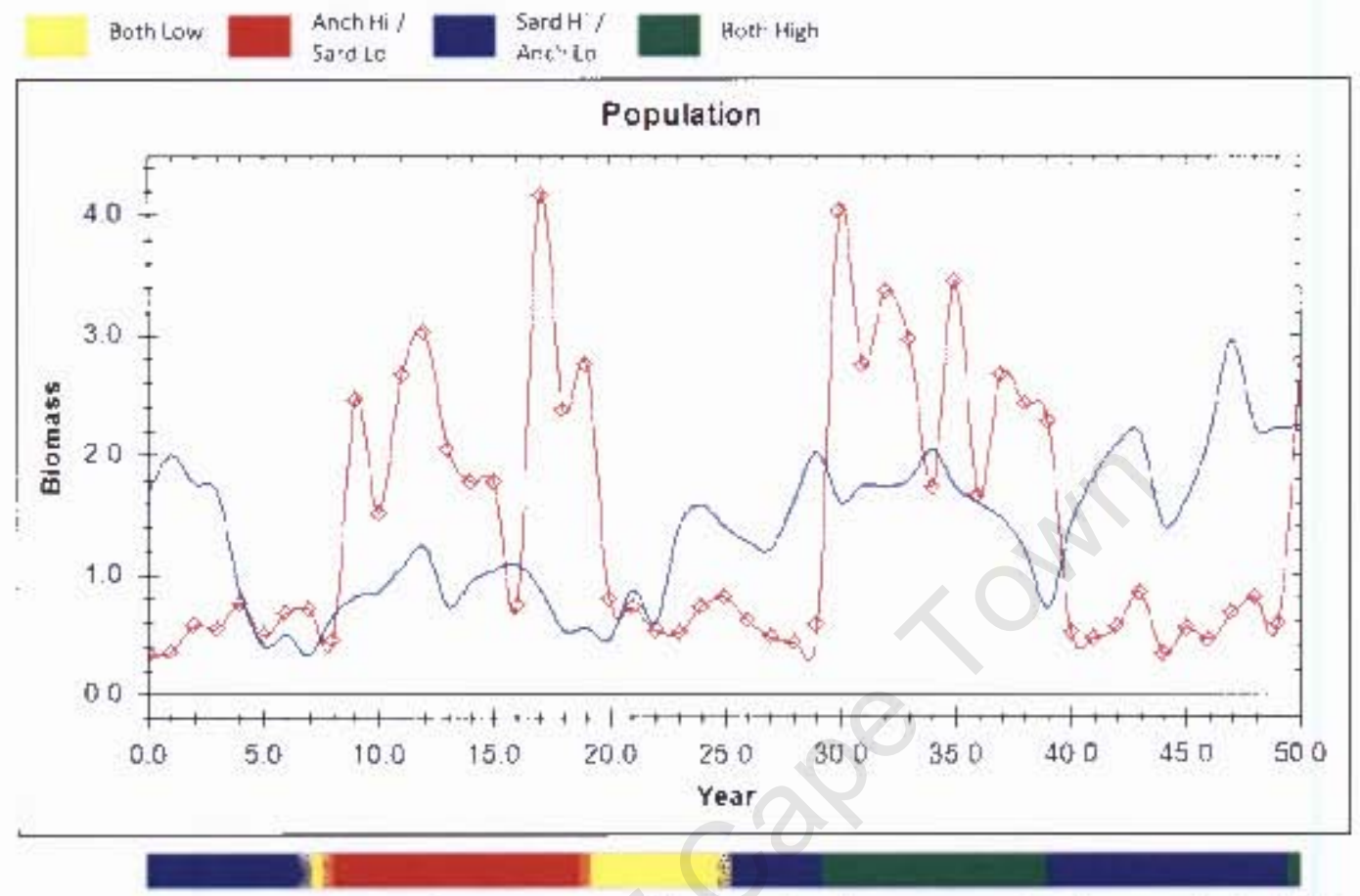

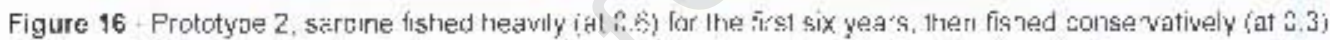
fo' the resl of the run initue l: $r e$ ind ca:es sarcine, red ind cates anchow). The 'low' sardine trames celayed the sardine recowery for al:host two cerades bul once hack ,n the "high" frames. the stock remainec there unde sLstained modera:e f shirg.

Ir, the rodel run shown ir. Figure 16, wh ch was perfo ered with Ac:ive Manage ner:, the sardiac stock was heavily expizited (at 0.6 ) lor the irst six years to force the ecosystem ir.to a sarc ".e "low" frame. From that point, the sardine fishing was mocera: $\{0.3\}$ for the ress of tre ru-a. Desp :e :he celatively conservat ve level of fishir:g, the sarc "le populatior, took twenty yoars to ascape the "low" frames, although orce in t"e "high" frames it remained hig" for the rest of te model run. The perforrance of the rrocelled sacdine stork in this exar.ple sonewnat irirrors toc population data from :he mid-1960s through the '70s anc early ' 80 s, where heavy exploitation in the early ' 60 s precipitated a low population state for the next 20 years.

The effect of juverile sardine bycatch from anchovy fishing was also vey clear. Heawy fishing on anchowy in a "Iow" sardine frame cou a prevent or celay a rerowery of the rrodelled sarcine 
population. Tgure 17 stows a rccovering sardine model popu alio" being crashed by excessive juvernile sardine bycatch due to increased anchovy fisning. Again, the sardine stork was heaviy fishod (at 0.6) to prompt a strif: to a "low" sardine frame, and then the sardine fishing was greatly reduced (to 0.2). From year 30 the anchovy fishing was increased dramiatica, $y$ in esponse to the "brigt" anchowy frame. This halted the sardine recovery and ultimately srashed the sardine stock.

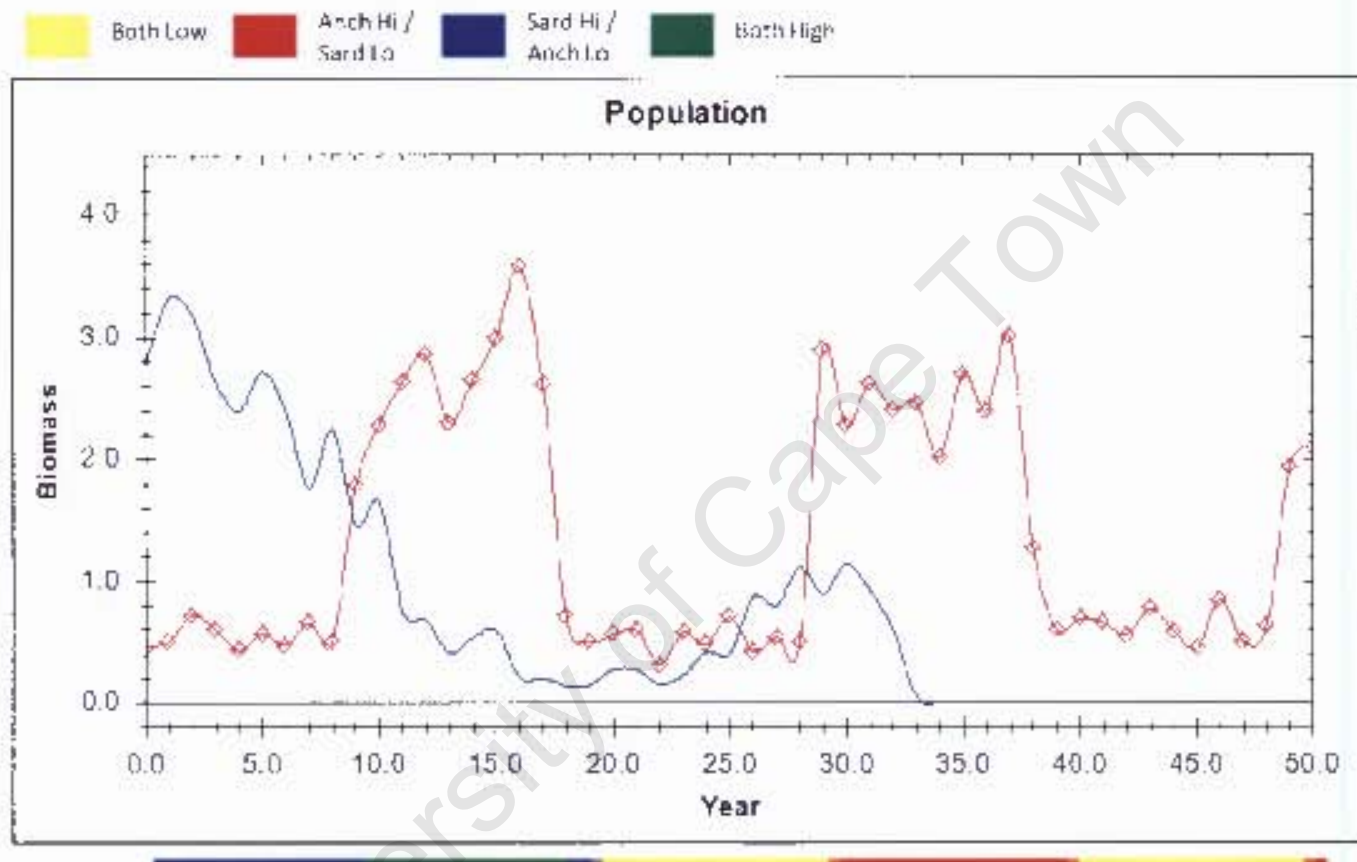

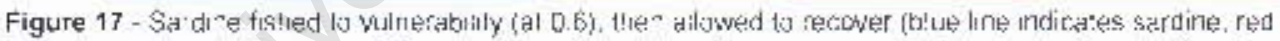
indicates anchowy). (rom year 30 . anchow are fished heavily $n$ response to high stocks Bycatch from the astrowy fistıng causes a roliapse of lte sardine populalion ever' under liagl: $(0.2)$ fist:ing +

With the sardire density dependence of Prototype 2, the sardine population showed good resilience en fishing pressu oc in the "righ" sardine frames, alt ough sufficient y high fishing could always crash the stocks (note the deliberate initial overtis!'ing whic' was Jsed in the previous two examples'. In she "low" frames, towever, tre combination o' bycatch and reduced recruit ment made? the: pop.latio: highly vulnerable to overfishing- 
The visinerability of the modelled sardine stock in the "low" frames cans for active management and ongoing monitoring. The hign varability of recruitment can casse sulficient decline in the population even under moderate rishirle, to prompt a shift to a "low" frame, and if management intervention is not taken, sustained fishing in "low" sardine frome con quickly cause a collapse. Figure 18 shows ten successive runs of an unmonitored syscem with sustained fishing sit constisnt TACs. Although the level of the TAC was conservative $\{0.4\}$, and on nine of the runs the oosulation stayed hish, on one run the posulation declined sar enowgh that it crashed. Interwention when the sardine went into a

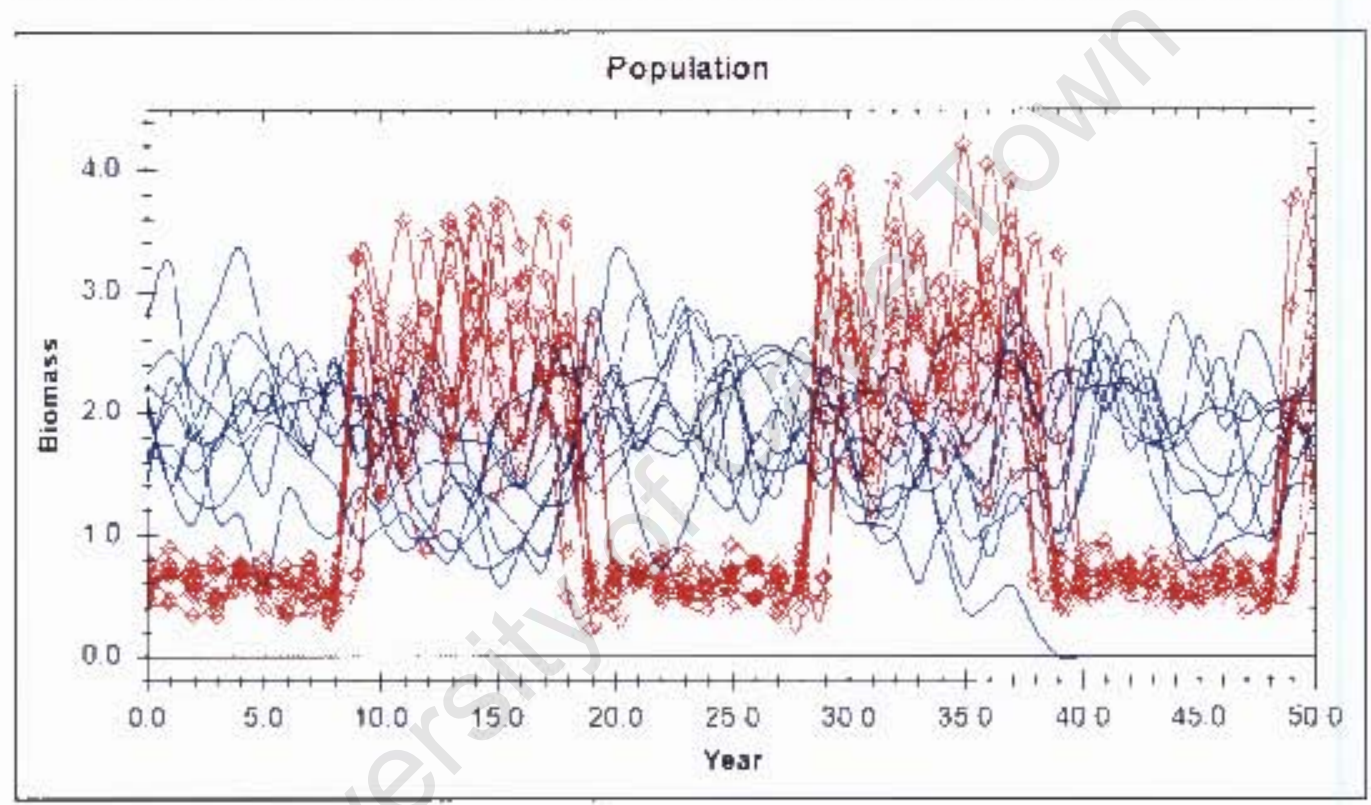

Figure 18 Prototype 2, wit7 ten suncessive runs of the model on ststamed urmonimied fishirg at a modes ale level i $0.4 j$ for each entire run (blue lines ind ca:e sard. he red indicate anconowy) a theugh the

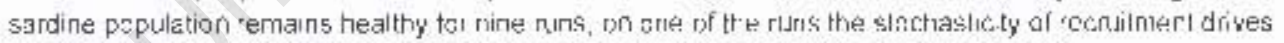
the sicck 10 a vul cerable state and lack of management compensation crashes the stock

"low" frame on that run would mos; likely have awoided the crash. Thus managenent which adapts to "egular and reliable survey data is necessary for safe exploit at ion of the stocks, as impiemented to some degree in the curren: OMP's (de Moor and Butteworth, 2008). Irnpor:antly, t"e model is seen to behave in a realistic way, reinforcing its Doien;ial value as a training tool for management. 


\subsubsection{Environmental scenarios}

\section{a. Impact of ESI periodicity on management}

A*ter observing ste ef "ec: of ESI periodirity on the anr.hovy frame behavinur of the modei, $\bar{n}$ comparison was made $o^{2}$ the sardine fishing perfurmance under differen: ESI cycle times. Measurements were saken at she standard ESI cycle $0^{2} 10$ years and comparrd with roadings from the model runining a 5 yoar cycle. The rxperiments were repedted at Automanage severity settings of $0 \%, 50 \%$ and $100 \%$. The indicators recorded for the sardine fishery were rverage :atal time spent in the "low" sardine frames, the dverage annud catch and the recuency of sardirs: stork crashes. Meas, rements wror : aken aver 1000 model runs with three replicates of each test, and the results averaged. The measurements are summarised in Table 12

Dur.rall, the prrformance of thr. fistiery is similar at 5 and 10 year $t S \mid$ cycle times. The shorter periud did signiticancly improve performance of the fishery at higher severity of ${ }^{2}$ ishing strategy. showing a small reduction in crashes and time in "low" sardine trames, despite the overage catches being uncha eed. It was shown in the sensitivizy ana.ysis (5oction 4.2.3) that with $\pi$ shurter cycle sime, the dinchovy population spends increased time in she "low" anchovy frames. The greatest risk of sardine sroc <crash ocrurs in the Anchowy high / Sardine Low frame, where the school trap actor is at is maxim. $m$. and shus it is possible tha: the red .ced sime in the "righ" anchovy "rames under a b-yr cycle tirne red uces the ris < of sardine stuck crash. The modelled anchovy population espond to climate forcing after a 2.3 year lag timir, and the. impact af climate function on frame behaviour increases as the wave periodicity approaches the lac time. 
Table 12 - Comparison of sardine fishing pertormance at warlous levêts of ALloblanaoge sever ty with ESI cycle :irres ot 5 and 1 il years

\begin{tabular}{|c|c|c|c|c|}
\hline $\begin{array}{l}\text { ESI cycle time } \\
\text { (yrs) }\end{array}$ & $\begin{array}{l}\text { AutoManage } \\
\text { severity }\end{array}$ & $\begin{array}{l}\text { Low Sardine } \\
\text { frames (yrs) }\end{array}$ & $\begin{array}{l}\text { Average } \\
\text { annual catch }\end{array}$ & $\begin{array}{l}\text { Crashes } \\
\text { (per } 1000 \text { runs) }\end{array}$ \\
\hline 5 & $0 \%$ & 0.13 & 0.342 & 0 \\
\hline 10 & $0 \%$ & 0.14 & 0.343 & 0 \\
\hline 5 & $50 \%$ & 3.40 & 0.420 & 25 \\
\hline 10 & $50 \%$ & 4.23 & 0.419 & 30 \\
\hline 5 & $100 \%$ & 25.99 & 0.338 & 574 \\
\hline 10 & $100 \%$ & 26.53 & 0.337 & 601 \\
\hline
\end{tabular}

In terms of rccommendations for the f shine management, toe model suggests that a variation in ESI cycle time does nut equire a different managr ment st atcgy, as the comparative fismeries performance across different severity setlines u"der the 10-and 5 -yr cycles times is vory similar.

\section{b. Effects of survey accuracy}

Introducing randarr sampling erru into the survey results could lead to " "tcresting thought experiments. $A$ - example of the impact of survey error is secn in Figure 19. This irodel r. " was conductro with the Auto Mandge function at a fairly conservative setting (20\% scurrity). and with a randor simulased survey erro each yea of up in $20 \%$. Typic.ral survey crrors ass maled by stock assessors in the region are: of the order of 15-30\% ie.e. de Mour et al., 2008\}, Over-

estimatio "i" the years $30-32$ res.lted $i$ " excess fish"ng when the sardine stock was at a scastive level and forced the stock into a "low" Irame, where it remained lo. 15 years.

Note trat al other staes of the model in $n$, there was litele observabie effect from survoy Inaccuracy. During the years 30-32, however, the sardine stocs was at a vulnerable level, and the

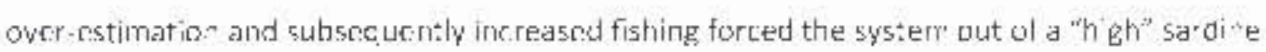
lrare. Un ke other poirts in the un where ine su voy data was innccurate, dur ing these years 
the actual modelled sardire population was on the threshold of a "low" trame transitio-", and the high fishing likely tipped the balance. The sensitivity of the model to fisheries management decisions hased on inaccurate survey da: a should ne explored fu ther.

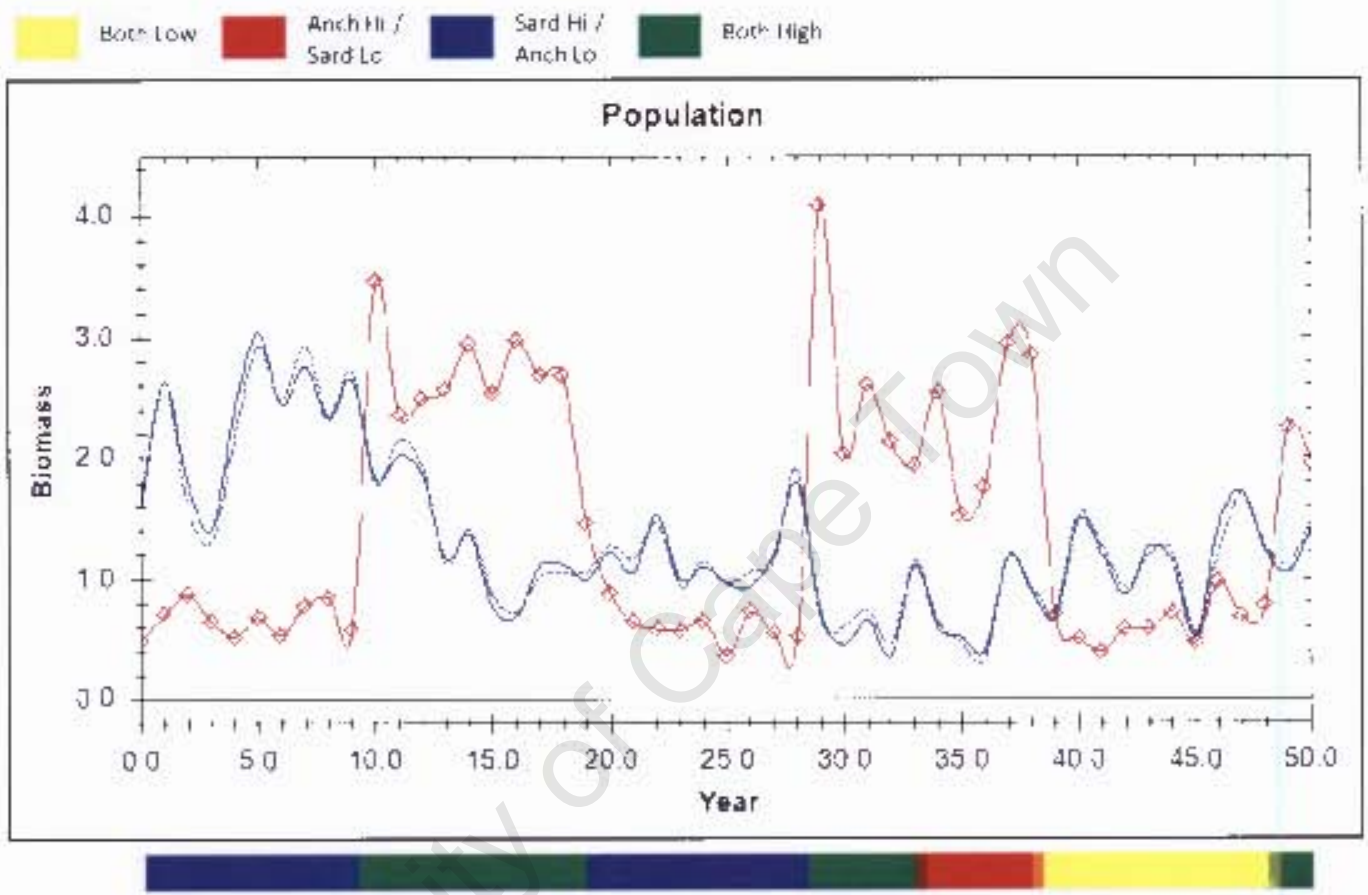

Figure 19 - A mode fun on Frotype 2 with survey data errit unde' a cinserwative Aul: Wanage setting (20\% severity). The scris blue lune is the dchual moctelled sarcinc population, the dotted blue I ne is the (inarcurate) assessed popu alion (the red line s the modelled anchisy pispulatisny Surby friar is scl al up $1020 \% 0^{*}$ the modellent sart he bumass lar cach year Gencrally. 17ere was little observable ettact 'rism ir accurate surseys except $n$ the case if years 30-32. where the ac:ual popilatori was cose ts a frame switch threshold. Over-

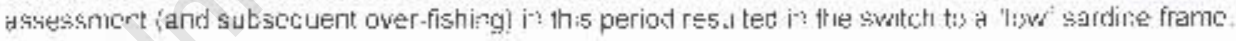




\section{Discussion}

\subsection{Is the model useful?}

The purpose of this study is to explore the usefulness of the frame-based modelling technique with respect to small pelagic populations in the southern Benguela. Attempting to represent "real" ecosystem dynamics in a model presupposes a detailed understanding of the ecosystem dynamics which may be difficult to achieve. The development of a model may be useful as a thought experiment to investigate assumptions about the operation of the real ecosystem. The model allows us to explore the operation of our idealised "model world", and in doing so, improves our understanding of the real ecosystem.

To clarify the distinctions between the real world and our "model world", consider Figure 20. The real world is represented by an irregular shape because it is complex and not fully understood. We reduce the real world to a more orderly "model world" by making appropriate assumptions and simplifications, based on the aspects of the real world that we wish to explore and our understanding of the dynamics of the real world. It is in this idealised world that our model exists. The simplicity and clear relationships of the model world allow us to observe and interpret interactions which result from our experiments with the model. Because our understanding of the dynamics in the model world is good, we can then interpret these results in the real world. This will either support or challenge our understanding of the real world.

"Data" is also a simplified representation of the real world, rather than being a complete picture of it. How good the representation is depends on the quality the sampling and also on the nature of the relationships we are trying to represent. We use data to calibrate the model, but our stochastic model does not aim to reproduce a certain data set: we are rather interested in representing the system dynamics, a particular replicate of which happened to produce the set of available data (because in a stochastic world, reality is just one replicate). Discrepancies between the model results 
and the data record can thus inform our understanding of both systems: the model results can be challenged where they appear to be giving results inconsistent with the data, but the model outputs may also highlight shortcomings of the data.

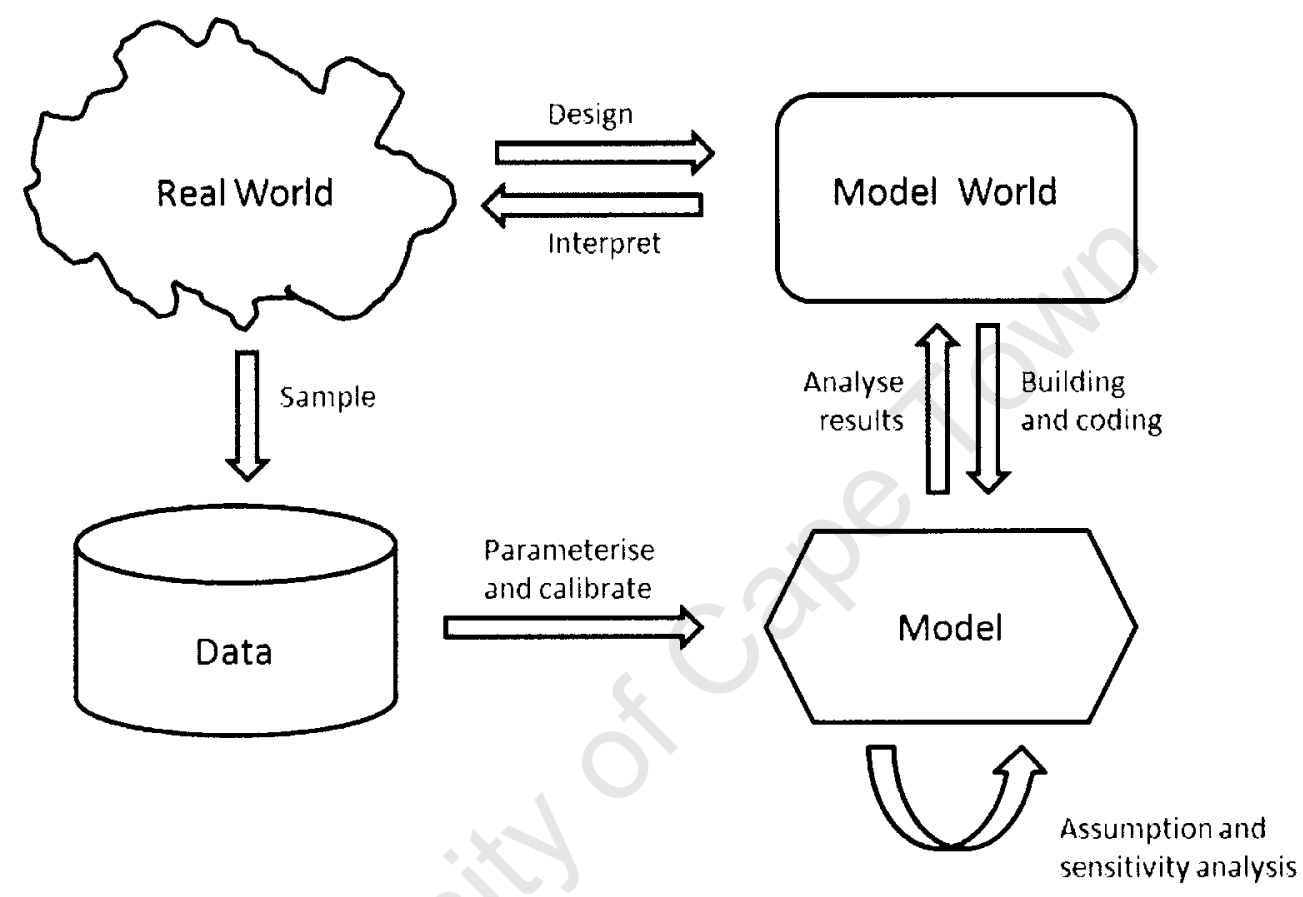

Figure 20 - Relationships between the model world (in which our model is built and tested) and the real world. The model world is an appropriately simplified version of the real world which retains the system dynamics of the real-world interactions that our model is designed to explore (After Starfield and Jarre, in review). Note that data from the real world is used to calibrate the model, but our model does not aim to directly reproduce the data.

With this in mind, we aimed to include the key characteristics of the small pelagic ecosystem in the southern Benguela in our model. It is admittedly less accurate than a stock assessment model (e.g. de Moor et al., 2008), but it was not developed with the objective of performing stock assessment. The frame-based model described here has the advantage that it provides a long-term perspective for model users trying to understand the implications of management strategies. It also includes the effects of climate variability and climate change, and the intuitive user interface makes it far more 
accessible as a training tool for users who may not come from a highly mathematical or scientific background. This is taken up further in Section 5.5.1.

\subsection{Usefulness of the frame-based approach}

\subsubsection{Frame-based modelling in a context where the understanding of the system is evolving}

The modular design of a frame-based model has important advantages in a system where the underlying mechanics may be subject to change, or may be poorly understood. Because each frame is effectively a separate model (although different frames may share many characteristics), the predominant forcing factors and significant components of each frame can be established independently.

In the southern Benguela ecosystem at present, there appears to be a movement of many species (including the small pelagics) from the West Coast to the South Coast. It is not clear whether this is in response to human intervention, changing climatic conditions, or is simply a cyclical trend with a particularly long frequency. But even while the causes are poorly understood it can be handled fairly simply under a frame-based model with the inclusion of additional frames. As the data for a theoretical "South Coast frame" improve, it would be possible to refine and re-test that frame without influencing the behaviour of other frames. Of course, the switching rules for the daemons may need certain adaptations.

In this respect, the frame-based approach stands distinct from more complex deterministic approaches such as NEMURO.FISH, where the dynamics of the system (particularly at a primary productivity level) are well understood. Although the NEMURO approach allows for detailed numerical outputs, it requires a fine-scale tuning of regional parameters to large volumes of data. The time and cost of development of a large and complex ecosystem model are orders of magnitude greater than for a frame-based model. The stochastic processes in our model also allow us to 
explore probabilities of certain outcomes (such as regime shifts or particular stock levels being maintained), which may be non-deterministic in the real world.

With regards to the crashing model sardine population, it could be argued that reducing a fish stock to zero is unrealistic: if the sardine were truly fished down to such a low level, the effort required to find and catch the few remaining schools would not be worth the value of the fish. An argument could thus be made, for instance, for setting the sardine at an arbitrary "very low" figure in the event of a crash. This would simulate stocks dropping to an "unfishable" level, although over decades they may still recover. Although this might be marginally more accurate in terms of representing the ecosystem, it is not necessary in terms of our model objectives: if the modelled sardine population drops to zero, the management has failed. Equally important, assumptions of an "inevitable" sardine recovery neglect to consider the possibility that the ecosystem may change irrecoverably to a new frame in the absence of the species. In the northern Benguela such a change appears to have taken place, as the niche previously filled by sardine and anchovy has largely been taken over by jellyfish and gobies following over-exploitation of the sardine stocks (Roux and Shannon, 2004). As with the suggested "South Coast frame", if an entirely new ecosystem state such as jellyfish/goby dominance were to emerge in the southern Benguela, such a shift could be incorporated into the current model by invoking additional frames.

\subsubsection{Extracting more information from population thresholds}

Traditional fisheries biology frequently uses two reference points for the biomass indicator of the target stock (e.g. ICES, 1998: p. 6-7). Above the precautionary (upper) reference point, the stock is considered to be in good condition, but once the stock size drops below this point, management measures are recommended to assist the stock recovery. If the stock size drops below the limit (lower) reference point, the stock is unacceptably low and harsher management measures (such as 
closure of the fishery) are requested or required. Such reference points are used for North Sea Cod (ICES, 2000: p. 239). Including the frame state allows us to draw different conclusions from the same biomass in different situations. The sardine daemon in the model has thresholds for switching frames which are similar to the precautionary and lower reference points: if the sardine is in a "high" frame, the stock must drop right down below the lower reference point (annual average $<0.6$ for three years) before a frame switch is caused. But once in the "low" frame, the stock must recover past the upper reference point (annual average $>1.0$ for three years) before it is considered to be in a "high" frame again. In the real population, a healthy sardine stock should recover from a temporary period of excessive fishing more easily than a stock which has been suppressed for a long period. Sardine at an intermediate population level (for example 0.8) in a "low" frame would be more likely to have sub-optimal schooling behaviour and therefore show reduced productivity than sardine in a "high" frame at the same population level. Thus the frame state allows us to easily consider the condition and behaviour of the stock as well as its size.

The health of the stock is considered in many fisheries, but is typically determined by a lengthy evaluation process. By encoding the evaluation into the daemon rules, our model gives a quick and easily understood indicator for the state of the modelled stock.

The examples below show the implications of frame state on two modelled sardine populations under similar management. In Figure 21, the modelled sardine stock was fished heavily (at 0.6) for years $0-9$, which caused a rapid decline in the population. From year 9 , the fishing pressure was reduced to 0.3 , and because the modelled sardine stock was still in a high frame, it recovered quickly and the continued moderate fishing did not imperil the stock. 


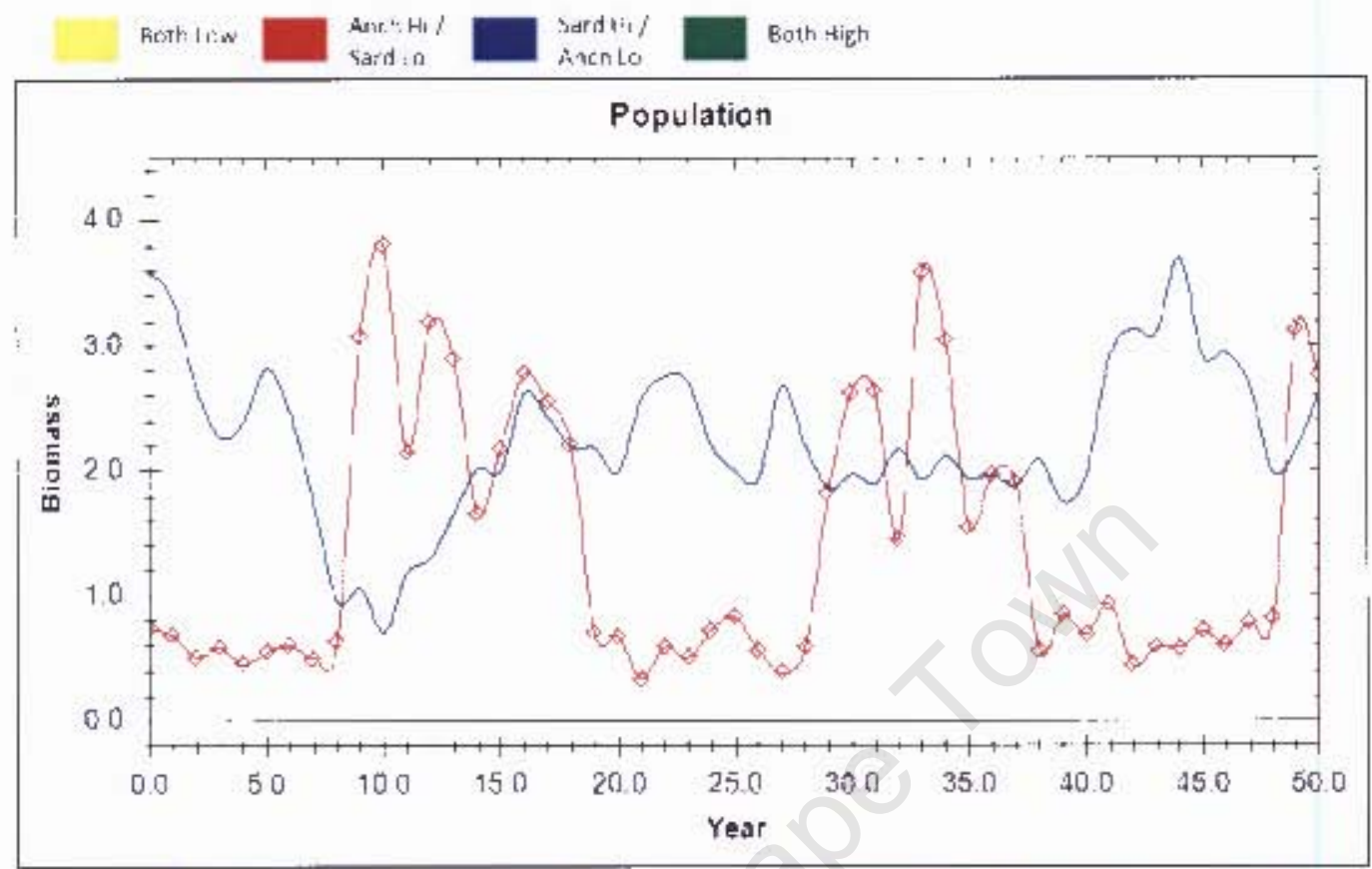

Figure 21 - Prololype 2 , under heavy sand r.e fisting (at 0.6 for the first 5 years bol, le line indicatis sardine, red ind ca:es archouy) n respor:se to the dech ne of the modelled sardine stock. fishing was reduced to 0.3 for the rest of the rLI.. and sardine remained in a "high ' frame

By cuntrast, Fieure 22 stows a simila: :rend for the fis: 9 yra's of the model run, which also resul:nd from 9 years of hea wy fist ing (d: 0.6 ). The sardine fishing was stopped entire y fiom yca- 9

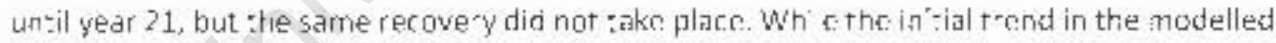
sardine: population is similar to the previous example, in this run the popula:ion dropped below the critical transition threshold and the sys:em switched to a sardiac "low" frame. Recall that the fishing stratcgy in thesc twa test: was identical, and the difference in frame bel:aviour s due to the stochas :icisy o: sardine recruitme:t, The :ra:sition to a "low" frame in this casc necrssitated a closurc of the fizhery and rezulted in 12 years oi vulnerable sardine, Althougt: yea's 14-21 ex-ibi: a sustained model ed sardine populatio $)$ of $>0.8$, the 'rames ind cate tha: the sardine stock is s:ill vulnerable and advise a conservative mandgement approach: From year 21 , sard ne fist?ing was resumed a: D. 3 for the remainder of the rur. 


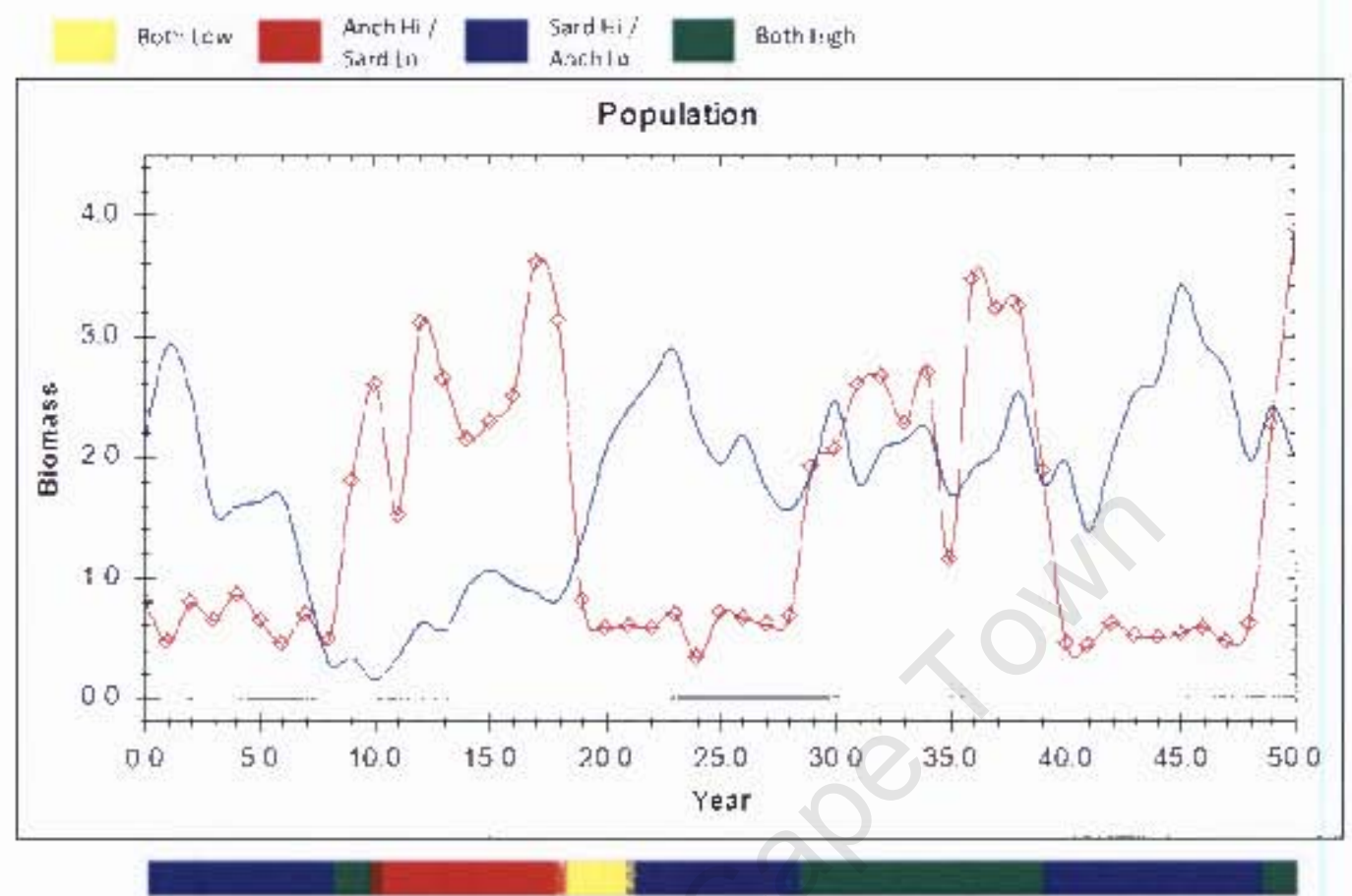

Figure 22 - Protolype 2 under reaxy sardine $f$ shing $(0.6)$ or the fi'st 9 years $(0$ ue h.7e ind cates sardine. red

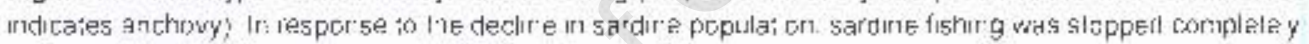
until year 21. wher it was resur:ed at 0.3 for the rest of the rur.

\subsubsection{Frame-based models as aids to inter-disciplinary communication}

From a development perspective, the Irame-based paradipm serves as a useful intertace wetween, software developers ano ecosystem hiologists. In an eqvironment in which tre rooing and mocel cesign work are oflen performied by programining spec'alists, assed on descriptions from hiologists with perhaps limiteo programming expertise, it is vital to be able to comm, icate concepts between the different groups.

Frame-oased mode's are also a useful way for bologists and managers to descr be ecusys:ems, as Shey help to move triaking towaros long te'm effec:s of manrsemen: actions. By sett ing the ecusystem into a specific frame for eacn, time step, the frame based system highl'gn.ts tre important 
factors which are at play in the system at that point. For instance, if a real ecosystem goes into a "low" sardine frame, the user of this model now understands the hazards implicit in that state.

Such models also fit naturally into well-encapsulated computer code. It has already been noted that an ecosystem model which is compartmentalised into multiple sub-models (the frames) is easy to expand if a new ecosystem description becomes necessary (such as the proposed "South Coast frame" in the southern Benguela model), or if the understanding of the behaviour of a particular frame changes. This kind of model also translates into well-structured and easily maintained programme code.

III-defined software specifications rarely result in well-written or stable programmes. However, with high inherent uncertainty in ecosystem dynamics and major gaps in our understanding it is difficult (or rather impossible) for biologists to give an exact specification of the requirements of an ecosystem model. Frames and rapid prototyping are modelling techniques well suited to dealing with incremental increases in knowledge and understanding of the real world.

\subsection{Advantages of rapid prototyping}

The experiences with modelling sardine density dependence are illustrative of the strong advantages of rapid prototyping as a modelling technique. We were able to build a first model based on initial assumptions, test those assumptions, build a refined model, test it, refine the parameters of the second model and retest it very quickly. The development of the first prototype, including planning, software development and testing, took about one month to complete. By eliminating unnecessary complications from the model, it became much clearer to see which components were influencing the population behaviour in different ways, and refine and test the model accordingly. 
Our first attempts to model the sardine density dependence were over-simplified, and even with the second prototype our initial levels of density dependence resulted in a modelled sardine population that was excessively resistant to fishing: the effect of the increase in recovery rate at low population levels was such that the sardine were very hard to fish down, which is not consistent with historical evidence (e.g. Boyer and Hampton, 2001; Fairweather et al., 2006a; Coetzee et al., 2006). Density dependence should help a healthy sardine population to recover from a mild setback, but in fact the recruitment variability was far more significant in our model. A classic Schaeffer model would imply that it is possible to keep the stocks at a constant moderate population level and rely on density dependence to keep the system stable, but the results from our model suggest that this may be over-simplified. With such high variability in recruitment, if sardine fishing is to achieve maximum sustainable yields (in the classical sense), the importance of recruit surveys can scarcely be overstated (Csirke, 1988). Estimating the actual stock size for a given year is vital for setting safe fishing levels, particularly if the stocks are in a vulnerable state, for instance in a "low" frame or near a frame transition point.

\subsection{Applications of the model}

The model was not built to perfectly replicate the real ecosystem, and it is admittedly a much simplified representation. However, it is sufficiently realistic to show potential to perform as a "training tool" for management. By providing a mechanism to exert varying degrees of fishing pressure on the stocks, the model allows a prospective manager to experiment with a simplified version of the stocks and immediately see the impact of their actions. Such experiments also help a prospective manager to appreciate the levels of unpredictability in the system and the need for a conservative approach to fisheries management. By separating the graphical interface from the complicated programming behind it, the model gives easily understood outputs of modelled 
populations and frame states to a non-specialist user, while also displaying more detailed statistics on the diagnostics tab for the more advanced user.

Further uses of the model involve generating probabilities of outcomes based on particular management actions, in order to feed into an expert system for predicting long-term ecosystem changes. This is discussed in more detail in Section 5.5.2.

\subsection{Proposed further research and model expansion}

\subsubsection{For use as a training tool}

The influence of variability in accuracy of survey data should be explored further. In particular, it would be interesting to evaluate the effect of decreasing survey accuracy on the system, investigating to what extent fisheries management strategy informed by inaccurate data affects the sardine population performance. In the model, the survey data is equally likely to over-report or under-report, but the consequences of these errors are very different. An under-estimated sardine stock would result in less fishing activity for the year, and thus less income for the fishing industry than could otherwise have been enjoyed, but the impact of the error (benefit for the sardine population, loss of potential bonus catch for the fishing industry) will only span that single year. An over-reported stock size, in contrast, would result in higher catches than would have been recommended from an accurate survey. Depending on the stock level, this increased fishing could not only increase the income of the fishing industry in that year, but it could also imperil the sardine stock, potentially even crashing the population. Thus although the magnitude of survey error may be symmetrical in either direction, we would expect it to have an overall negative effect on sardine performance. A thorough exploration of this (with a study of important thresholds of accuracy) would be useful in suggesting the extent of biomass surveys which were necessary for safe fishing. 
With respect to the current user interface, the inclusion of help screens and explanatory notes providing more information on the reaction of the system to user inputs would increase the value of the programme as a training tool. A well-designed and interactive user interface greatly increases the potential user base of the tool, allowing (for instance) fisheries managers, conservationists and researchers to experiment with and learn from the model (as also observed by Quadling and Starfield, 2002).

Including a population model for anchovy would allow us to test the assumptions of the response of the anchovy stock to fishing pressure. The anchovy daemon would still need to base its switching rules largely on the ESI, as the environmental factors are by far the most significant on the anchovy population (Miller and Field, 2002). In the current sardine population model, the recruitment parameter receives a small negative adjustment in an Anchovy High frame based on the assumption that the environment is sub-optimal for sardine. A similar approach could be taken with an anchovy population model, where the recruitment parameter was increased significantly in the "high" anchovy frames (i.e., when the climate is favourable), and thus the modelled anchovy population would recover very quickly from severe fishing in these frames. In the "low" anchovy frames, with no environmental boost, they could be crashed by similar fishing levels.

In order to increase model accuracy, the population model used for sardine could be refined by including age-structure. The different spawning potentials of different age-classes of adult fish do not currently affect the model, but there is evidence that this is a factor in the real fish population (van der Lingen et al., 2006c; de Oliveira, 2006).

\subsubsection{For use in an expert system to predict regime shifts}

Models which offer a long-term view to species population changes are an important component in attempting to predict regime shifts on an ecosystem scale (Jarre et al., 2006). Although such an 
ecosystem shift would have impact on a wide range of species, indicators of shifts at a community level may be difficult to measure (see various contributions in Daan et al., 2005). A synthesis of such data as are available is necessary to derive an holistic view of trends in a multi-species system incorporating several trophic levels (Jarre et al., 2006). Small pelagic populations are particularly well suited as an indicator, due to their "wasp-waist" position in the ecosystem, with a small number of species supporting a relatively high species richness at higher trophic levels.

Ideal indicators at an ecosystem level would come from the primary productivity (Tester et al., 1997; Rupp et al., 2000b). Many of the physical data (such as sea surface temperature, transport current strength and upwelling strength) which are summarised in the Environmental Suitability Index in the model are available for use as indicators, and show evidence of regime shifts (Howard et al., 2007). However, our understanding of plankton dynamics is currently insufficient to observe regime shifts in the available data (Demarcq et al., 2008). As small pelagics occupy a low trophic level in the food web, it is useful to employ them for modelling ecosystem regime shifts.

Predators such as seabirds, seals, predatory fish and some cetaceans are highly sensitive to changes in small pelagic fish abundance, as well as suffering incidental mortality from small pelagic-directed fishing activity (Shannon et al., 2004). Predator species at higher trophic levels could be added to the existing model, preying on the small pelagics which "escape" the fisheries, but this extension was outside the scope of the present project. Certain aspects of predator dynamics (such as the need for available forage near seabird nesting sites) would not be suitable for inclusion because these interactions occur at specific spatial scales.

A suitable synthesis of environmental and small pelagic indicators in the model, as well as the longterm perspective, offer potential to contribute to the assessment of probabilities of change for an expert system to predict regime shifts. Modelling the likely effect of fishing activity on small pelagic populations, such as implemented in this model, can give probabilities of fishing activity initiating or contributing to an ecosystem shift. For this to be possible, the model should be configured to 
specifically record probabilities of relevant outcomes rather than averaged data. At present, the data displayed at the end of each run are more geared towards the training applications, with averaged figures, crash data and thresholds for specific performance evaluation (e.g. the $>80 \%$ "good year" index). The individual data for each year of each model run are retained in the programme, so configuring the outputs to provide probability data rather than averages would be straightforward.

\subsubsection{Additional possibilities}

We have so far assumed no long-term trend in the climate parameters in the ESI. It would be interesting to investigate the frame and population behaviour in the model if the baseline ESI (the midpoint about which the function fluctuates) were gradually increased over the course of the model run.

It may be useful to link the existing frame-based model to a similar model of the social system (as proposed by Jarre et al., 2007) in order to connect the influence of social drivers (and their changes in the long term) to fishing pressure. However, there is already potential to increase the scope of questions which can be addressed with the existing model by including, for example, economic indicators. The inclusion of economic indicators might allow us to evaluate, for example, different catch compositions due to different market values of sardine and anchovy. Along similar lines, a sensitivity analysis which evaluated the effects of varying levels of illegal, unregulated and unreported fishing (perhaps by varying the catch above the suggested TAC level for a particular year) could also be of benefit in establishing suitable levels of monitoring and compliance enforcement. 


\section{Conclusions}

- A semi-qualitative second prototype model was developed to investigate dominance shifts between sardine and anchovy in the southern Benguela. The modelled sardine population was found to be sensitive to the fishing strategy, including both sardine-directed fishing and modelled sardine bycatch from the anchovy fishery. Frame-switching behaviour was moderately sensitive to the daemon parameters, and highly sensitive to sardine fishing strategy.

- While our general results increased confidence in the model, the high degree of stochasticity in the modelled system suggested caution in analysing real-world data series and inferring cause-and-effect relationships.

- Although not suitable for stock assessment, the frame-based model described here offers a long-term perspective to aid understanding of the impact of fisheries management strategies under long-term climate variability and change on small pelagics in the southern Benguela.

- The modular design which results from a frame-based modelling approach results in a flexible and easily adapted model which can be incrementally updated as understanding of the system evolves. Additional frames can even be added to the model where it appears that the ecosystem is entering a previously unobserved state. Rapid prototyping allowed us to test assumptions quickly and refine the model accordingly during the development cycle.

- The frame-based paradigm provides a natural "common ground" to facilitate communication between biologists and computer programmers. Frame-based models encourage well-structured and easily maintained computer programmes. 
- The graphical population output and clear frame display allow a user to experiment with the model and learn from it even without a detailed understanding of the programming behind it. Further development in this regard could broaden the potential user base of the model as a training tool. The model allows users to explore differing fisheries strategies and see the likely impact on the modelled stocks.

- Some minor data processing adaptations would allow the model to contribute probabilities of change to an expert system for predicting long-term ecosystem changes.

- The inclusion of frames in the outputs gives the user a greater depth of understanding of the condition and behaviour (and hence vulnerability) of the modelled stocks than simple population indicators would. The frame concept is also valuable in highlighting the most important factors at play in the system at any particular point in the model run. By encoding any calculations and rules within the daemons, the frames state serves as a quick "summary" indicator of the modelled stock condition. 


\section{Acknowledgements}

First and foremost, I would like to thank my supervisors, Astrid Jarre and Tony Starfield. This project would have been unthinkable without Astrid's tireless efforts at teaching an engineer / computer programmer something about marine biology and fisheries, as well as her invaluable guidance in structuring the research project. Tony's phenomenal experience and expertise as a modeller of the highest calibre gave the project a polish and thoroughness that might otherwise have been lacking, and his constant challenging of assumptions and model dynamics led to a greatly improved final product.

Marine and Coastal Management generously allowed us to use their expanded data set for the sardine and anchovy stock assessment.

I would like to thank JChampion of The Code Project and the ZedGraph team for use of the ZedGraph component, and Copper of The Code Project for use of the ColorBar component. Both of these modules helped speed up the development of the model GUIs. Thanks also to Tim Victor for the use of his adapted daemon icon.

Thanks also to the Convenors and Co-ordinators of the Applied Marine Science master's course, John Field, Coleen Moloney and Pavitray Pillay; and the lecturers for their support and teaching through the coursework which laid the foundation for this research. Thanks also to Gilly Smith for suggesting the course and streamlining all of the administrative procedures - thanks mom!

Huge thanks and love also go to the family and friends who supported me through the period of research: my fiancée Christina; my parents and friends in Cape Town; my brothers; and my classmates from the AMS course of 2008/2009, especially Janine, Dan and Will for beer and encouragement.

This work is based upon research supported by the South African Research Chairs Initiative of the Department of Science and Technology and National Research Foundation. 


\section{References}

Alheit, J., Niquen, M. 2004. Regime shifts in the Humboldt Current ecosystem. Progress in Oceanography, 60, 201-222

Bakun, A. 2001. 'School-mix feedback': a different way to think about low frequency variability in large mobile fish populations. Progress in Oceanography, 49, 485-511

Bakun, A., Cury, P. 1999. The "school trap": a mechanism promoting large-amplitude out-of-phase population oscillations of small pelagic fish species. Ecology Letters, 2, 349-351

Baumgartner, T.R., Soutar, A., Ferreira-Bartrina, V. 1992. Reconstruction of the history of Pacific sardine and northern anchovy populations over the past two millennia from sediments of the Santa Barbara Basin, California. CalCOFI Rep., 33, 24-40

Borges, M.F., Santos, A.M.P., Crato, N., Mendes, H., Mota, B. 2003. Sardine regime shifts off Portugal: a time series analysis of catches and wind conditions. Scientia Marina, 67(1), 235-244

Boyer, D.C., Hampton, I. 2001. An overview of the living marine resources of Namibia. In: A.I.L. Payne, S.C. Pillar, R.J.M. Crawford (eds), A Decade of Namibian Fisheries Science. South African Journal of Marine Science, 23, 5-35

Coetzee, J.C., van der Lingen, C.D., Fairweather, T., Hutchings, L., 2006. Has fishing pressure caused a major shift in the distribution of South African sardine? ICES CM, B, 11

Csirke, J. 1988. Small shoaling pelagic fish stocks. In: J.A. Gulland (ed), Fish Population Dynamics, Second Edition (pp. 271-302). Wiley-Interscience, Chichester, UK.

Cury, P., Shannon, L. 2004. Regime shifts in upwelling ecosystems: observed changes and possible mechanisms in the northern and southern Benguela. Progress in Oceanography, 60, 223-243

Cury, P., Bakun, A., Crawford, R.J.M., Jarre[-Teichmann], A., Quiñones, R., Shannon, L.J., Verheye, H.M. 2000. Small pelagics in upwelling systems: patterns of interaction and structural changes in "wasp-waist" ecosystems. ICES Journal of Marine Science, 57, 603-618

Daan, N., Christensen, V., Cury, P. (eds) 2005. Qualitative ecosystem indicators for fisheries management. ICES Journal of Marine Science, 62 , no. 3.613 pages

de Moor [Cunningham], C.L., Butterworth, D.S. 2008. OMP-08. Marine and Coastal Management, Cape Town, unpublished working document. MCM/2008/SWG-PEL/23, 15 pages 
de Moor [Cunningham], C.L., Butterworth, D.S., Coetzee, J.C. 2008. Revised estimates of abundance of South African sardine and anchovy from acoustic surveys adjusting for echosounder saturation in earlier surveys and attenuation effects for sardine. African Journal of Marine Science, 30(2), 219-232 de Oliveira, J. 2006. Long-term harvest strategies for small pelagic fisheries under regime shifts: the South African fishery for pilchard and anchovy. In: R. Hannesson, M. Barange, S.F. Herrick (eds), Climate Change and the Economics of the World's Fisheries: examples of small pelagic stocks (pp. 151-204). Edward Elgar Publishing Ltd., Cheltenham, UK.

Degnbol, P. 2003. Science and the user perspective: the scale gap and the need for co-management. In: D.C. Wilson, J. Raakjaer Nielsen, P. Degnbol (eds) The Fisheries Co-Management Experience. Accomplishments, Challenges and Prospects (pp. 31-49). Kluwer Academic Publishers, Dordrecht, The Netherlands.

Demarcq, H., Richardson, A.J., Field, J.G. 2008. Generalised model of primary production in the southern Benguela upwelling system. Marine Ecology Progress Series, 354, 59-74

Fairweather, T.P., van der Lingen, C.D., Booth, A.J., Drapeau, L., van der Westhuizen, J.J. $2006 a$. Indicators of sustainable fishing for South African sardine Sardinops sagax and anchovy Engraulis encrasicolus. African Journal of Marine Science, 28(3\&4), 661-680

Fairweather, T.P., Hara, M., van der Lingen, C.D., Raakjær, J., Shannon, L.J., Louw, G.G., Degnbol, P., Crawford, R.J.M. 2006b. A knowledge base for management of the capital-intensive fishery for small pelagic fish off South Africa. African Journal of Marine Science, 28(3\&4), 645-660

FAO. (C 2005-2009. Fisheries Topics: Resources. State of world marine fishery resources. Text by Michel Lamboeuf. In: FAO Fisheries and Aquaculture Department [online]. Rome. Updated 27 May 2005. http://www.fao.org/fishery/topic/426/en

Howard, J.A.E., Jarre, A., Clark, A.E., Moloney, C.L. 2007. Application of the sequential t-test algorithm for analysing regime shifts to the southern Benguela ecosystem. African Journal of Marine Science, $29(3), 437-451$

Howard, J.A.E. 2007. Application of the sequential t-test algorithm for analysing regime shifts to the southern Benguela ecosystem. MSc thesis, University of Cape Town, Rondebosch

ICES. 1998. Report of the ICES Advisory Committee on Fishery Management, 1997, Part 1. International Council for the Exploration of the Seas, Cooperative Research Report No.223, 413 pp. 
ICES. 2000. Report of the ICES Advisory Committee on Fishery Management, 1999, Part 1.

International Council for the Exploration of the Seas, Cooperative Research Report No. 236, 416 pp.

Jarre[-Teichmann], A., Shannon, L.J., Moloney, C.L., Wickens, P.A. 1998. Comparing trophic flows in the southern Benguela to those in other upwelling ecosystems. In: S.C. Pillar, C.L. Moloney, A.I.L. Payne, F.A. Shillington (eds), Benguela dynamics: impacts of variability on shelf-sea environments and their living resources. South African Journal of Marine Sciences, 19, 391-414

Jarre, A., Moloney, C.L., Shannon, L.J., Fréon, P., van der Lingen, C.D., Verheye, H.M., Hutchings, L., Roux, J-P., Cury, P. 2006. Developing a Basis for Detecting and Predicting Long-Term Ecosystem Changes. In: V. Shannon, G. Hempel, P. Malanotte-Rizzoli, C. Moloney, J. Woods (eds), Benguela: Predicting a Large Marine Ecosystem (pp. 239-272). Large Marine Ecosystems Series, 14. Elsevier, Amsterdam.

Jarre, A., Paterson, B., Moloney, C. 2007. Tools for decision support for an Ecosystem Approach to Fisheries in South Africa. Report of a workshop held in Pringle Bay, Western Cape, South Africa, 6-7 Nov. 2007 (13p + 6 App.). Marine Research Institute, University of Cape Town.

Jarre, A., Paterson, B., Moloney, C.L., Miller, D.C.M., Field, J.G., Starfield, A.M. 2008. Knowledgebased systems as decision support tools in an ecosystem approach to fisheries: Comparing a fuzzylogic and a rule-based approach. Progress in Oceanography, 79, 390-400

Jordán, R., Csirke, J., Tsukayama, I. 1978. Situacion de los recursos anchoveta, sardina, jurel y caballa al Junio 1978. Instituto del Mar del Peru, 56, 32

Lluch-Belda, D., Schwartzlose, R.A., Serra, R., Parrish, R.H., Kawasaki, T., Hedgecock, D., Crawford, R.J.M. 1992. Sardine and anchovy regime fluctuations of abundance in four regions of the world oceans: a workshop report. Fisheries Oceanography, 1(4), 339-347

McQueen, N., Griffiths, M. 2004. Influence of sample size and sampling frequency on the quantitative dietary descriptions of a predatory fish in the Benguela ecosystem. African Journal of Marine Science, 26(1), 205-217

Miller, D.C.M., Field, J.G. 2002. Predicting anchovy recruitment in the southern Benguela ecosystem: developing an expert system using classification trees. South African Journal of Science, 98, 465-472 Nicolson, C.R., Starfield, A.M., Kofinas, G.P., Kruse, J.A. 2002. Ten heuristics for interdisciplinary modeling projects. Ecosystems, 5, 376-384 
Pauly, D., Tsukayama, I. (eds). 1987. The Peruvian anchoveta and its upwelling ecosystem: three decades of change (351). ICLARM Studies and Reviews, 15. International Center for Living Aquatic Resources Management, Manila, Philippines.

Pauly, D., Palomares, M.L. 1989. New estimates of monthly biomass, recruitment and related statistics of anchoveta (Engraulis ringens) off Peru (4-14S), 1953-1985. In: D. Pauly, P. Muck, J. Mendo, 1. Tsukayama (eds), Peruvian Upwelling Ecosystem: Dynamics and Interactions (pp. 189206). ICLARM Conference Proceedings, 18. International Center for Living Aquatic Resources Management, Manila, Philippines.

Quadling, H.S., Starfield, A.M. 2002. Exploiting object-oriented programming structures in the quest for an individual-based population model with an attractive user interface. South African Journal of Science, 98, 449-454

Roux, J-P, Shannon, L. J. 2004. Ecosystem approach to fisheries management in the northern Benguela: The Namibian experience. Africa Journal of Marine Science, 26, 79-93

Roy, C., Weeks, S., Rouault, M., Nelson, G., Barlow, R., van der Lingen, C. 2001. Extreme oceanographic events recorded in the Southern Benguela during the 1999-2000 summer season. South African Journal of Science, 97 11-12: 465-471

Roy, C., van der Lingen, C., Coetzee, J., Lutjeharms, J. 2007. Abrupt environmental shift associated with changes in the distribution of Cape anchovy Engraulis encrasicolus spawners in the southern Benguela. African Journal of Marine Science, 29(3): 309-319

Rupp, T.S., Starfield, A.M., Chapin, F.S. 2000a. A frame-based spatially explicit model of subarctic vegetation response to climate change: comparison with a point model. Landscape Ecology, 15, 383400

Rupp, T.S., Chapin, F.S., Starfield, A.M. 2000b. Response of subarctic vegetation to transient climatic change on the Seward Peninsula in north-west Alaska. Global Change Biology, 6, 541-555

Schwartzlose, R.A., Alheit, J., Bakun, A., Baumgartner, T.R., Cloete, R., Crawford, R.J.M., Fletcher, W.J., Green-Ruiz, Y., Hagen, E., Kawasaki, T., Lluch-Belda, D., Lluch-Cota, S.E., MacCall, A.D., Matsuura, Y., Nevarez-Martinez, M.O., Parrish, R.H., Roy, C., Serra, R., Shust, K.V., Ward, M.N., Zuzunaga, J.Z. 1999. Worldwide large- scale fluctuations of sardine and anchovy populations. South African Journal of Marine Science, 21, 289-347 
Shannon, L.J., Moloney, C.L., Jarre, A., Field, J.G. 2003. Trophic flows in the southern Benguela during the 1980 s and 1990s. Journal of Marine Systems, 39 (1-2), 83-116

Shannon, L.J., Christensen, V., Walters, C.J. 2004. Modelling stock dynamics in the southern Benguela ecosystem for the period 1978-2002. African Journal of Marine Science, 26, 179-196 Shannon, L.J., Cury, P.M., Nel, D., van der Lingen, C.D., Leslie, R.W., Brouwer, S.L., Cockcroft, A.C., Hutchings, L. 2006. How can science contribute to an ecosystem approach to pelagic, demersal and rock lobster fisheries in South Africa? African Journal of Marine Science, 28(1), 115-157

Shannon, L.J., Coll, M., Neira, S. 2009. Examining indicators of ecosystem changes and effects of exploitation from trophic models fitted to time series data in three ecosystems. Ecological Indicators, in press

Shin, Y., Shannon, L.J., Cury, P.M. 2004. Simulations of fishing effects on the southern Benguela fish community using an individual-based model : Lessons from a comparison with ECOSIM. African Journal of Marine Science, 26, 95-114

Starfield, A.M. 1997. A pragmatic approach to modeling for adaptive management. Journal of Wildlife Management, 61, 166-174

Starfield, A.M., Bleloch, A.L. 1991. Building models for conservation and wildlife management (253pp). Interaction Book Company, Edina, Minnesota.

Starfield, A.M., Chapin, F.S. 1996. Model of transient changes in Arctic and boreal vegetation in response to climate and land use change. Ecological Applications, 6(3), 842-864

Starfield, A.M., Jarre, A. (in review). Expected publication: late 2009. Interdisciplinary modelling for an ecosystem approach to management in marine socioecological systems. Invited contribution to: R. Ommer, I. Perry, P. Cury, K. Cochrane (eds), World Fisheries: a social-ecological analysis. WileyBlackwells' Fish and Aquatic Resources Book Series.

Tester, J.R., Starfield, A.M., Frelich, L.E. 1997. Modeling for ecosystem management in Minnesota pine forests. Biological Conservation, 80, 313-324

van der Lingen, C.D. 1994. Effect of particle size and concentration on the feeding behaviour of adult pilchard Sardinops sagax. Marine Ecology Progress Series, 109, 1-13

van der Lingen, C.D., Hutchings, L., Merkle, D., van der Westhuizen, J.J. and Nelson, J. 2001.

Comparative spawning habitats of anchovy (Engraulis capensis) and sardine (Sardinops sagax) in the 
southern Benguela upwelling ecosystem. In: G.H. Kruse, N. Bez, T. Booth, M. Dorn, S. Hills, R. Lipicius, D. Pelletier, C. Roy, S. Smith and D. Witherell (eds), Spatial Processes and Management of Marine Populations (pp. 185-209). Fairbanks: University of Alaska Sea Grant, AK-SG-00-04.

van der Lingen, C.D., Shannon, L.J., Cury, P., Kreiner, A., Moloney, C.L., Roux, J-P., Vaz-Velho, F. 2006a. Resource and Ecosystem Management, Including Regime Shifts, in the Benguela Current System. In: V. Shannon, G. Hempel, P. Malanotte-Rizzoli, C. Moloney, J. Woods (eds). Benguela: Predicting a Large Marine Ecosystem (pp. 147-184). Large Marine Ecosystems Series, 14. Elsevier, Amsterdam.

van der Lingen, C., Hutchings, L., Field, J. 2006b. Comparative trophodynamics of anchovy Engraulis encrasicolus and sardine Sardinops sagax in the southern Benguela: are species alternations between small pelagic fish trophodynamically mediated? African Journal of Marine Science, 28(0), 465-477

van der Lingen, C.D., Fréon, P., Fairweather, T.P., van der Westhuizen, J.J. 2006c. Density dependent changes in reproductive parameters and condition of southern Benguela sardine Sardinops sagax. African Journal of Marine Science, 28(3\&4), 625-636

Verheye, H.M., Richardson, A.J. 1998. Long-term increase in crustacean zooplankton abundance in the southern Benguela upwelling region (1951-1996): bottom-up or top-down control? ICES Journal of Marine Science, 55, 803-807

Verheye, H.M., Richardson, A.J., Hutchings, L., Marska, G., Gianakouras, D. 1998. Long-term trends in the abundance and community structure of the coastal zooplankton in the southern Benguela system, 1951-1996. In: Pillar SC, Moloney CL, Payne AIL and Shillington FA (Eds), Benguela dynamics: impacts of variability on shelf-sea environments and their living resources. South African Journal of Marine Science 19, 317-332 


\section{Appendices}

9.1 Appendix A: Sensitivity and assumption analyses data (for Table 6, Section 4.2.1)

Section 4.2 .1 rontains a summary table of the results of the eses performed for tre broad scensitivity and assumption a"alysis. Inclucied are the data from the tes:s themselves. Frame behaviour figures reso d the time spent in the "Both High" frame. Fished system figu es ars: all pe formed on the Auiomanage :unction at the most "conservative" seiting.

\begin{tabular}{|c|c|c|c|c|c|c|c|c|}
\hline & \multicolumn{2}{|c|}{ Average Population } & \multicolumn{2}{|c|}{ Sardine catch } & \multicolumn{2}{|c|}{ Ànchovy catch } & \multicolumn{2}{|c|}{ Frame behaviou } \\
\hline & 5ard & Anct & Ave & std ter & Avg & bycatch & Duration & Res. \\
\hline \multicolumn{9}{|l|}{$\begin{array}{l}\text { AidoManage } \\
\text { sardine threstiolds }\end{array}$} \\
\hline \multicolumn{9}{|l|}{$\begin{array}{l}\text { MuloManagh } \\
\text { sardine TAC levels }\end{array}$} \\
\hline & & & & & 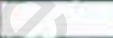 & & & \\
\hline $\begin{array}{l}\text { Sardine Daemon: } \\
\text { Curnulative } 453 \text { years }\end{array}$ & 11. & 13 & 1.3 & 1.4 & 25 & 1.5 & 1.7 & 1.8 \\
\hline $\begin{array}{l}\text { Sardine switching limits: } \\
\text { Thres olds }\end{array}$ & 21 & 22 & 23 & 2.2 & 25 & 2.6 & 2.7 & 2.8 \\
\hline $\begin{array}{l}\text { Arichovy Daemor: } \\
\text { Cumulative vs } 3 \text { years }\end{array}$ & $\sqrt{1}$ & 3.2 & 3.3 & 3.4 & 3.5 & 3.6 & $3: 7$ & 3.8 \\
\hline $\begin{array}{l}\text { Anchovy switchir: limits: } \\
\text { Uppei toreshold }\end{array}$ & II & 4.2 & 4.3 & 4,4 & 4.5 & 4.6 & $4 i$ & 4.8 \\
\hline $\begin{array}{l}\text { Archovy 5witching limits: } \\
\text { Poor yeer :heshold }\end{array}$ & 81 & 5.2 & 2.9 & 5.4 & 55 & 5.6 & 5.7 & 5,8 \\
\hline $\begin{array}{l}\text { Sardine recovery rote } \\
\text { scale factor }\end{array}$ & 6.1 & 6.2 & E., 3 & 7.4 & 65 & 66 & 6.7 & 6.3 \\
\hline $\begin{array}{l}\text { Sardine schoo trap } \\
\text { faltor }\end{array}$ & 1 & $7: 2$ & 73 & 74 & 75 & 7.6 & 77 & 7.38 \\
\hline Variance of clima:e & 2,1 & 8.2 & 8.3 & 8.4 & B.S. & 15,6 & 8.1 & 8.13 \\
\hline \multicolumn{9}{|l|}{ Colour key: } \\
\hline Neshlscible et'cet & & & & Extremely & ensitive & & & \\
\hline
\end{tabular}

Tren fina indicator colour given io a ce was based on all the co"sibu:ing figures. For example, sor Ceii 1.1, : re culuur was based or the observed changrs in avrrage sardine population levei in the unfished and fished system at bo:h the "cumulalive sum" and the "set of 3 " se:t "gs. 


\section{Validation 1: AutoManage Sardine Thresholds}

Tests on the AutoManage function were only performed on the fished system. The standard configuration regards the sardine as safe for high exploitation at a population of 1.0, and moderate exploitation if the population is above 0.5 . The robot manager will stop fishing if the population is below 0.5 . Tests were performed with thresholds lowered to 0.8 and 0.4 , or raised to 1.2 and 0.6 .

\begin{tabular}{|l|l|rrr|r|}
\hline Test Settings & Metric & Test runs & & \multicolumn{1}{l|}{ avg } \\
\hline Thresholds 1.0/0.5 & Sard. Avg. Pop. & 1.063 & 1.0364 & 1.0335 & 1.0443 \\
Fished system & Anch. Avg. Pop & 1.2693 & 1.2715 & 1.2816 & 1.2741 \\
& Sardine catch & 0.3278 & 0.3341 & 0.3313 & 0.3311 \\
& Sardine Catch std. deviation & 0.1002 & 0.1001 & 0.1058 & 0.102 \\
& Anchovy catch & 0.4204 & 0.4236 & 0.4273 & 0.4238 \\
& Juvenile sardine bycatch & 0.0084 & 0.0112 & 0.01 & 0.0099 \\
& Both Hi frame duration (yrs) & 17.48 & 18.59 & 17.52 & 17.863 \\
& Both Hi frame residence (yrs) & 8.55 & 8.74 & 8.055 & 8.4483 \\
\hline Thresholds 0.8/0.4 & Sard. Avg. Pop. & 0.7908 & 0.9063 & 0.8485 & 0.8485 \\
Fished system & Anch. Avg. Pop & 1.2602 & 1.2574 & 1.2683 & 1.262 \\
& Sardine catch & 0.3111 & 0.3207 & 0.3102 & 0.314 \\
& Sardine Catch std. deviation & 0.1128 & 0.1017 & 0.1021 & 0.1055 \\
& Anchovy catch & 0.418 & 0.4168 & 0.4209 & 0.4186 \\
& Juvenile sardine bycatch & 0.0181 & 0.0151 & 0.0139 & 0.0157 \\
& Both Hi frame duration (yrs) & 11.6 & 13.35 & 13.46 & 12.803 \\
& Both Hi frame residence (yrs) & 6.385 & 6.665 & 6.825 & 6.625 \\
\hline Thresholds 1.2/0.6 & Sard. Avg. Pop. & 1.2149 & 1.2385 & 1.1823 & 1.2119 \\
& Anch. Avg. Pop & 1.2636 & 1.2575 & 1.265 & 1.262 \\
& Sardine catch & 0.3108 & 0.3082 & 0.3058 & 0.3083 \\
& Sardine Catch std. deviation & 0.0968 & 0.1018 & 0.1032 & 0.1006 \\
& Anchovy catch & 0.4181 & 0.418 & 0.4204 & 0.4188 \\
& Juvenile sardine bycatch & 0.0002 & 0.001 & 0.0018 & 0.001 \\
& Both Hi frame duration (yrs) & 20.93 & 20.98 & 20.62 & 20.843 \\
& Both Hi frame residence (yrs) & 9.655 & 9.645 & 9.505 & 9.6017 \\
\hline
\end{tabular}




\section{Validation 2: AutoManage TAC levels}

The standard configuration of the AutoManage function has a high sardine exploitation level of 0.4 , and uses a TAC of 0.2 for moderate exploitation. Tests were performed with TAC levels lowered to 0.2 and 0.1 , or raised to 0.5 and 0.3 .

\begin{tabular}{|l|l|rrr|r|}
\hline Test Settings & Metric & Test runs & \multicolumn{2}{l|}{ avg } \\
\hline TAC levels 0.4/0.2 & Sard. Avg. Pop. & 1.063 & 1.0364 & 1.0335 & 1.0443 \\
Fished system & Anch. Avg. Pop & 1.2699 & 1.2576 & 1.278 & 1.2685 \\
& Sardine catch & 0.3278 & 0.3341 & 0.3313 & 0.3311 \\
& Sardine Catch std. deviation & 0.1002 & 0.1001 & 0.1058 & 0.102 \\
& Anchovy catch & 0.422 & 0.4126 & 0.4173 & 0.4173 \\
& Juvenile sardine bycatch & 0.0084 & 0.0112 & 0.01 & 0.0099 \\
& Both Hi frame duration (yrs) & 17.48 & 18.59 & 17.52 & 17.863 \\
& Both Hi frame residence (yrs) & 8.55 & 8.74 & 8.055 & 8.4483 \\
\hline TAC levels 0.3/0.1 & Sard. Avg. Pop. & 1.3037 & 1.3264 & 1.333 & 1.321 \\
& Anch. Avg. Pop & 1.2638 & 1.2769 & 1.2802 & 1.2736 \\
& Sardine catch & 0.2644 & 0.2652 & 0.2656 & 0.2651 \\
& Sardine Catch std. deviation & 0.0416 & 0.0426 & 0.0405 & 0.0416 \\
& Anchovy catch & 0.4218 & 0.4182 & 0.4199 & 0.42 \\
& Juvenile sardine bycatch & 0.002 & 0.0012 & 0.0018 & 0.0017 \\
& Both Hi frame duration (yrs) & 20.35 & 20.97 & 20.68 & 20.667 \\
& Both Hi frame residence (yrs) & 9.47 & 9.69 & 9.46 & 9.54 \\
\hline TAC levels 0.5/0.3 & Sard. Avg. Pop. & 0.7794 & 0.7832 & 0.7218 & 0.7615 \\
& Anch. Avg. Pop & 1.2578 & 1.2621 & 1.2612 & 1.2604 \\
& Sardine catch & 0.3665 & 0.3642 & 0.3421 & 0.3576 \\
& Sardine Catch std. deviation & 0.1766 & 0.1832 & 0.1831 & 0.181 \\
& Anchovy catch & 0.4191 & 0.4184 & 0.4192 & 0.4189 \\
& Juvenile sardine bycatch & 0.023 & 0.0232 & 0.0207 & 0.0223 \\
& Both Hi frame duration (yrs) & 11.13 & 10.34 & 10.17 & 10.547 \\
& Both Hi frame residence (yrs) & 6.51 & 5.89 & 5.705 & 6.035 \\
\hline
\end{tabular}


Test 1: Sardine Daemon switching rules (cumulative sum vs set of three good years)

Cumulative sum:

- $\quad$ switch to low if total pop from last three years $<1.5$

- Switch to high if total pop from last three years $>3.0$

Set of 3:

- Switching to low if 3 consecutive yrs of pop $<0.5$

- Switching to high if 3 consecutive yrs of pop $>1.5$

\begin{tabular}{|c|c|c|c|c|c|}
\hline Test Settings & Metric & Test runs & & +2 & avg \\
\hline \multirow{4}{*}{$\begin{array}{l}\text { Cumulative sum: } \\
\text { Unfished system }\end{array}$} & Sard. Avg. Pop. & 2.0526 & 2.1055 & 2.2044 & 2.1208 \\
\hline & Anch. Avg. Pop & 1.2853 & 1.2697 & 1.2515 & 1.2688 \\
\hline & Both Hi frame duration (yrs) & 21.13 & 21.14 & 21.51 & 21.26 \\
\hline & Both Hi frame residence (yrs) & 9.74 & 9.725 & 9.91 & 9.7917 \\
\hline \multirow{4}{*}{$\begin{array}{l}\text { Set of } 3: \\
\text { Unfished system }\end{array}$} & Sard. Avg. Pop. & 2.1512 & 2.1585 & 2.1678 & 2.1592 \\
\hline & Anch. Avg. Pop & 1.2533 & 1.2569 & 1.2517 & 1.254 \\
\hline & Both Hi frame duration (yrs) & 21.06 & 21.12 & 20.99 & 21.057 \\
\hline & Both Hi frame residence (yrs) & 9.725 & 9.685 & 9.655 & 9.6883 \\
\hline \multirow{8}{*}{$\begin{array}{l}\text { Cumulative sum: } \\
\text { Fished system }\end{array}$} & Sard. Avg. Pop. & 1.0489 & 1.0983 & 1.0578 & 1.0683 \\
\hline & Anch. Avg. Pop & 1.2837 & 1.2653 & 1.2705 & 1.2732 \\
\hline & Sardine catch & 0.3388 & 0.3371 & 0.3372 & 0.3377 \\
\hline & Sardine Catch std. deviation & 0.0988 & 0.0937 & 0.0963 & 0.0963 \\
\hline & Anchovy catch & 0.4279 & 0.4219 & 0.4227 & 0.4242 \\
\hline & Juvenile sardine bycatch & 0.0124 & 0.0080 & 0.0109 & 0.0104 \\
\hline & Both Hi frame duration (yrs) & 16.65 & 16.84 & 18.08 & 17.19 \\
\hline & Both Hi frame residence (yrs) & 8.305 & 8.16 & 8.67 & 8.3783 \\
\hline \multirow{8}{*}{$\begin{array}{l}\text { Set of } 3 \text { : } \\
\text { Fished system }\end{array}$} & Sard. Avg. Pop. & 1.0565 & 1.0716 & 1.0378 & 1.0553 \\
\hline & Anch. Avg. Pop & 1.2547 & 1.2633 & 1.2729 & 1.2636 \\
\hline & Sardine catch & 0.3337 & 0.3351 & 0.3214 & 0.3301 \\
\hline & Sardine Catch std. deviation & 0.0906 & 0.0907 & 0.0986 & 0.0933 \\
\hline & Anchovy catch & 0.4169 & 0.4183 & 0.424 & 0.4197 \\
\hline & Juvenile sardine bycatch & 0.0033 & 0.0035 & 0.0018 & 0.0029 \\
\hline & Both Hi frame duration (yrs) & 20.09 & 19.82 & 19.91 & 19.94 \\
\hline & Both Hi frame residence (yrs) & 9.475 & 9.31 & 9.455 & 9.4133 \\
\hline
\end{tabular}


Test 2: Sardine Daemon switching thresholds: threshold sensitivity

- Switching to low if total pop $<1.5$ from last three years

- Switching to high if total pop $>3.0$ from last three years

For the "lowered" and "raised" settings, both thresholds are lowered or raised by 0.3.

\begin{tabular}{|c|c|c|c|c|c|}
\hline Test Settings & Metric & \multicolumn{3}{|c|}{ Test runs } & avg \\
\hline \multirow{4}{*}{$\begin{array}{l}p<1.5, p>3.0 \\
\text { Unfished system }\end{array}$} & Sard. Avg. Pop. & 2.1479 & 2.1035 & 2.2186 & 2.1567 \\
\hline & Anch. Avg. Pop & 1.259 & 1.267 & 1.3462 & 1.2907 \\
\hline & Both Hi frame duration (yrs) & 21.19 & 21.08 & 21.27 & 21.18 \\
\hline & Both Hi frame residence (yrs) & 9.7 & 9.745 & 9.81 & 9.7517 \\
\hline \multirow{4}{*}{$\begin{array}{l}p<1.2, p>2.7 \\
\text { Unfished system }\end{array}$} & Sard. Avg. Pop. & 2.1758 & 2.1263 & 2.0954 & 2.1325 \\
\hline & Anch. Avg. Pop & 1.264 & 1.2596 & 1.2775 & 1.267 \\
\hline & Both Hi frame duration (yrs) & 21.13 & 21.51 & 21.16 & 21.267 \\
\hline & Both Hi frame residence (yrs) & 9.745 & 9.915 & 9.725 & 9.795 \\
\hline \multirow{4}{*}{$\begin{array}{l}p<1.8, p>3.3 \\
\text { Unfished system }\end{array}$} & Sard. Avg. Pop. & 2.1342 & 2.1161 & 2.1202 & 2.1235 \\
\hline & Anch. Avg. Pop & 1.2586 & 1.2486 & 1.2647 & 1.2573 \\
\hline & Both Hi frame duration (yrs) & 21.02 & 21.1 & 20.88 & 21.00 \\
\hline & Both Hi frame residence (yrs) & 9.68 & 9.77 & 9.595 & 9.6817 \\
\hline \multirow{8}{*}{$\begin{array}{l}p<1.5, p>3.0 \\
\text { Fished system }\end{array}$} & Sard. Avg. Pop. & 1.063 & 1.0364 & 1.0335 & 1.0443 \\
\hline & Anch. Avg. Pop & 1.276 & 1.2646 & 1.2452 & 1.2619 \\
\hline & Sardine catch & 0.3278 & 0.3341 & 0.3313 & 0.3311 \\
\hline & Sardine Catch std. deviation & 0.1002 & 0.1001 & 0.1058 & 0.102 \\
\hline & Anchovy catch & 0.4254 & 0.4212 & 0.4126 & 0.4197 \\
\hline & Juvenile sardine bycatch & 0.0084 & 0.0112 & 0.01 & 0.0099 \\
\hline & Both Hi frame duration (yrs) & 17.48 & 18.59 & 17.52 & 17.863 \\
\hline & Both Hi frame residence (yrs) & 8.55 & 8.74 & 8.055 & 8.4483 \\
\hline \multirow{8}{*}{$\begin{array}{l}p<1.2, p>2.7 \\
\text { Fished system }\end{array}$} & Sard. Avg. Pop. & 1.0662 & 1.0472 & 1.0347 & 1.0494 \\
\hline & Anch. Avg. Pop & 1.2831 & 1.2577 & 1.2698 & 1.2702 \\
\hline & Sardine catch & 0.3335 & 0.3295 & 0.3303 & 0.3311 \\
\hline & Sardine Catch std. deviation & 0.0932 & 0.0974 & 0.0971 & 0.0959 \\
\hline & Anchovy catch & 0.4281 & 0.4173 & 0.4232 & 0.4229 \\
\hline & Juvenile sardine bycatch & 0.0058 & 0.0048 & 0.0056 & 0.0054 \\
\hline & Both Hi frame duration (yrs) & 18.34 & 19.05 & 19.23 & 18.873 \\
\hline & Both Hi frame residence (yrs) & 7.91 & 8.483 & 8.305 & 8.2327 \\
\hline \multirow{8}{*}{$\begin{array}{l}p<1.8, p>3.3 \\
\text { Fished system }\end{array}$} & Sard. Avg. Pop. & 1.0881 & 1.0423 & 1.0774 & 1.0693 \\
\hline & Anch. Avg. Pop & 1.2611 & 1.2634 & 1.2863 & 1.2703 \\
\hline & Sardine catch & 0.3391 & 0.3349 & 0.3347 & 0.3362 \\
\hline & Sardine Catch std. deviation & 0.0928 & 0.0971 & 0.0972 & 0.0957 \\
\hline & Anchovy catch & 0.4186 & 0.4202 & 0.4296 & 0.4228 \\
\hline & Juvenile sardine bycatch & 0.0085 & 0.0102 & 0.0096 & 0.0095 \\
\hline & Both $\mathrm{Hi}$ frame duration (yrs) & 17.06 & 18.81 & 16.99 & 17.62 \\
\hline & Both $\mathrm{Hi}$ frame residence (yrs) & 8.335 & 8.86 & 8.61 & 8.6017 \\
\hline
\end{tabular}


Test 3: Anchovy Daemon switching rules: Cumulative ESI vs three good years

Cumulative:

- Switch to high if running ESI total $>15$

- Switch to low if $\mathrm{ESI}<4$

Set of 3:

- Switch to high three consecutive years with ESI > 5

- Switch to low if three consecutive years with $\mathrm{ESI}<4$

\begin{tabular}{|c|c|c|c|c|c|}
\hline Test Settings & Metric & Test runs & +8 & & avg \\
\hline \multirow{4}{*}{$\begin{array}{l}\text { Cumulative sum: } \\
\text { Unfished system }\end{array}$} & Sard. Avg. Pop. & 2.1017 & 2.1735 & 2.1257 & 2.1336 \\
\hline & Anch. Avg. Pop & 1.2827 & 1.2635 & 1.2774 & 1.2731 \\
\hline & Both Hi frame duration (yrs) & 21.3 & 21.06 & 21.36 & 21.24 \\
\hline & Both Hi frame residence (yrs) & 9.79 & 9.715 & 9.835 & 9.78 \\
\hline \multirow{4}{*}{$\begin{array}{l}\text { Set of 3: } \\
\text { Unfished system }\end{array}$} & Sard. Avg. Pop. & 2.1179 & 2.1507 & 2.1061 & 2.1249 \\
\hline & Anch. Avg. Pop & 1.2668 & 1.2901 & 1.2768 & 1.2779 \\
\hline & Both Hi frame duration (yrs) & 24.98 & 25.29 & 25.3 & 25.19 \\
\hline & Both Hi frame residence (yrs) & 7.96 & 8.073 & 8.07 & 8.0343 \\
\hline \multirow{8}{*}{$\begin{array}{l}\text { Cumulative sum: } \\
\text { Fished system }\end{array}$} & Sard. Avg. Pop. & 1.1011 & 1.011 & 1.0089 & 1.0403 \\
\hline & Anch. Avg. Pop & 1.272 & 1.2749 & 1.2507 & 1.2659 \\
\hline & Sardine catch & 0.3399 & 0.3273 & 0.3298 & 0.3323 \\
\hline & Sardine Catch std. deviation & 0.0928 & 0.1067 & 0.1061 & 0.1019 \\
\hline & Anchovy catch & 0.4227 & 0.425 & 0.4131 & 0.4203 \\
\hline & Juvenile sardine bycatch & 0.0097 & 0.011 & 0.0101 & 0.0103 \\
\hline & Both Hi frame duration (yrs) & 17.51 & 16.6 & 16.73 & 16.947 \\
\hline & Both Hi frame residence (yrs) & 8.43 & 8.215 & 8.36 & 8.335 \\
\hline \multirow{8}{*}{$\begin{array}{l}\text { Set of } 3 \text { : } \\
\text { Fished system }\end{array}$} & Sard. Avg. Pop. & 1.0249 & 1.0489 & 1.0363 & 1.0367 \\
\hline & Anch. Avg. Pop & 1.2491 & 1.2816 & 1.264 & 1.2649 \\
\hline & Sardine catch & 0.3312 & 0.3319 & 0.3322 & 0.3318 \\
\hline & Sardine Catch std. deviation & 0.1042 & 0.1042 & 0.1049 & 0.1044 \\
\hline & Anchovy catch & 0.4196 & 0.4305 & 0.4244 & 0.4248 \\
\hline & Juvenile sardine bycatch & 0.0111 & 0.0096 & 0.0117 & 0.0108 \\
\hline & Both Hi frame duration (yrs) & 20.58 & 21.1 & 19.76 & 20.48 \\
\hline & Both $\mathrm{Hi}$ frame residence (yrs) & 6.693 & 6.995 & 6.59 & 6.7593 \\
\hline
\end{tabular}


Test 4: Anchovy switching limits: Upper threshold sensitivity

Anchovy switch to high if running total ESI $>15$. Sensitivity tests done at $+/-3$.

\begin{tabular}{|c|c|c|c|c|c|}
\hline Test Settings & Metric & Test runs & & & avg \\
\hline \multirow{4}{*}{$\begin{array}{l}\text { ESI > } 15 \\
\text { Unfished system }\end{array}$} & Sard. Avg. Pop. & 2.167 & 2.126 & 2.1565 & 2.1498 \\
\hline & Anch. Avg. Pop & 1.2784 & 1.2577 & 1.2614 & 1.2658 \\
\hline & Both Hi frame duration (yrs) & 21.06 & 21.36 & 21.42 & 21.28 \\
\hline & Both Hi frame residence (yrs) & 9.71 & 9.825 & 9.885 & 9.8067 \\
\hline \multirow{4}{*}{$\begin{array}{l}\text { ESI }>12 \\
\text { Unfished system }\end{array}$} & Sard. Avg. Pop. & 2.1363 & 2.1223 & 2.1789 & 2.1458 \\
\hline & Anch. Avg. Pop & 1.3075 & 1.3002 & 1.2944 & 1.3007 \\
\hline & Both Hi frame duration (yrs) & 22.11 & 22.14 & 22.05 & 22.1 \\
\hline & Both Hi frame residence (yrs) & 10.055 & 10.07 & 10.025 & 10.05 \\
\hline \multirow{4}{*}{$\begin{array}{l}\text { ESI > } 18 \\
\text { Unfished system }\end{array}$} & Sard. Avg. Pop. & 2.0849 & 2.1283 & 2.1649 & 2.126 \\
\hline & Anch. Avg. Pop & 1.2016 & 1.2005 & 1.2073 & 1.2031 \\
\hline & Both Hi frame duration (yrs) & 19.14 & 19.25 & 19.14 & 19.177 \\
\hline & Both Hi frame residence (yrs) & 9.07 & 9.125 & 9.07 & 9.0883 \\
\hline \multirow{8}{*}{$\begin{array}{l}\text { ESI > } 15 \\
\text { Fished system }\end{array}$} & Sard. Avg. Pop. & 1.0412 & 1.0655 & 0.9843 & 1.0303 \\
\hline & Anch. Avg. Pop & 1.27 & 1.2742 & 1.2798 & 1.2747 \\
\hline & Sardine catch & 0.3383 & 0.34 & 0.3312 & 0.3365 \\
\hline & Sardine Catch std. deviation & 0.1007 & 0.0917 & 0.1028 & 0.0984 \\
\hline & Anchovy catch & 0.4226 & 0.4239 & 0.4269 & 0.4245 \\
\hline & Juvenile sardine bycatch & 0.0117 & 0.0081 & 0.0108 & 0.0102 \\
\hline & Both Hi frame duration (yrs) & 17.03 & 18.35 & 18.02 & 17.8 \\
\hline & Both Hi frame residence (yrs) & 8.35 & 8.795 & 8.255 & 8.4667 \\
\hline \multirow{8}{*}{$\begin{array}{l}\text { ESI > } 12 \\
\text { Fished system }\end{array}$} & Sard. Avg. Pop. & 1.0198 & 1.0301 & 1.0392 & 1.0297 \\
\hline & Anch. Avg. Pop & 1.3008 & 1.2927 & 1.2877 & 1.2937 \\
\hline & Sardine catch & 0.33 & 0.3353 & 0.3328 & 0.3327 \\
\hline & Sardine Catch std. deviation & 0.105 & 0.1055 & 0.1003 & 0.1036 \\
\hline & Anchovy catch & 0.438 & 0.4345 & 0.4321 & 0.4349 \\
\hline & Juvenile sardine bycatch & 0.01 & 0.0119 & 0.011 & 0.011 \\
\hline & Both Hi frame duration (yrs) & 18.31 & 17.88 & 17.66 & 17.95 \\
\hline & Both Hi frame residence (yrs) & 9.09 & 8.44 & 8.465 & 8.665 \\
\hline \multirow{8}{*}{$\begin{array}{l}\text { ESI }>18 \\
\text { Fished system }\end{array}$} & Sard. Avg. Pop. & 1.0783 & 1.09 & 1.0553 & 1.0745 \\
\hline & Anch. Avg. Pop & 1.1894 & 1.2017 & 1.1904 & 1.1938 \\
\hline & Sardine catch & 0.338 & 0.3391 & 0.3322 & 0.3364 \\
\hline & Sardine Catch std. deviation & 0.0911 & 0.0938 & 0.1008 & 0.0952 \\
\hline & Anchovy catch & 0.3853 & 0.3905 & 0.3849 & 0.3869 \\
\hline & Juvenile sardine bycatch & 0.0072 & 0.0078 & 0.0083 & 0.0078 \\
\hline & Both Hi frame duration (yrs) & 16.51 & 16.54 & 15.81 & 16.287 \\
\hline & Both Hi frame residence (yrs) & 7.975 & 8.185 & 7.915 & 8.025 \\
\hline
\end{tabular}


Test 4: Anchovy switching limits: poor year threshold sensitivity

Anchovy switch to low and reset running ESI total if yearly ESI $<4$. Tests done at $+/-1$ of normal.

\begin{tabular}{|c|c|c|c|c|c|}
\hline Test Settings & Metric & Test runs & & & avg \\
\hline \multirow{4}{*}{$\begin{array}{l}\text { ESI }<4 \\
\text { Unfished system }\end{array}$} & Sard. Avg. Pop. & 2.1654 & 2.1338 & 2.1112 & 2.1368 \\
\hline & Anch. Avg. Pop & 1.2544 & 1.2651 & 1.2601 & 1.2599 \\
\hline & Both Hi frame duration (yrs) & 21.07 & 21.01 & 21.17 & 21.083 \\
\hline & Both Hi frame residence (yrs) & 9.7 & 9.72 & 9.74 & 9.72 \\
\hline \multirow{4}{*}{$\begin{array}{l}\text { ESI }<3 \\
\text { Unfished system }\end{array}$} & Sard. Avg. Pop. & 2.1486 & 2.1472 & 2.1564 & 2.1507 \\
\hline & Anch. Avg. Pop & 1.392 & 1.3925 & 1.3831 & 1.3892 \\
\hline & Both $\mathrm{Hi}$ frame duration (yrs) & 24.62 & 24.75 & 24.87 & 24.747 \\
\hline & Both Hi frame residence (yrs) & 11.485 & 11.525 & 11.535 & 11.515 \\
\hline \multirow{4}{*}{$\begin{array}{l}\text { ESI }<5 \\
\text { Unfished system }\end{array}$} & Sard. Avg. Pop. & 2.1352 & 2.1236 & 2.1284 & 2.1291 \\
\hline & Anch. Avg. Pop & 1.1278 & 1.1404 & 1.1284 & 1.1322 \\
\hline & Both Hi frame duration (yrs) & 17.75 & 17.52 & 17.41 & 17.56 \\
\hline & Both Hi frame residence (yrs) & 8.085 & 7.99 & 7.97 & 8.015 \\
\hline \multirow{8}{*}{$\begin{array}{l}\text { ESI }<4 \\
\text { Fished system }\end{array}$} & Sard. Avg. Pop. & 1.0582 & 1.0917 & 1.0211 & 1.057 \\
\hline & Anch. Avg. Pop & 1.2636 & 1.2613 & 1.2543 & 1.2597 \\
\hline & Sardine catch & 0.3402 & 0.3397 & 0.3319 & 0.3373 \\
\hline & Sardine Catch std. deviation & 0.0992 & 0.0941 & 0.1026 & 0.0986 \\
\hline & Anchovy catch & 0.4197 & 0.4184 & 0.4154 & 0.4178 \\
\hline & Juvenile sardine bycatch & 0.0121 & 0.0092 & 0.0101 & 0.0105 \\
\hline & Both Hi frame duration (yrs) & 16.69 & 17.5 & 17.09 & 17.093 \\
\hline & Both Hi frame residence (yrs) & 7.95 & 8.34 & 8.282 & 8.1907 \\
\hline \multirow{8}{*}{$\begin{array}{l}\text { ESI }<3 \\
\text { Fished system }\end{array}$} & Sard. Avg. Pop. & 1.0614 & 0.9962 & 1.0433 & 1.0336 \\
\hline & Anch. Avg. Pop & 1.4023 & 1.3886 & 1.3934 & 1.3948 \\
\hline & Sardine catch & 0.3358 & 0.3294 & 0.3319 & 0.3324 \\
\hline & Sardine Catch std. deviation & 0.0976 & 0.1056 & 0.1024 & 0.1019 \\
\hline & Anchovy catch & 0.4843 & 0.4785 & 0.4811 & 0.4813 \\
\hline & Juvenile sardine bycatch & 0.01 & 0.0126 & 0.0102 & 0.0109 \\
\hline & Both Hi frame duration (yrs) & 20.77 & 18.9 & 20.29 & 19.987 \\
\hline & Both Hi frame residence (yrs) & 9.717 & 9.205 & 9.522 & 9.4813 \\
\hline \multirow{8}{*}{$\begin{array}{l}\text { ESI }<5 \\
\text { Fished system }\end{array}$} & Sard. Avg. Pop. & 1.0665 & 1.0183 & 1.0327 & 1.0392 \\
\hline & Anch. Avg. Pop & 1.153 & 1.1424 & 1.1452 & 1.1469 \\
\hline & Sardine catch & 0.3356 & 0.3254 & 0.3319 & 0.331 \\
\hline & Sardine Catch std. deviation & 0.1008 & 0.1014 & 0.0978 & 0.1 \\
\hline & Anchovy catch & 0.3667 & 0.1014 & 0.3641 & 0.2774 \\
\hline & Juvenile sardine bycatch & 0.0085 & 0.0083 & 0.0077 & 0.0082 \\
\hline & Both Hi frame duration (yrs) & 14.89 & 14.23 & 14.96 & 14.693 \\
\hline & Both Hi frame residence (yrs) & 7.46 & 6.9 & 6.975 & 7.1117 \\
\hline
\end{tabular}


Test 6: Sardine recovery rate: scale factor

In the high sardine frames, the density dependent increase in recovery rate is based on how low the population is from a capacity figure, scaled by a factor of 0.1 . Tests were done with $f_{D D}$ at $+/-0.1$ of the normal figure.

\begin{tabular}{|c|c|c|c|c|c|}
\hline Test Settings & Metric & Test runs & & & avg \\
\hline \multirow{4}{*}{$\begin{array}{l}f_{D D}=0.1 \\
\text { Unfished system }\end{array}$} & Sard. Avg. Pop. & 2.2602 & 2.2484 & 2.2475 & 2.252 \\
\hline & Anch. Avg. Pop & 1.2805 & 1.2528 & 1.2619 & 1.2651 \\
\hline & Both Hi frame duration (yrs) & 21.31 & 21.01 & 21.07 & 21.13 \\
\hline & Both Hi frame residence (yrs) & 9.77 & 9.62 & 9.675 & 9.6883 \\
\hline \multirow{4}{*}{$\begin{array}{l}f_{D D}=0 \\
\text { Unfished system }\end{array}$} & Sard. Avg. Pop. & 2.1421 & 2.1326 & 2.1396 & 2.1381 \\
\hline & Anch. Avg. Pop & 1.2529 & 1.2595 & 1.256 & 1.2561 \\
\hline & Both Hi frame duration (yrs) & 21.05 & 21.12 & 21.3 & 21.157 \\
\hline & Both Hi frame residence (yrs) & 9.755 & 9.765 & 9.76 & 9.76 \\
\hline \multirow{4}{*}{$\begin{array}{l}f_{D D}=0.2 \\
\text { Unfished system }\end{array}$} & Sard. Avg. Pop. & 2.3663 & 2.3582 & 2.3771 & 2.3672 \\
\hline & Anch. Avg. Pop & 1.2904 & 1.2693 & 1.2788 & 1.2795 \\
\hline & Both Hi frame duration (yrs) & 21.6 & 21.17 & 21.5 & 21.423 \\
\hline & Both Hi frame residence ( $\mathrm{vrs}$ ) & 9.96 & 9.75 & 9.89 & 9.8667 \\
\hline \multirow{8}{*}{$\begin{array}{l}f_{D D}=0.1 \\
\text { Fished system }\end{array}$} & Sard. Avg. Pop. & 1.4265 & 1.4446 & 1.4607 & 1.4439 \\
\hline & Anch. Avg. Pop & 1.2736 & 1.2728 & 1.2769 & 1.2744 \\
\hline & Sardine catch & 0.3336 & 0.3316 & 0.3353 & 0.3335 \\
\hline & Sardine Catch std. deviation & 0.081 & 0.0808 & 0.0754 & 0.0791 \\
\hline & Anchovy catch & 0.4235 & 0.4235 & 0.4256 & 0.4242 \\
\hline & Juvenile sardine bycatch & 0.0003 & 0.0007 & 0 & 0.0003 \\
\hline & Both Hi frame duration (yrs) & 21.12 & 21.36 & 20.96 & 21.147 \\
\hline & Both Hi frame residence (yrs) & 9.735 & 9.835 & 9.665 & 9.745 \\
\hline \multirow{8}{*}{$\begin{array}{l}f_{D D}=0 \\
\text { Fished system }\end{array}$} & Sard. Avg. Pop. & 1.186 & 1.185 & 1.1955 & 1.1888 \\
\hline & Anch. Avg. Pop & 1.2562 & 1.2695 & 1.276 & 1.2672 \\
\hline & Sardine catch & 0.305 & 0.3026 & 0.3092 & 0.3056 \\
\hline & Sardine Catch std. deviation & 0.1012 & 0.1052 & 0.1021 & 0.1028 \\
\hline & Anchovy catch & 0.4173 & 0.4234 & 0.4255 & 0.4221 \\
\hline & Juvenile sardine bycatch & 0.0015 & 0.0017 & 0.0011 & 0.0014 \\
\hline & Both Hi frame duration (yrs) & 20.7 & 20.68 & 20.93 & 20.77 \\
\hline & Both Hi frame residence (yrs) & 9.64 & 9.63 & 9.595 & 9.6217 \\
\hline \multirow{8}{*}{$\begin{array}{l}f_{D D}=0.2 \\
\text { Fished system }\end{array}$} & Sard. Avg. Pop. & 1.6427 & 1.6633 & 1.6621 & 1.656 \\
\hline & Anch. Avg. Pop & 1.2538 & 1.2651 & 1.2838 & 1.2676 \\
\hline & Sardine catch & 0.3479 & 0.3482 & 0.3468 & 0.3476 \\
\hline & Sardine Catch std. deviation & 0.0611 & 0.0619 & 0.0635 & 0.0622 \\
\hline & Anchovy catch & 0.4158 & 0.4204 & 0.4282 & 0.4215 \\
\hline & Juvenile sardine bycatch & 0.0002 & 0.0004 & 0 & 0.0002 \\
\hline & Both Hi frame duration (yrs) & 21.05 & 21.16 & 21.6 & 21.27 \\
\hline & Both Hi frame residence (yrs) & 9.66 & 9.765 & 9.91 & 9.7783 \\
\hline
\end{tabular}




\section{Test 7: School trap factor}

The school trap is only effective in the fished system, as the unfished system never goes into a sardine "low" frame. Normal $\mathrm{f}_{\mathrm{st}}$ value is 0.2 / 0.4 in frames Both Low / Anchovy High. Tests were done at $0.1 / 0.3$ and $0.3 / 0.5$.

\begin{tabular}{|c|c|c|c|c|c|}
\hline Test Settings & Metric & Test runs & & & avg \\
\hline \multirow{8}{*}{$\begin{array}{l}f_{s t}=0.2 / 0.4 \\
\text { Fished system }\end{array}$} & Sard. Avg. Pop. & 1.118 & 1.0968 & 1.117 & 1.1106 \\
\hline & Anch. Avg. Pop & 1.2625 & 1.2561 & 1.2698 & 1.2628 \\
\hline & Sardine catch & 0.3 & 0.2946 & 0.2978 & 0.2975 \\
\hline & Sardine Catch std. deviation & 0.106 & 0.1097 & 0.1075 & 0.1077 \\
\hline & Anchovy catch & 0.4198 & 0.4174 & 0.4217 & 0.4196 \\
\hline & Juvenile sardine bycatch & 0.0029 & 0.0048 & 0.0019 & 0.0032 \\
\hline & Both Hi frame duration (yrs) & 19.86 & 19.12 & 20.36 & 19.78 \\
\hline & Both Hi frame residence (yrs) & 9.365 & 9.215 & 9.46 & 9.3467 \\
\hline \multirow{8}{*}{$\begin{array}{l}f_{s t}=0.1 / 0.3 \\
\text { Fished system }\end{array}$} & Sard. Avg. Pop. & 1.0999 & 1.1461 & 1.1023 & 1.1161 \\
\hline & Anch. Avg. Pop & 1.2756 & 1.2631 & 1.2652 & 1.268 \\
\hline & Sardine catch & 0.2971 & 0.3027 & 0.2967 & 0.2988 \\
\hline & Sardine Catch std. deviation & 0.1069 & 0.1018 & 0.107 & 0.1052 \\
\hline & Anchovy catch & 0.4253 & 0.4197 & 0.4201 & 0.4217 \\
\hline & Juvenile sardine bycatch & 0.0018 & 0.0007 & 0.0017 & 0.0014 \\
\hline & Both Hi frame duration (yrs) & 20.17 & 20.76 & 20.1 & 20.343 \\
\hline & Both Hi frame residence (yrs) & 9.515 & 9.695 & 9.45 & 9.5533 \\
\hline \multirow{8}{*}{$\begin{array}{l}f_{s t}=0.3 / 0.5 \\
\text { Fished system }\end{array}$} & Sard. Avg. Pop. & 1.1159 & 1.1389 & 1.1195 & 1.1248 \\
\hline & Anch. Avg. Pop & 1.2582 & 1.2598 & 1.2531 & 1.257 \\
\hline & Sardine catch & 0.2975 & 0.3005 & 0.3003 & 0.2994 \\
\hline & Sardine Catch std. deviation & 0.1076 & 0.1062 & 0.1045 & 0.1061 \\
\hline & Anchovy catch & 0.4168 & 0.4188 & 0.416 & 0.4172 \\
\hline & Juvenile sardine bycatch & 0.002 & 0.0019 & 0.0016 & 0.0018 \\
\hline & Both Hi frame duration (yrs) & 20.3 & 20.78 & 20.83 & 20.637 \\
\hline & Both $\mathrm{Hi}$ frame residence (yrs) & 9.435 & 9.655 & 9.63 & 9.5733 \\
\hline
\end{tabular}




\section{Test 8: Climate variability}

Base variability of the ESI is $+/-1$ about the underlying climate function. Tests were done at $+/-0$ (i.e., the ESI follows the underlying function exactly), and $+/-2$.

\begin{tabular}{|c|c|c|c|c|c|}
\hline Test Settings & Metric & Test runs & & & avg \\
\hline \multirow{4}{*}{$\begin{array}{l}\text { ESI = function +/-1 } \\
\text { Unfished system }\end{array}$} & Sard. Avg. Pop. & 2.261 & 2.2512 & 2.2879 & 2.2667 \\
\hline & Anch. Avg. Pop & 1.2699 & 1.2576 & 1.278 & 1.2685 \\
\hline & Both Hi frame duration (yrs) & 21.27 & 21.24 & 21.09 & 21.2 \\
\hline & Both Hi frame residence (yrs) & 9.785 & 9.81 & 9.685 & 9.76 \\
\hline \multirow{4}{*}{$\begin{array}{l}\text { ESI = function } \\
\text { Unfished system }\end{array}$} & Sard. Avg. Pop. & 2.2796 & 2.2487 & 2.2513 & 2.2599 \\
\hline & Anch. Avg. Pop & 1.2679 & 1.2741 & 1.2813 & 1.2744 \\
\hline & Both Hi frame duration (yrs) & 21.22 & 21.31 & 21.42 & 21.317 \\
\hline & Both Hi frame residence (yrs) & 9.835 & 9.73 & 9.845 & 9.8033 \\
\hline \multirow{4}{*}{$\begin{array}{l}\text { ESI = function }+/-2 \\
\text { Unfished system }\end{array}$} & Sard. Avg. Pop. & 2.2657 & 2.2784 & 2.2972 & 2.2804 \\
\hline & Anch. Avg. Pop & 1.2656 & 1.2432 & 1.2367 & 1.2485 \\
\hline & Both Hi frame duration (yrs) & 21.09 & 20.53 & 20.92 & 20.847 \\
\hline & Both Hi frame residence (yrs) & 9.685 & 9.435 & 9.63 & 9.5833 \\
\hline \multirow{8}{*}{$\begin{array}{l}\mathrm{ESI}=\text { function }+/-1 \\
\text { Fished system }\end{array}$} & Sard. Avg. Pop. & 1.4512 & 1.4886 & 1.4793 & 1.473 \\
\hline & Anch. Avg. Pop & 1.2693 & 1.2715 & 1.2816 & 1.2741 \\
\hline & Sardine catch & 0.3335 & 0.3367 & 0.337 & 0.3357 \\
\hline & Sardine Catch std. deviation & 0.082 & 0.0758 & 0.0762 & 0.078 \\
\hline & Anchovy catch & 0.4204 & 0.4236 & 0.4273 & 0.4238 \\
\hline & Juvenile sardine bycatch & 0.0002 & 0 & 0.0001 & 0.0001 \\
\hline & Both Hi frame duration (yrs) & 20.76 & 21.44 & 21.31 & 21.17 \\
\hline & Both Hi frame residence (yrs) & 9.54 & 9.86 & 9.845 & 9.7483 \\
\hline \multirow{8}{*}{$\begin{array}{l}\text { ESI = function } \\
\text { Fished system }\end{array}$} & Sard. Avg. Pop. & 1.4491 & 1.4416 & 1.4587 & 1.4498 \\
\hline & Anch. Avg. Pop & 1.2834 & 1.2793 & 1.2662 & 1.2763 \\
\hline & Sardine catch & 0.3355 & 0.3306 & 0.3363 & 0.3341 \\
\hline & Sardine Catch std. deviation & 0.0798 & 0.0815 & 0.0787 & 0.08 \\
\hline & Anchovy catch & 0.4286 & 0.4256 & 0.4209 & 0.425 \\
\hline & Juvenile sardine bycatch & 0.0004 & 0.0001 & 0.0004 & 0.0003 \\
\hline & Both Hi frame duration (yrs) & 21.43 & 21.29 & 21.19 & 21.303 \\
\hline & Both Hi frame residence ( $\mathrm{yrs}$ ) & 9.805 & 9.785 & 9.71 & 9.7667 \\
\hline \multirow{8}{*}{$\begin{array}{l}E S I=\text { function }+/-2 \\
\text { Fished system }\end{array}$} & Sard. Avg. Pop. & 1.4284 & 1.4855 & 1.4462 & 1.4534 \\
\hline & Anch. Avg. Pop & 1.2396 & 1.2525 & 1.2584 & 1.2502 \\
\hline & Sardine catch & 0.3316 & 0.3376 & 0.3353 & 0.3348 \\
\hline & Sardine Catch std. deviation & 0.0846 & 0.0748 & 0.0767 & 0.0787 \\
\hline & Anchovy catch & 0.4087 & 0.4133 & 0.4173 & 0.4131 \\
\hline & Juvenile sardine bycatch & 0.0002 & 0.0002 & 0.0001 & 0.0002 \\
\hline & Both Hi frame duration (yrs) & 20.6 & 20.58 & 20.79 & 20.657 \\
\hline & Both Hi frame residence (yrs) & 9.495 & 9.48 & 9.575 & 9.5167 \\
\hline
\end{tabular}


AutoManage Seyerity Test Data: Catch vs Crashes (section 4,2.2)

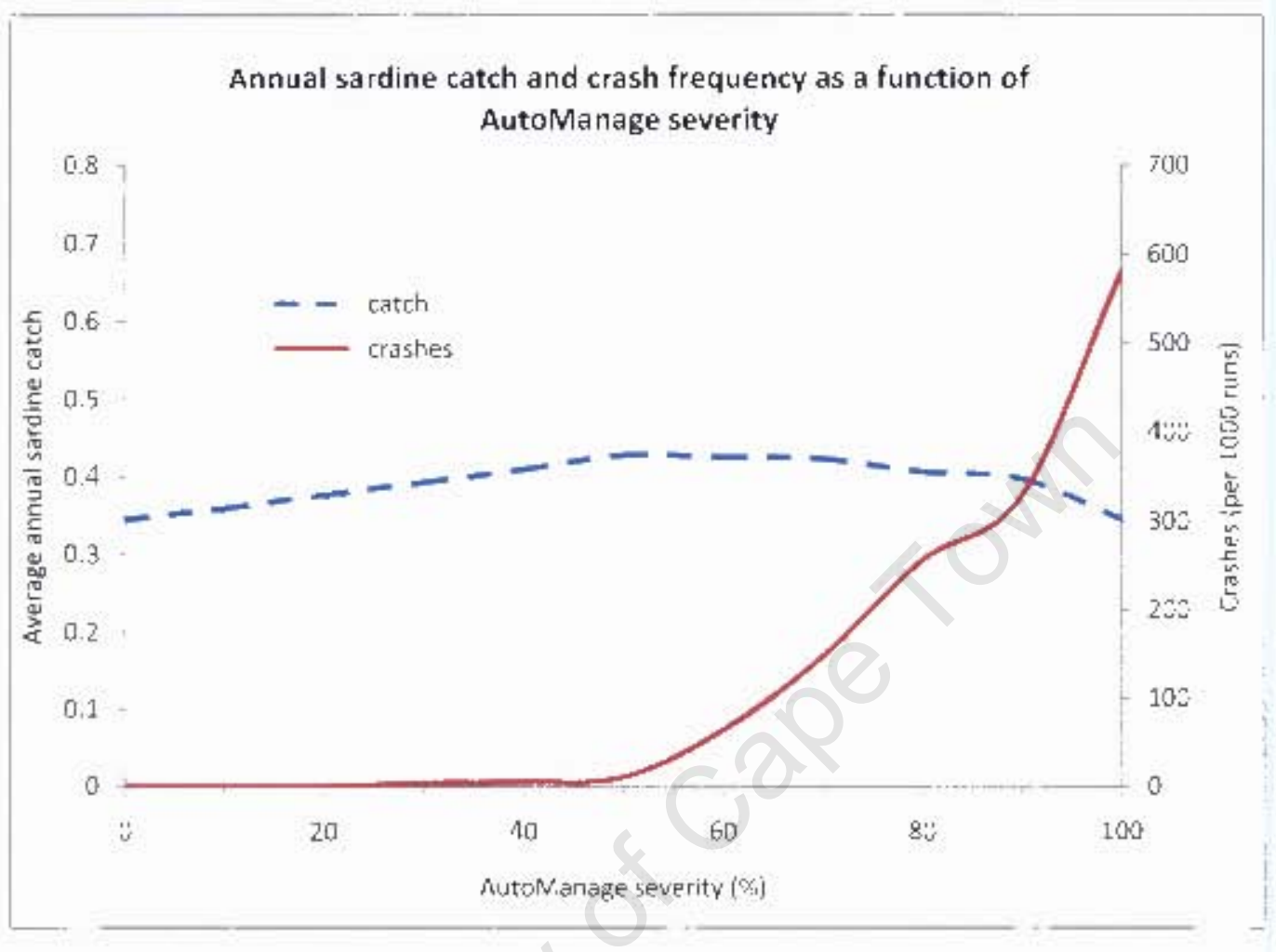

\begin{tabular}{|c|c|c|c|c|c|c|c|c|}
\hline \multirow[t]{2}{*}{ Severity (\%) } & \multicolumn{2}{|l|}{ Test 1} & \multicolumn{2}{|l|}{ Test $\mathbf{Z}$} & \multicolumn{2}{|l|}{ Test 3} & \multicolumn{2}{|c|}{ Aweraged results } \\
\hline & catch & crashes & catch & crashes & Catch & crashes & catch & crashes \\
\hline 0 & 03456 & 0 & 0.3435 & 0 & 0.3435 & 0 & 0.3442 & 0 \\
\hline 10 & 0.3585 & 0 & 0.3596 & 0 & 0.3579 & 0 & 0. 3.58667 & D \\
\hline 20 & 0.3793 & 0 & 0.3746 & 0 & 0.3747 & 0 & 0.3762 & 0 \\
\hline 30 & 03912 & 0 & 0.3939 & 0 & 0.3908 & 12 & 0.391967 & 4 \\
\hline 40 & 0.4101 & 0 & 0.4079 & 17 & 0.4074 & 0 & 0.408467 & 5.666667 \\
\hline 50 & 0.427 & 0 & 0.4262 & 16 & 0.4271 & 16 & 0.426767 & 10. 66667 \\
\hline 60 & 0.438 & 19 & 0.4218 & 87 & 0.413 .5 & 85 & 0.424433 & 63.666667 \\
\hline 70 & 0.4034 & 187 & 0.4392 & 114 & 0.4239 & 140 & 0.422167 & 147 \\
\hline 80 & 0.4151 & 244 & 0.4028 & 260 & 0.3988 & 262 & 0.405557 & 255.3333 \\
\hline 90 & 0.413 & 269 & 0.3873 & 371 & 0.3887 & 345 & 0.396333 & 3283333 \\
\hline 100 & 0.3462 & 566 & 0.35 .35 & 609 & 0.3347 & 561 & 0.3448 & 578.6667 \\
\hline
\end{tabular}


AutoManage Severity Test Data: Catch vs Acceptable vears (section 4.2.2)

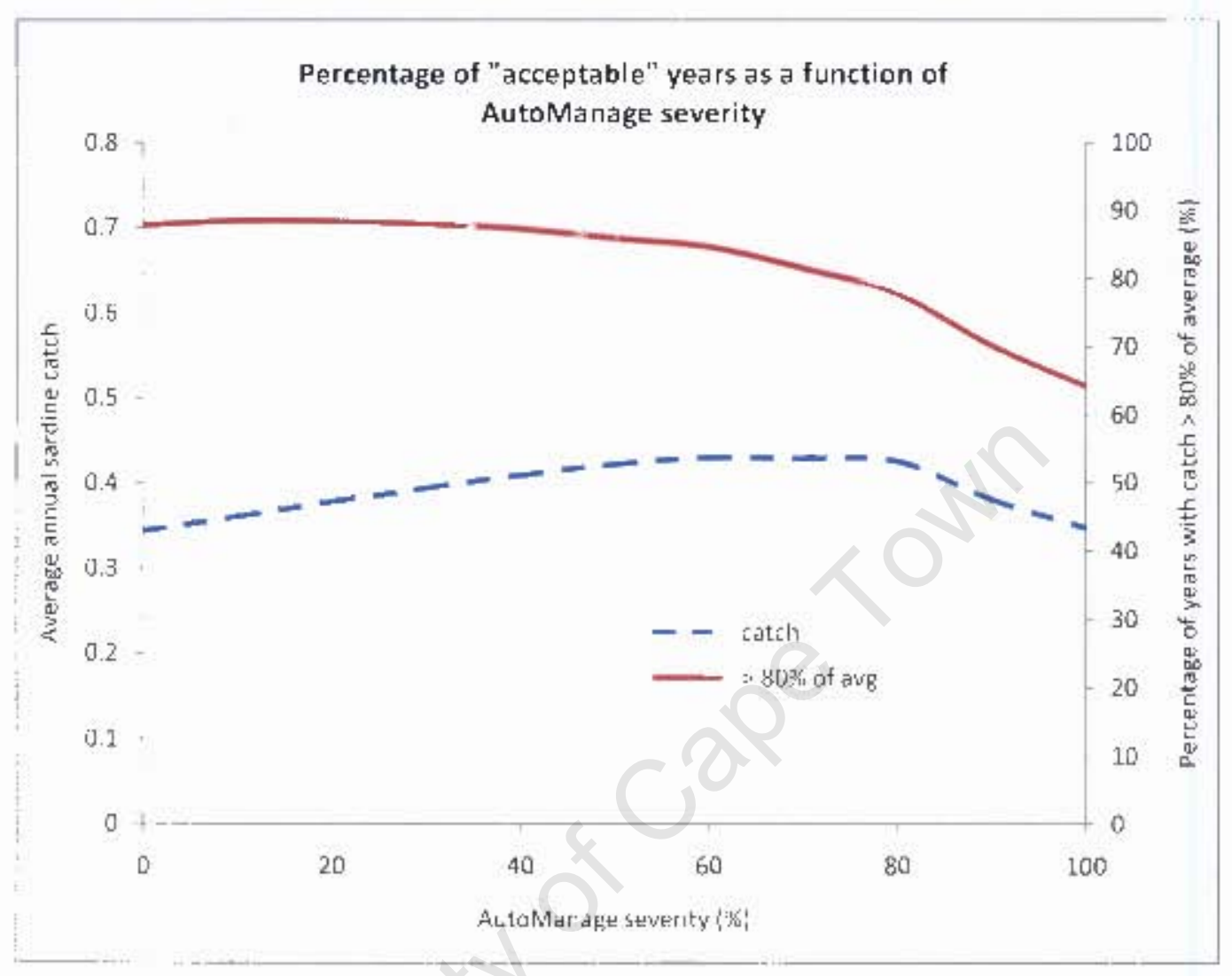

\begin{tabular}{|c|c|c|c|c|c|c|c|c|}
\hline \multirow[t]{2}{*}{ Severity $(\%)$} & \multicolumn{2}{|l|}{ Test 1} & \multicolumn{2}{|l|}{ Test 2} & \multicolumn{2}{|l|}{ Test 3} & \multicolumn{2}{|c|}{ Averaged results } \\
\hline & catch & $>80 \%$ & catch & $>80 \%$ & catch & $>80 \%$ & tatch & $380 \%$ \\
\hline 0 & 0.3426 & 87.3618 & 0.3441 & 88.4979 & 0.3429 & 87.5416 & 0.3432 & 87.80043 \\
\hline 10 & 0.3605 & 88.9018 & 0.3599 & 88.5765 & 0.3585 & 87.84 .37 & 0.359633 & 88.44067 \\
\hline 20 & 0.3779 & 88.6439 & 0.3766 & 88.4928 & 0.3766 & 88.0256 & 0.377033 & 88.38743 \\
\hline 30 & 0.3936 & 87.891 & 0.3942 & 88.4184 & 0.3924 & 87.4235 & 0.3934 & 87.91097 \\
\hline 40 & D. 4087 & 87.1144 & 0.4086 & 87.2419 & 0.4088 & 87.3054 & 0.4087 & 87.22057 \\
\hline 50 & 0.419 & 85.3782 & 0.4214 & 85.7473 & 0.42 .36 & 86.4364 & 0.4213 .33 & 85.85397 \\
\hline 60 & 0.4236 & 83.2255 & 0.4327 & 85.2999 & 0.4319 & 85.2799 & 0.4294 & 84.60177 \\
\hline 70 & 0.430 .3 & 81.9872 & 0.4258 & 81.1965 & 0.428 & 81.2436 & 0.428033 & 81.47577 \\
\hline 80 & 0.4132 & 77.2528 & 0,4192 & 77.8361 & 0.4428 & 78.0764 & 0.425067 & 77.72177 \\
\hline 90 & 0.375 & 69.2837 & 0.3791 & 70.2857 & 0.3867 & 70.9582 & 0.380267 & 70.17587 \\
\hline 100 & 0.3316 & 62.1727 & 0.3524 & 65.2 .31 & 0.3567 & 65.3584 & 0.3469 & 64,25403 \\
\hline
\end{tabular}




\section{Climate Function Periodicity Tests}

Full results for the tests on adjusting climate cycle time in Table 11 (section 4.2.2):

\begin{tabular}{|r|r|r|r|r|r|r|r|r|}
\hline Cycle Time & \multicolumn{2}{|l|}{$\mathbf{5}$ yrs } & \multicolumn{2}{|l|}{$\mathbf{7}$ yrs } & \multicolumn{1}{l|}{$\mathbf{1 0}$ yrs } & \multicolumn{1}{l|}{ yrs } \\
\cline { 2 - 9 } & Sard Hi & Both Hi & Sard Hi & Both Hi & Sard Hi & Both Hi & Sard Hi & Both Hi \\
\hline Test 1 & 28.816 & 21.184 & 27.523 & 22.477 & 28.821 & 21.179 & 24.635 & 25.365 \\
Test 2 & 28.738 & 21.262 & 27.498 & 22.502 & 28.755 & 21.245 & 24.604 & 25.396 \\
Test 3 & 28.776 & 21.224 & 27.478 & 22.522 & 28.752 & 21.248 & 24.622 & 25.378 \\
\hline Average & 28.7767 & 21.2233 & 27.4997 & 22.5003 & 28.776 & 21.224 & 24.62033 & 25.37967 \\
\hline
\end{tabular}

Full results for the effect of climate cycle time on sardine performance at various levels of AutoManage severity in Table 12 (section 4.3.2):

\begin{tabular}{|c|c|c|c|c|c|c|c|c|c|}
\hline \multirow[t]{2}{*}{$\begin{array}{l}5 \text { yr cycle } \\
\text { periodicity }\end{array}$} & \multicolumn{3}{|c|}{$0 \%$ severity } & \multicolumn{3}{|c|}{$50 \%$ severity } & \multicolumn{3}{|c|}{$100 \%$ severity } \\
\hline & $\begin{array}{l}\text { sard lo } \\
\text { (yrs) }\end{array}$ & $\begin{array}{l}\text { avg } \\
\text { catch }\end{array}$ & crash & $\begin{array}{l}\text { sard lo } \\
\text { (yrs) }\end{array}$ & $\begin{array}{l}\text { avg } \\
\text { catch }\end{array}$ & crash & $\begin{array}{l}\text { sard lo } \\
\text { (yrs) }\end{array}$ & $\begin{array}{l}\text { avg } \\
\text { catch }\end{array}$ & crash \\
\hline Test 1 & 0.13 & 0.3408 & 0 & 3.44 & 0.4202 & 26 & 26.7 & 0.3316 & 594 \\
\hline Test 2 & 0.08 & 0.3424 & 0 & 3.18 & 0.4175 & 34 & 26.11 & 0.3449 & 573 \\
\hline Test 3 & 0.19 & 0.3419 & 0 & 3.58 & 0.4223 & 14 & 25.15 & 0.3368 & 554 \\
\hline Average & 0.1333 & 0.3417 & 0 & 3.4 & 0.4200 & 24.67 & 25.987 & 0.3378 & 573.67 \\
\hline \multirow[t]{2}{*}{$\begin{array}{l}10 \text { yr cycle } \\
\text { periodicity }\end{array}$} & \multicolumn{3}{|c|}{$0 \%$ severity } & \multicolumn{3}{|c|}{$50 \%$ severity } & \multicolumn{3}{|c|}{$100 \%$ severity } \\
\hline & $\begin{array}{l}\text { sard lo } \\
\text { (yrs) }\end{array}$ & $\begin{array}{l}\text { avg } \\
\text { catch }\end{array}$ & crash & $\begin{array}{l}\text { sard lo } \\
\text { (yrs) }\end{array}$ & $\begin{array}{l}\text { avg } \\
\text { catch }\end{array}$ & crash & $\begin{array}{l}\text { sard lo } \\
\text { (yrs) }\end{array}$ & $\begin{array}{l}\text { avg } \\
\text { catch }\end{array}$ & crash \\
\hline Test 1 & 0.15 & 0.3429 & 0 & 4.31 & 0.4176 & 36 & 25.95 & 0.3463 & 563 \\
\hline Test 2 & 0.21 & 0.3425 & 0 & 4.6 & 0.4184 & 29 & 26.51 & 0.338 & 616 \\
\hline Test 3 & 0.07 & 0.3441 & 0 & 3.77 & 0.4208 & 26 & 27.13 & 0.3273 & 624 \\
\hline Average & 0.1433 & 0.3432 & 0 & 4.2267 & 0.4189 & 30.333 & 26.53 & 0.3372 & 601 \\
\hline
\end{tabular}

